\title{
Pregnancy, a window of opportunity to quit smoking! : the development, implementation and evaluation of a minimal intervention strategy for pregnant women and their partners
}

Citation for published version (APA):

Bakker, M. J. (2001). Pregnancy, a window of opportunity to quit smoking! : the development, implementation and evaluation of a minimal intervention strategy for pregnant women and their partners. [Doctoral Thesis, Maastricht University]. Universiteit Maastricht. https://doi.org/10.26481/dis.20011207mb

Document status and date:

Published: 01/01/2001

DOI:

10.26481/dis.20011207mb

Document Version:

Publisher's PDF, also known as Version of record

Please check the document version of this publication:

- A submitted manuscript is the version of the article upon submission and before peer-review. There can be important differences between the submitted version and the official published version of record. People interested in the research are advised to contact the author for the final version of the publication, or visit the $\mathrm{DOI}$ to the publisher's website.

- The final author version and the galley proof are versions of the publication after peer review.

- The final published version features the final layout of the paper including the volume, issue and page numbers.

Link to publication

\footnotetext{
General rights rights.

- You may freely distribute the URL identifying the publication in the public portal. please follow below link for the End User Agreement:

www.umlib.nl/taverne-license

Take down policy

If you believe that this document breaches copyright please contact us at:

repository@maastrichtuniversity.nl

providing details and we will investigate your claim.
}

Copyright and moral rights for the publications made accessible in the public portal are retained by the authors and/or other copyright owners and it is a condition of accessing publications that users recognise and abide by the legal requirements associated with these

- Users may download and print one copy of any publication from the public portal for the purpose of private study or research.

- You may not further distribute the material or use it for any profit-making activity or commercial gain

If the publication is distributed under the terms of Article $25 \mathrm{fa}$ of the Dutch Copyright Act, indicated by the "Taverne" license above, 


\section{Pregnancy, a window of opportunity to quit smoking!}

The development, implementation and evaluation of a minimal intervention strategy for pregnant women and their partners 

Pregnancy, a window of opportunity to quit smoking!

The development, implementation and evaluation of a minimal intervention strategy for pregnant women and their partners

\section{Proefschrift}

ter verkrijging van de graad van doctor aan de Universiteit Maastricht, op gezag van de Rector Magnificus, Prof. Dr. A. C. Nieuwenhuijzen Kruseman, volgens her besluit van her College van Dekanen, in het openbaar te verdedigen op vrijdag 7 december 2001 om 14.00 uur

door

Martijntje J. Bakker 


\section{Promotores:}

Prof. dr. H. de Vries

Prof. P. Dolan-Mullen (University of Texas, USA)

Prof. dr. G.J. Kok

\section{Thesis Committee:}

Prof. dr. N.K. de Vries (voorzitter)

Prof. dr. R.P.T.M. Grol

Dr. A.N. Mudde

Prof. dr. C.P. van Schayck

Prof. R.A. Windsor (George Washington University, USA)

Bakker, Martijntje

Pregnancy, a window of opportunity to quit smoking! The development, implementation and evaluation of a minimal intervention strategy for pregnant women and their partners

ISBN: 90-9015152-4

Cover design by Peter van Seuren

Printed by Den Haag media groep

The study presented in this thesis was performed at the Maastricht Health Research Institute for Prevention and Care (HEALTH), which participates in the Netherlands School of Primary Care Research (CaRe), acknowledged in 1995 by the Royal Dutch Academy of Science (KNAW).

The study described in this thesis was supported by a grant of the Netherlands Heart Foundation (NHF 43.018) the Dutch Cancer Society (DCS 94-687) and the Prevention Fund (PF 28.2283). The development of the educational materials was also supported by the Dutch Organisation on Smoking and Health (Stivoro).

Financial support by the Netherlands Heart Foundation and the Dutch Cancer Society for the publication of this thesis is gratefully acknowledged. 
Contents

Chapter 1

Overview

Chapter 2

Predictors of providing smoking cessation advice to pregnant women. A preliminary investigation among Dutch midwives

Chapter 3

Use and appreciation of midwives of a Dutch smoking cessation and relapse prevention protocol for pregnant women

Chapter 4 Smoking cessation by participants in a Dutch multi-media smoking cessation program for pregnant women and their partners

Chapter 5 Effects six months postpartum of a Dutch multi-media smoking cessation and relapse prevention program for pregnant women and their partncrs

Summary

Samenvatring

Dankwoord 
国

目 
Chapter 1

Overview 


\section{Overview}

\section{Introduction}

This dissertation describes the development, implementation and evaluation of a Dutch multi-media smoking cessation and relapse prevention program for pregnant women and their partners. The study was conducted between August 1994 and March 1998.

Not all smoking women automatically quit smoking when they learn they are pregnant although many negative health effects of smoking during pregnancy might occur. In the Netherlands it is expected that $35 \%$ of women will be smokers when they become pregnant. Approximately $70 \%$ of these women still smoke when they visit their midwife for their first prenatal consult, resulting in an average of $26 \%$ of Dutch smoking pregnant women (1).

Midwives, the usual providers of prenatal care in the Netherlands do not pay systematic attention to smoking. Most midwives ask during the first prenatal visit whether a woman smokes since this is one of the questions, which needs to be answered on the standardized intake form. However, if women indicate to be smokers most midwives will not provide smoking cessation counseling or guidance. Although midwives are motivated to provide smoking cessation counseling, they do not feel sufficiently capable to provide this information (Chapter 2).

Based on this information it was decided to develop a smoking cessation and relapse prevention intervention, which would help women to quit smoking during pregnancy and to prevent relapse after delivery. For the planning of the development of the intervention the $\mathrm{ABC}$-planning model was used in order to structure the different steps, which are important to take into account (2-5). The planning model is described in the next paragraph. Subsequently an overview of the study in this thesis is given following the steps of the planning model.

The second chapter provides insight in determinants of midwives with regard to providing smoking cessation advice to their pregnant clients. This study was conducted before the development of the intervention to investigate whether midwives see themselves as the right intermediaries to provide smoking cessation advice to pregnant 
women. It gave insight in determinants of giving smoking cessation advice and provided information for the development of guidelines for the intervention. For the purpose of this study 368 questionnaires were mailed to midwives of which 237 were returned (64.4\%).

The third chapter describes the results of a process evaluation conducted among participating midwives. The aim of this study was to investigate satisfaction of midwives with the intervention and the feasibility of implementing the intervention in routine care. For the purpose of this study all 118 midwives who participated in the study received a questionnaire after the implementation period of the study was finished. In total, $58.4 \%$ of questionnaires were returned. To verify reports of midwives, questions about performance of midwives with regard to providing smoking cessation advice and satisfaction and appreciation of advice received were added to the effcct evaluation questionnaires distributed among pregnant women.

To study the effectiveness of the intervention a pretest posttest randomized control design was used. Women were included in the study if they reported smoking (intake smokers) or to have stopped smoking in the previous six months (spontaneous quitters). Women who agreed to participatte completed a written questionnaire at intake at the midwife's office and three telephone interviews six weeks post intervention (approximately 18 weeks gestation), six weeks postpartum and six months postpartum.

The fourth chapter describes the results of the intervention on quit efforts and point prevalence abstinence by pregnant women during pregnancy and early postpartum. For the purpose of this study data were used collected among 318 intake smokers six weeks post intervention and six weeks postpartum.

The fifth and final chapter provides information about the long-term effects of the study. Data of both intakc smokers as well as spontaneous quitters (556 women in total) gathered six weeks and six months postpartum were used to study effects of the intervention on point previlence abstinence six months postpartum and continued point prevalence abstincnce (indicating abstinence six weeks and six months postpartum). 


\section{The ABC model}

The ABC-planning model (2-5) considers planning to be a circular process. It builds on planning models like the PRECEDE-PROCEED framework of Green and colleagues (6-7) and a simplified version of the PRECEDE-PROCEED framework for developing educational activities described by Kok (8).

The ABC-planning model consists of three phases: the analysis, behavioral intervention and continuation phase. Each phase is divided into sub phases as described in figure 1.1.

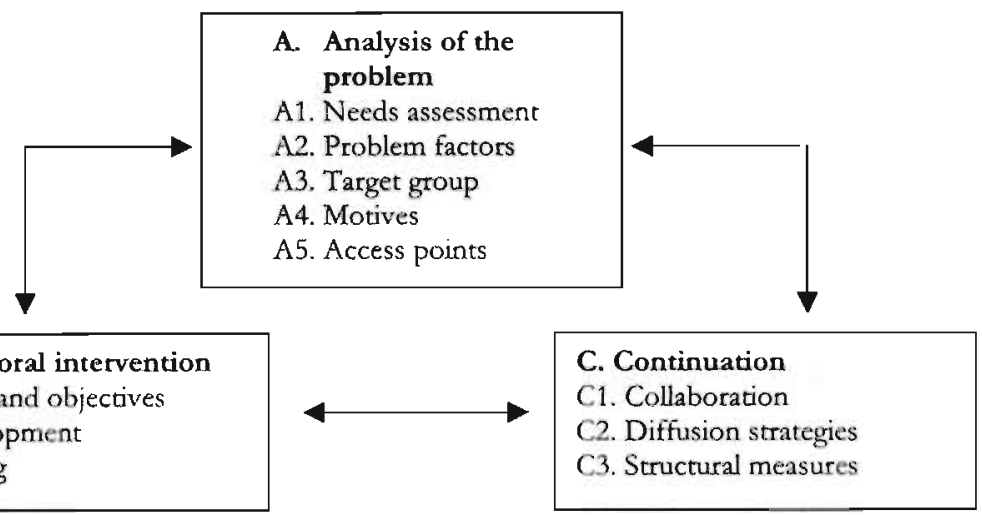

Figure 1.1 The ABC-planning model (5)

The analysis phase

The analysis phase is divided into 5 sub phases: needs assessment, problem factors, target group, motives and access points. The first sub phase refers to the analysis of the problem. Green and Kreuter (7) refer to this phase as the analysis of the quality of life. Issues this phase deals with are for instance, how serious is the problem, how many people are affected by it and what are the consequences. The second sub phase, problem factors, is meant to investigate whether the problem is related to the behavior of an individual or to environmental factors. The outcome of this sub phase will indicate whether the intervention needs to be developed at the micro, meso or 
macro level (or a combination). The micro level refers to an intervention developed for the individual, meso means that the intervention will target the environment of the individual, for instance an intervention at a worksite and macro refers to interventions developed to change issues at a broader level, for instance a national ban on smoking advertisements. The third sub phase, the analysis of the target group involves a detailed description of the group, which will be eargeted by the intervention. Which characteristics of the target group, such as gender, age, educational level etc. need to be taken into account when developing the intervention. It is important in this sub phase to describe all target groups involved. Both the final target group for the intervention but also intermediaries if they are used to deliver the intervention. The fourth sub phase deals with the analysis of determinants. Many different socio-psychological models such as for instance the Attitude-Social influences-Efficacy model (abbreviated as the ASE-model) $(9,10)$ can be used as a theoretical framework in studies aiming at the description of relevant determinants. The ASE-model was derived from the Theory of Reasoned Action (TRA) $(11,12)$ and the Social Cognitive Theory (SCT) (13) and to some degree resembles the Theory of Planned Behavior (TPB) (14). However, it has evolved as a separate model with several differences, predominantly of a methodological nature. Similar to the TPB, the ASE-model suggests that behavior is determined by the intention to perform this behavior. This intention is determined by three important factors: attitude, social influence and self-efficacy (Figure 1.2) $(10,15)$. The final sub phase describes the access points analysis. The aim of this final sub phase is to describe which access points can be used to reach the target group and what preferences the target group and intermediaries indicate.

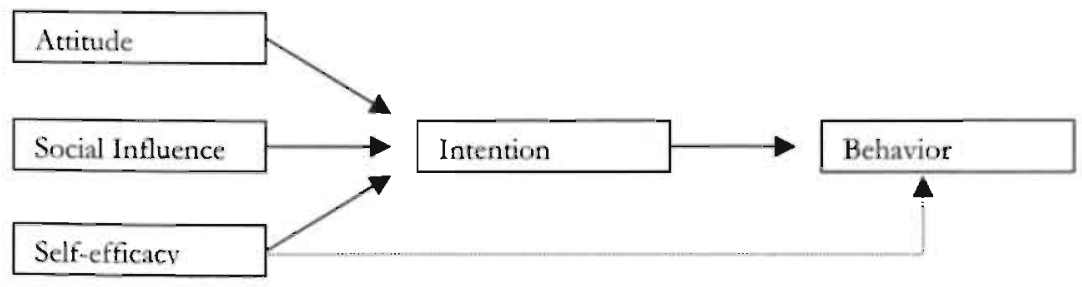

Figure 1.2 The ASE-model (10) 


\section{The behavioral intervention phase}

The behavioral intervention phase consists of 3 sub phases: goals and objectives of the intervention, development of the intervention and testing. The first sub phase describes the objectives of the intervention. There are several different objectives, which can be defined. Most commonly used objectives for the development of interventions targeted at behavior change are behavioral objectives, motivational objectives which refer to for instance awareness, attitude, social influence and selfefficacy and mastery objectives which refer to skills the target group needs to develop in order to change his or her behavior. Behavioral objectives, which were set for this project were for instance a long-term reduction of the percentage of smokers in the experimental group with $20 \%$ compared to $5 \%$ in the control group. A second behavioral objective was to reduce postpartum relapse with $20 \%$ compared to the control group among intake smokers.

The second sub phase involves the actual development of the intervention. In this sub phase important issues are target group characteristics, which might influence the effectiveness of the intervention, but also message and source chatacteristics. Message characteristics refer to the messages, which are important to bring across to motivate people to change their behavior. Source characteristics, as for instance reliability, attractiveness and competence are important to identify who will be most successful in convincing the target group to change. Additionally, in this sub phase the channel(s) which will be used to reach the target group will be identified. In this sub phase the persuasion communication matrix of McGuire (16) can be used as a tool for program development of the intervention, where principles of program development can be used such as program matrixing $(5,16)$ and intervention mapping (17). It is important in this phase to pretest the different progtam components in order to check whether the target group and intermediaries understand the materials and 'like' them. The third sub phase deals with the actual testing of the effectiveness of the intervention in a preferable randomized control group design.

\section{The continuation phase}

In the final phase of the $\mathrm{ABC}$-model three sub phases are described. In the first 
sub phase it is important to collaborate with all partners, which might be involved in the implementation of the intervention when proven successfull. It is important to start the collaboration with all stakeholders as soon as plans for development of an intervention exist. In this way it will be easier to take into account all relevant opinions of the different partners. The second sub phase involves the development of diffusion strategies. First, an analysis of determinants needs to be conducted to identify the perceived pros and cons of the intervention. Second, based on this determinant analysis strategies for diffusion can be developed. The final sub phase deals with structural measures, which might improve the diffusion of the intervention.

Although the three phases are described in this order, the ABC-planning model should be used as a circular process. As can be derived from the description of the final phase it is important to identify the relevant stakeholders before the intervention can be developed. Therefore, necessary interaction between the different phases will occur during the development process.

The next paragraphs will provide a description of the application of the ABC model to the problem of smoking during pregnancy and postpartum relapse. First, the information collected in national and international literature is described. If necessary, additional studies were conducted to solve lacks in information. These studies are described at the end of each phase.

\section{A. The analysis phase}

\section{A1. Needs assessment: Smoking during pregnancy and relapse postpartum, a problem?}

Health effects of prenatal and postpartum smoking

In 1957, the first study was published which found an average loss of birth weight of 200 grams in babies of smoking women compared to babies of non-smoking women (18). Since then many studies have been conducted to study the adverse effects of smoking prenatal and postpartum on the health of the fetus and young child. 
- Fetal growth

In the developed world, smoking during pregnancy carries the highest attributable risk for low birth weight. Assuming a smoking prevalence of 20 to $40 \%$ in women of childbearing age, smoking can be attributed to 22 to $36 \%$ of cases of low birth weight (19). Even after controlling for confounding factors, babies of mothers who smoked during pregnancy weigh on average 170 to 200 grams less compared to babies of mothers who did not smoke. This is partly due to the increased risk of preterm birth but also to the risk for fetal growth retardation $(19,20)$. Studies have indicated that there is a dose-response relationship between the number of cigarettes smoked by the mother and the birth weight of the baby $(21,22)$. If women quit smoking during pregnancy the adverse effects on birth weight of the period they did smoke decreases.

\section{- Spontaneous abortion}

The commonly used definition of spontaneous abortion, usually called miscarriage, is a spontaneous fetal dcath in the first 20 wecks of gestation. A few methodologically sound studies have cited an association betwecn maternal smoking and spontaneous abortion. But several have failed to include relevant confounders such as alcohol consumption or showed methodological weaknesses. Methodologically sound studies have reported an increased risk of 30 to $50 \%$ for spontaneous abortion among heavy smokers during pregnancy. The association was particularly strong among second trimester fetal deaths (23-25). There are also indications of an association between environmental tobacco smoke (ETS) and spontaneous abortion. However, more research needs to be conducted before conclusions with regard to this can be reached (25).

\section{- Infant mortality}

The term 'perinatal death' refers to both stillborn infants and infants who die shortly after birth. However, one of the main problems in comparing the results of studies, which investigate the relationship between maternal smoking and perinatal death is the variety of definitions that are used. DiFranza and Lew (26), conducted a meta-analysis to analyze the effect of smoking on perinatal death. In this way it was possible to combine undersized studies into a larger and more powerful study. For 
cohort studies a pooled relative risk was found of 1.26 and for case control studies a pooled odds ratio of 1.23 . Therefore, it can be concluded that maternal smoking does contribute to an increased risk for perinatal death (26).

- Sudden Infant Deatb Syndrome

Sudden Infant Death Syndrome (SIDS) is defined as an unexplained death in an infant, which is unexpected by history and in which postmortem examination fails to demonstrate an adequate cause of death. Studies have been conducted to investigate the role of maternal smoking during pregnancy in the incidence of SIDS as well as the role of environmental tobacco smoke (ETS). A metaanalysis (26) calculated a pooled odds ratio of 3.0 for maternal smoking during pregnancy. Two case-control studies, which controlled for relevant confounders $(27,28)$ have studied the effect of ETS on SIDS. The study conducted by KlonoffCohen et al. (27) found increased risks for SIDS for postnatal maternal smoking $(\mathrm{OR}=2.3)$, paternal smoking $(\mathrm{OR}=3.5)$, total cigarette exposure per day with an odds ratio of 22.7 for more than 21 household cigarettes. The study by Blair et al. (28) confirms these results.

\section{- Infant respiratory infections}

Several studies were conducted to investigate the effect of passive smoke exposure on infant respiratory infections (29). Several studies have documented increased risk for respiratory infections, including pneumonia, bronchitis, tracheitis, laryngitis, and otitis media. Children of smokers who suffer from these infections are hospitalized three times more often than children of non-smokers (30).

\section{A2. Problem factors: is smoking during pregnancy an individual or environmental factor}

The adverse health effects for the fetus and newborn child described in the previous paragraph are almost all related to the smoking behavior of the woman. Therefore it can easily be concluded that this issue should be treated as an individual problem and the intervention should be developed at the micro level. However, is smoking during pregnancy a purely individual choice? 


\section{Smoking prevalence among pregnant women and relapse rates after delivery}

A study published in 1991 reported that in the Netherlands about $35 \%$ of all pregnant women were estimated to be pre pregnancy smokers. At the time of their first prenatal consult $70 \%$ of them would still be smoking and $30 \%$ would report recent quitting, resulting in an average of $26 \%$ of Dutch women smoking while pregnant (1). An unpublished study conducted by TNO in the Netherlands in 1996 showed that $25 \%$ of women indicated to be smokers just before pregnancy and $21 \%$ during pregnancy. This percentage can be compared to the current percentage of pregnant smokers in the United States of approximately $20 \%$ (31).

Although women who quit during pregnancy usually abstain from smoking for six months or more, approximately $65 \%$ to $70 \%$ return to smoking within six months postpartum and half do so in the first six weeks (32-35) There are no Dutch data on relapse rates of women postpartum available.

\section{Smoking not just an individwal's choice}

Besides the fact that smoking is a decision an individual makes, it is also determined by the environment of the indiridual. With regard to smoking cessation of pregnant women it has been cited by several studies $(33,36-38)$ that having a smoking partner seriously decreases the chance of becoming a non-smoker during pregnancy and remaining a non-smoker postpartum. Additionally, the results of a prospective study specifically designed to identify predictors of postpartum relapse indicated that women who reported that most or ald of the family members they saw regularly were smokers were more likely to relapse than those who had fewer family members who smoked. Social pressure to maintain abstinence might reduce postpartum (33). Smoking during pregnancy seems to be less accepted by the environment than smoking postpartum.

Pregnant women cite health care providers as the most important source of information about health behavior in pregnancy (39). However, evidence shows that health care providers do not routinely offer smoking cessation and counseling to pregnant smokers (40). In the Netherlands, studies among both pregnant women (41) as well as midwives (42) indicated that pregnant women in general do not receive 
smoking cessation advice from their midwife.

Referring to the $A B C$-model it can be concluded that it is important to develop interventions at the micro level (a smoking cessation and relapse prevention intervention for pregnant women) and meso level (social support and smoking cessation intervention for the smoking partner and training for midwives about how to provide effective smoking cessation advice). Development of interventions at the macro level might also be important. Fxamples of such interventions are for instance regulations on systematic provision of cessation education by midwives, practicing with smoking cessation counseling during formal training for midwives and mandatory monitoring of smoking behavior and counseling after the birth of the baby at the various contacts with the health care system (for instance visits to baby well-care centers).

\section{A3. Target group: pregnant women, partners and midwives}

In the past years extensive research has been conducted concerning demographic and social factors of smoking pregnant women. Literature shows that most women who continue to smoke have a smoking partner, are heavy smokers themselves, have been pregnant several times, are living with other smokers (43), have had little education, come from a lower social class, are single, younger (44), unemployed, earn less money and start with prenatal care later in pregnancy (45).

Target groups for the meso level are smoking partners of pregrant women and midwives. With regard to smoking partners of pregnant women no specific characteristics could be found in national or international literature. However, characteristics of all smokers are that they are usually younger, less educated and from a lower socio-economic background compared to non-smokers. With regard to midwives only characteristics are given of Dutch midwives since the prenatal care system in the Netherlands is very unique and therefore difficult to compare with other countries. The vast majority of Dutch midwives are women who work independently in private practices (solo, duo or group), organized into regional networks. No national data are available on smoking rates of midwives. Since little information was available about midwives it was decided to conduct a study among midwives to gather 
information about for instance midwife and practice characteristics and smoking behavior (Chapter 2).

\section{A4. Motives: determinants of smoking during pregnancy}

\section{Determinants of smoking in pregnant women}

According to Gillies (44) smoking pregnant women indicate that they smoke because they are addicted and smoking helps them to control moods, relaxes, calms nerves, is pleasurable and relieves boredom. For some women smoking helps to cope with everyday situations. Dowsett (40) found that smokers are less convinced of the harmful effects of smoking for the unborn child. Another important finding from this study was that only few respondents reported to have received information from a health professional about smoking during pregnancy. Panjari (47) reports that smoking women are less convinced of the adverse effects of smoking for themselves and their baby. Smokers also indicated to experience more stress in their lives compared to nonsmokers. Furthermore, smokers associated the following situations with the temptation to smoke: drinking alcohol, tea or coffee, pressure from work, children or other demands, needing time for self experiencing and strong physical cravings. Wakefield (48) found in her study that pregnant smokers sometimes feel guilty about their smoking behavior and think that other people feel badly about them because they smoke. They, however continue to smoke because smoking gives them important benefits, like relaxation and coping with depression. Continuing smokers are also less convinced or aware of the health consequences of smoking during pregnancy. Haug (49) reports that the most important predictor of reduced cigarette consumption is the encouragement of a daily smoking partner to quit smoking, even if this partner does not adjust his own smoking behavior.

In 1991 a cross sectional study was conducted to gain insight into determinants of smoking cessation of Dutch pregnant women (41). The study used a combination of the ASE-model (9) and the stages of change construct of the Transtheoretical model (50). The target group of the study were smoking pregnant women and women who had quit smoking during their pregnancy or in the last year before their pregnancy.

In total 144 pregnant women retumed the questionnaire, 104 smokers and 40 
spontaneous quitters. The main outconnes were that precontemplators (women who do not intend to quit) were not convinced of the advantages of quituing for themselves and their baby. They were also more convinced of the emotional disadvantages of quitting such as feelings of tension and unpleasantness. Contemplators (women who intend to quit) did not show any differences on the atritudinal beliets compared to actors, maintainers and relapsers. However, they were less convinced of their ability to quit smoking (low self-efficacy). Actors (women who quit smoking, but no longer than six months ago) were convinced of the advantages of not smoking but had somewhat lower self-efficacy levels compared to maintainers (women who quit smoking more than six months ago but less than one year). Relapsers (women who quit smoking before or during pregnancy but had started again) were still convinced of the advantages of not smoking but reported the lowest self-efficacy scores.

To gain more specific information about relevant beliefs with regard to smoking cessation it was decided to conduct in depth interviews among pregnant smokers. The two key questions were, what are the behavioral determinants of women who continue to smoke during pregnancy, and in what way do midwives provide smoking cessation advice to their pregnant clients.

No specific information is available in both national and international literature about determinants of smoking of partners of pregnant women. It would have been very interesting to conduct such a determinant study among partners, but within the time available for the study, this was unfortunately impossible.

\section{Determinants of providing smoking cessation advice to pregnant women}

A physician's advice to quit is considcred an important motivator for attempting to quit smoking by the gencral population of smokcrs $(51,52)$. For pregnant women this does not differ (39). Unfortunately, only about half of current smokers report having ever been asked about their smoking status or urged to quit $(53,54)$. For pregnant women only $4 \%$ to $19 \%$ report cror having received information about health behavior in pregnancy (55). Reasons why clinicians do not confront their clients consistently with their tobacco use may be attributed to time constraints, perceived lack of skills to be effective in this role, frustration due to low success rates, and the 
belief that providing smoking cessation advice is not an important professional responsibility (56). Mullen \& Holcomb (57): studied predictors of providing health promotion counseling for 10 areas of health promotion and disease prevention including smoking by three groups of health professionals, dental hygienists, dieticians and certified nurse-midwives. Results of their study indicate a relationship between self-efficacy and the provision of advice. This finding suggests the importance of skills training for health care providers, including the provision of actual or simulated counseling experience and modeling by others in the same professional group. Additionally, it would be useful to provide data regarding the impact of professionals' counseling on the behavior of their patients, through evaluation literature and patients' feedback. Zapka et al. (58) conducted a study to assess providers' performance of smoking cessation counseling steps at community health centers providing care to lowincome pregnant and postpartum women. Results indicate that providers with greater smoking-related knowledge, who are older, and perceive smoking cessation as a priority were more likely to provide better counseling. However, beyond assessment of smoking behavior and advice, most providers did not provide real assistance to quit. Results of a Dutch study among general practitioners into reasons which might hamper the systematic implennentation of smoking cessation advice in general practice included that GPs are used to work cure oriented (not provide preventive care), do not wish to be considered patronizing by their clients (my patient is responsible for his uwn lifestyle), lack of time and do not receive a separate reimbursement for providing preventive care (59).

To obtain more information about why midwives do not provide smoking cessation advice to their clients it was decided to conduct a study among midwives into psychosocial motives, which predict a positive role definition regarding providing smoking cessation advice (Chapter 2).

\section{A5. Access points: how to reach pregnant smokers}

\section{International literature}

Since the majority of pregnant women receive prenatal care from a health care provider (gynecologist, midwife) on a regular basis, the usual setring of smoking 
cessation interventions is a hospital or community antenatal clinic where women receive advice from their health care provider and self-help materials. $(31,60,61)$ Some smoking cessation interventions in addition make use of personal mailings to the woman's home address $(34,62)$ or telephone calls to discuss cessation efforts and to provide support (63). A study which was specifically aimed at relapse prevention postpartum did not involve prenatal health care providers but mailed relevant materials to the woman and provided telephone counseling (64).

\section{Dutch prenatal care}

In the Nutherlands, pregnancy care is provided by midwives, general practitioners (GPs) and gynecologists. Approximately $45 \%$ of the deliveries are supervised by midwives, who guide uncomplicated pregnancies. Approximately $10 \%$ are supervised by GPs when insufficient midwives are available or when women ask explicitly for guidance by their GP. The remaining $45 \%$ are supervised by a gynecologist when women are running increased risks during pregnancy for various reasons (65). Since gynecologists care for more risk-bearing pregnancies and they perceive themselves already overloaded with research and GPs only guide very little pregnancies a year, midwives seem to be the best intermediaries to provide smoking cessation advice.

Pregnant women visit their midwife on a regular basis during pregnancy until six weeks postpartum. At the beginning of pregnancy they see their midwife each month, but as the pregnancy progresses the time between visits decreases. At the first consultation the midwife checks by means of a standardized form any inheritable diseases or lifestyle behaviors, which might complicate the pregnancy. At subsequent visits the health of the mother and fetus are checked and any pregnancy related issues are discussed. If no complications occur during pregnancy, the midwife will deliver the baby. She will visit her client frequently in the first week after delivery. At six weeks postpartum the client visits her midwife for the last time. 


\section{Guidelines for development of the materials}

- pregnant women

Studies, which investigate the effectiveness of smoking cessation materials for pregnant women make use of materials specifically directed to pregnancy. Besides being tailored to pregnancy it is also important to adapt materials to low literacy levels, different languages and various ethnic groups. Brief counseling of 5-10 minutes has shown to be effective and more intensive counseling does not seem to reliably improve the effectiveness of the intervention (66).

Several studies have indicated that smokers, both general smokers $(9,67,68)$ and pregnant women (41) need specific information adapted to their stage of change. Precontemplators are usually not convinced of the advantages of quitting. Therefore, they will need information to change their attitude concerning smoking cessation. Contemplators and preparators, however are more convinced of the advantages of quitting but lack confidence of the ability to quit. Therefore, self-efficacy enhancing information is important for them to actually start a quit attempt. Based on these findings it is advised to stage match materials. In this way, materials will be relevant for all smokers and they can turn to the sections, which are relevant to them.

To gain additional information from Dutch pregnant women about how to reach them in depth interviews were conducted before the development of the intervention to ask them what kind of smoking cessation materials they would find interesting.

\section{- Midwives}

Since tesearch among health care providers indicates that they do not provide smoking cessation information to their patients due to time constraints, lack of skills, frustration of low success rates, do not perceive providing smoking cessation advice as their responsibility (56) and lack of knowledge (58) it will be important to address these issues when developing materials for midwives about how to provide effective smoking cessation counseling.

No information was available about Dutch midwives concerning these issues. Therefore, it was decided to gather information regarding under what conditions midwives would be willing to provide smoking cessation advice to their clients by 
means of a structured questionnaire and interviews with midwives who indicated they were willing to participate in a personal interview on their completed questionnaire.

\section{A. Results of studies conducted for this dissertation}

With the international and national literature available it was not possible to get. a complete picture of all information necessary before the development of the information. Therefore, it was decided to conduct some additional studies to fill these gaps.

\section{Pregnant women}

With regard to women more information was needed about relevant beliefs with regard to smoking cessation and information about what kind of smoking cessation information they would be interested in. Therefore 23 in-depth interviews were conducted with pregnant women. Results of this study indicated that pregnant smokers had minimal knowledge of the consequences of smoking during pregnancy on the filus. Furthcrmore, they indicated that it is very hard for them to quit smoking when their partner continues to smoke and they reported in general very low selfefficacy with regard to quitting. When asked which people they found most suitable to provide advice about smoking cessation during pregnancy most women indicated their midwife. However, they also reported that most midwives do not pay attention to smoking cessation. This indicates that it will be necessary to provide information about the consequences of smoking during pregnancy on the fetus to convince women of the harmful effects, to involve the partner to create positive social support, to provide skills to enhance self-efficacy of women with regard to quitting and to develop materials for midwives to make them aware of the role they can play in reducing smoking among their pregnant clients. Additionally, women indicated that they were overloaded with materials when they are pregnant. Therefore, it will be necessary to develop materials in a professional and colorful way to create attention. Furthermore, women said that they liked the materials to be designed as a magazine. In that way they would be able to read only information, which would be relevant and interesting to them. Therefore, information should be clustered in small segments with clear titles. 


\section{Midwives}

With regard to midwives little was known about theit smoking behavior, why they do not provide smoking cessation advice to their pregnant clients and under what conditions midwives would be willing to provide smoking cessation advice. Therefore it was decided to conduct a study by means of structured questionnaires among midwives and interviews with midwives who indicated to be willing to participate in a personal interview on their completed questionnaire.

Outcomes of the quantitative study among 237 midwives indicated that midwives who were more convinced of the advantages of giving smoking cessation advice, the positive perceived health benefits of quitting for mother and child and who perceived more support from their colleague midwives, general practitioners and gynecologists had a more positive role definition regarding providing advice. However, midwives were less positive about their ability to provide smoking cessation advice. These results indicate that it is important to stress health benefits for mother and child and the advantages of giving smoking cessation advice to convince midwives to provide this advice to their clients. Additionally it should be regarded good practice to provide smoking cessation advice to pregnant clients by health practicioners who are in contact with pregnant women to stimulate midwives to give smoking cessation advice. Skills training is needed to improve self-efficacy of midwives to give smoking cessation advice. With regard to smoking approximately $23 \%$ of Dutch midwives indicated to be smokers, which is considerably lower compared to the average smoking rate of the adult Dutch female population of $33.8 \%$. However, the response rate of this study was only $64.4 \%$ and the relatively low percentage may be attributed to selectivity (Chapter 2).

Outcomes of both the quantiative study and the interviews indicated that although midwives are motivated to give smoking cessation advice, they need materials and training to enable them to perform this role successfully. One of the issues midwives raised was that giving smoking cessation advice may not take too long. The first consultation lasts on average 30 minutes, subsequent consultations only ten. Since midwives are not reimbursed for giving smoking cessation advice, the advice needs to be incorporated in these consultations. Another issue, which was raised by midwives is 
that they experience that most of their pregnant smokers come from less advantaged backgrounds. Therefore materials should be adapted to characteristics of low SES women. Materials should be easily accessible and preferably not only written. Furthermore, midwives indicated that they also wanted materials for the smoking partner since they observe that it is especially hard for pregnant women to quit when their partner smokes. Finally, midwives indicated that it would be very hard for them to talk about the adverse effects of smoking during pregnancy on the fetus. They were afraid that talking about these health consequences will make the pregnant woman uncomfortable and the possibility of the woman changing to another practice might increase. Therefore, they wanted these consequences to be incorporated in the materials for the women so they would have the opportunity to decide to refer to the materials instead of talking about it themselves.

\section{Partners}

In both national and international literature we could not find any information about characteristics of partners of pregnant women who smoke or quit smoking, determinants of smoking of partners of pregnant women or information about how to reach these partners. Since having a smoking partner is one of the main predictors of relapse both during pregnancy as well as postpartum it will be very important to conduct studies to collect this information. However, within the time available to conduct the study, this was unfortunately impossible. Therefore, information about characteristics of general smokers and determinants of smoking were used as background information for the intervention for partners.

\section{B. The development of the Minimal Intervention Strategy for pregnant women}

\section{B1. Goals and objectives}

The outcomes of the analysis phase were used to design content and appearance of the materials for midwives, pregnant women and smoking partners. As a tool an application of McGuire's persuasion-communication matrix (16), the program 
matrix was used (69). The program matrix has been used before to develop smoking prevention programs $(69,70)$ and an aids prevention program (71). The program matrix states that the effectiveness of information depends on four education variables: characteristics of the target group, the message, the channel and the source. Furthermore, it is important that before changes in attitude, perceptions of social influences and self-efficacy expectations can occur, the target group needs to receive and understand the messages. It is important to realize that a channel, which might be useful to attract attention is not necessarily the ideal channel for for example attitude change. Therefore, it is usually necessary to use a range of channels to get the message across. Table 1.1 shows how the program matrix was applied to the development of the smoking cessation and relapse prevention intervention. (72) 


\begin{tabular}{|c|c|c|c|c|}
\hline PHASE & $\begin{array}{l}\text { TARGET } \\
\text { GROUP }\end{array}$ & MESSAGE & CHANNEL & SOURCE \\
\hline Attention & $\begin{array}{l}\text { - low/ moderate } \\
\text { motivation to quit: } \\
\text { other issues than } \\
\text { smoking are } \\
\text { important } \\
\text { - more LSES }\end{array}$ & $\begin{array}{l}\text { - worthwhile } \\
\text { quitting for baby's } \\
\text { health } \\
\text { - it is possible to } \\
\text { quit } \\
\text { - both parents are } \\
\text { responsible for the } \\
\text { health of the baby }\end{array}$ & $\begin{array}{l}\text { - personal } \\
\text { communications } \\
\text { - video } \\
\text { - cover self-help } \\
\text { guide }\end{array}$ & $\begin{array}{l}\text { - pregnant women } \\
\text { and partners } \\
\text { - gynecologist } \\
\text { - midwife }\end{array}$ \\
\hline Comprehension & $\begin{array}{l}\text { - low/ moderite } \\
\text { educational level }\end{array}$ & $\begin{array}{l}\text { - brief easy } \\
\text { messages }\end{array}$ & - video & $\begin{array}{l}\text { - pregnant women } \\
\text { from same SES- } \\
\text { group }\end{array}$ \\
\hline Attitude & $\begin{array}{l}\text { - not convinced of } \\
\text { advantages of NS } \\
\text { - not convinced of } \\
\text { disadvantages of S } \\
\text { for fetus and } \\
\text { thernselves } \\
\text { - unaware of risks } \\
\text { of passive smoking }\end{array}$ & $\begin{array}{l}\text { - pros NS for baby } \\
\text { - pros NS for } \\
\text { mother } \\
\text { - risks of passive } \\
\text { smoking for young } \\
\text { children }\end{array}$ & $\begin{array}{l}\text { - personal } \\
\text { communications } \\
\text { - video messages } \\
\text { - self-help guide } \\
\text { for pregnant } \\
\text { women }\end{array}$ & $\begin{array}{l}\text { - pregnani womes } \\
\text { and partners } \\
\text { - gynecologist } \\
\text { - midwife }\end{array}$ \\
\hline Social influences & $\begin{array}{l}\text { - smoking } \\
\text { behawior of } \\
\text { partner } \\
\text { - support of } \\
\text { partner, midwife } \\
\text { and social } \\
\text { environment }\end{array}$ & $\begin{array}{l}\text { - S-partner should } \\
\text { quit } \\
\text { - NS-partner can } \\
\text { help pregnant } \\
\text { smoker } \\
\text { - social } \\
\text { environment } \\
\text { should help }\end{array}$ & $\begin{array}{l}\text { - personal } \\
\text { communications } \\
\text { - self-help guide } \\
\text { for pregnant } \\
\text { women } \\
\text { - partner booklet } \\
\text { - video }\end{array}$ & $\begin{array}{l}\text { - pregnant women } \\
\text { - partners who } \\
\text { have quit smoking } \\
\text { and support their } \\
\text { wife } \\
\text { - midwife }\end{array}$ \\
\hline Self-efficacy & $\begin{array}{l}\text { - low levels of SE } \\
\text { towards quitting } \\
\text { - lower levels of } \\
\text { SE to maintain } \\
\text { quitting } \\
\text { postpartum }\end{array}$ & $\begin{array}{l}\text { - you can cope } \\
\text { with barners: } \\
\text { (social/ personal) } \\
\text { discuss and show } \\
\text { 'ways of coping } \\
\text { - how to set goals }\end{array}$ & $\begin{array}{l}\text { - video } \\
\text { - self-help guide } \\
\text { for pregnant } \\
\text { women } \\
\text { - personal } \\
\text { communications }\end{array}$ & $\begin{array}{l}\text { - pregnant women } \\
\text { who have quit } \\
\text { smoking. } \\
\text { - partners who } \\
\text { have quit smoking } \\
\text { - midwife }\end{array}$ \\
\hline Behavior change & $\begin{array}{l}\text { - need skills to } \\
\text { refrain from } \\
\text { smoking } \\
\text { - need alternatrives } \\
\text { tor smoking }\end{array}$ & $\begin{array}{l}\text { - practice skills to } \\
\text { cope with barriers }\end{array}$ & $\begin{array}{l}\text { - self-help guide } \\
\text { for pregnant } \\
\text { women } \\
\text { - personal } \\
\text { communication }\end{array}$ & $\begin{array}{l}\text { - pregnant women } \\
\text { and partners } \\
\text { - mid̛ifife }\end{array}$ \\
\hline $\begin{array}{l}\text { Behavior } \\
\text { maintenance }\end{array}$ & $\begin{array}{l}\text { - need skills to } \\
\text { refrain pressure tor } \\
\text { start, again } \\
\text { - need skills to } \\
\text { motivate partner to } \\
\text { remair nont- } \\
\text { smoker } \\
\text { - feedback }\end{array}$ & $\begin{array}{l}\text { continuation of } \\
\text { cessation is } \\
\text { important: passive } \\
\text { smoking, health of } \\
\text { young children and } \\
\text { parents }\end{array}$ & $\begin{array}{l}\text { - relapse } \\
\text { prevention bocklet } \\
\text { - self-help guide } \\
\text { for pregnant } \\
\text { women } \\
\text { - personal, } \\
\text { communications }\end{array}$ & $\begin{array}{l}\text { - women and } \\
\text { partners with } \\
\text { young children } \\
\text { - midwife } \\
\text { - gynecologist }\end{array}$ \\
\hline
\end{tabular}




\section{B2. The intervention}

Favorable results have been found for interventions used by specifically trained health care professionals, but delivery in routine care has been less successful and represents an important aspect for future study $(31,60,61)$. The aim of this study was therefore to develop a smoking cessation and relapse prevention intervention for pregnant women and their partners which could be easily implemented in regular Dutch prenatal care. Based on the results obtained in the analysis phase it was decided to develop materials for pregnant woman, partners of pregnant women and midwives.

The counseling strategy on which the intervention in this study was based has been tested before among a general population of smokers and among patients hospitalized for cardiac disease. Results of the intervention among a general population of smokers indicated a positive effect of the intervention both short term (one month after the intervention: $18.6 \%$ versus 3.8\%) and long term (12 months after the intervention: $13.4 \%$ versus $7.3 \%$ ). A significant predictor of abstinence besides receiving the intervention was being less addicted to nicotine. (59). Results of the intervention among patients hospitalized for cardiac disease indicated a positive effect of the intervention short term ( 3 months post intervention: $53.1 \%$ versus $36.8 \%$ ). However, these results could not be replicated 12 months after the interiontion $(73,74)$.

\section{Pretesting of materials}

Pretesting of materials is essential in order to be able to change any problems, which might influence the effectiveness. There are many different pretest methods available such as readability testing, focus groups, in-depth interviews and written questionnaires $(7,75)$.

For the pretesting of the materials of the pregnancy studies, two methods were used: focus groups to pretest the video and in-depth interviews to pretest the written materials. Materials were pretested among target group members, intermediaries and health education experts. 


\section{B3. Testing}

Several systematic reviews, which have been conducted study the effectiveness of smoking cessation interventions for pregnant women $(31,60,61)$. Outcomes of these reviews indicate that self-help minimal contact smoking cessation interventions have produced behavioral impact in public health maternity clinics and in obstetrical care in the US and non-US countries (31). Important aspects of these effective interventions are to tailor the intervention to pregnancy and to use multiple methods (counseling, written materials, follow-up) (60). Most of the trials, which are incorporated in these reviews made use of specifically trained health care personnel, only few trials were noted with interventions delivered by usual prenatal care practitioners $(76,77)$.

Studies, which focused on prenatal smoking cessation but also included a post delivery component were unable to report effects postpartum (64,78). Only one study, which started the intervention in prenatal care, achieved a significant improvement in maintenance up till 12 months postpartum (79). This intervention also produced a significant reduction in the proportion of fathers who smoked.

In the Netherlands, no effectiveness studies were conducted before of programs aimed at smoking cessation during pregnancy and relapse prevention postpartum.

Based on this information it was decided to test the effectiveness of the intervention in routine Dutch prenatal care. The main research questions were:

1. Is the intervention effective in reducing smoking rates among pregnant intake. smokers up till six months postpartum,

2. Is the intervention effective in reducing relapse rates postpartum among both intake smokers as well as spontaneous quitters,

3. Is the intervention effective in reducing smoking rates of partners of pregnant: women,

4. Is the intervention easy to implement in routine Dutch prenatal care.

To answer the first three questions a pretest posttest randomized control design was used, where women were nested within midwife practice and practices within four provinces, the latter being the unit of randomization to the experimental and control. condition. At intake at the midwife's office, both smokers as well as recent quitters. 
(quit smoking in the previous six months) were included in the study. Data among study participants were collected at four time points: a written questionnaire completed at intake at the midwife's office and three telephone interviews conducted six weeks after the intervention, six. weeks postpartum and six months postpartum.

To answer the fourth question, all midwives of midwife practices who had participated in the effectiveness study received a questionnaire after the implementation period of the effectiveness study was finished. To illuminate the reports of midwives, data collected among study participants were used. Details of the study and participant characteristics are described in chapters 3,4 and 5 .

\section{B Results of studies conducted for this dissertation}

For pregnant women a video, self-help guide and post delivery booklet were developed, for partners of pregnant women a partner booklet and for midwives a manual, intervention card and training. Details about the development of the materials and the health counseling protocol used by midwives are reported in chapter 3.

To pretest the video, focus groups were conducted with pregnant women and their partners (smokers as well as quitters), midwives and health education experts. First, the video was shown after which questions were asked regarding for instance the core message of the video, the models, credibility and completeness of the messages and sequence of the different issues. As a result, the sequence of some items was adapted according to stiggestions made. One of the smokers who was selected to be interviewed in the video was removed from the final version since women as well as midwives and experts indicated that she was a 'bad' model. Her comments created a negative feeling among the viewers, which distracted them too much from the core message. One item was replaced since its message was uncleat to the target group. The background music was changed and text was added to make some of the conclusions in the video more explicit.

To pretest the written materials, draft materials were sent to pregnant women and midwives. The partner booklet was sent to smoking partners. One week after receiving the materials they were contacted by phone. Based on the results of these interviews text was adapted (content, wording and sequence). 
After materials were adapted based on the results of the pretest, the effectiveness of the materials was tested in a pretest posttest randomized control design. The results of this study among intake smokers with dropouts included as smokers (intention to treat procedure) indicated a positive effect of the intervention on smoking behavior of pregnant women up till six weeks postpartum. At six weeks postpartum $21.3 \%$ of women in the experimental group indicated 7-day abstinence compared to $12 \%$ of women in the control group. Consistent predictors of smoking cessation were belonging to the experimental group, smoking less cigarettes a day at the time of the first visit with the midwife and having a non-smoking partner. Additional predictors of smoking cessation six weeks postpartum were starting smoking at a later age and being higher educated.

However, at six months postpartum the positive effect of the study has disappeared. Data collected among intake smokers as well as spontaneous quitters (women who indicate to have quit smoking up till six months prior to the first consultation) showed no positive effect of the intervention on 7-day abstinence or continued abstinence (indicating 7-day abstinence six weeks and six months postpartum). In total, $24.6 \%$ of women in the experimental group reported continued abstinence versus $25.3 \%$ of women in the control group. Significant predictors of abstinence six months postpartum and continued abstinence were starting smoking at a later age and smoking less cigarettes a day at the time of the first consultation with the midwife. Having a non-smoking partner and being a spontaneous quitter at intake were additional predictors of 7-day abstinence. Having a non-smoking partner was almost significant $(\mathrm{p}=0.07)$.

With regard to the partner no effects of the intervention on smoking behavior of the partner were found at any time point.

Results of the process evaluation indicated that midwives in most cases distributed the video, self-help guide and post delivery booklet to their clients. Although midwives in the experimental group perceived discussing smoking cessation with their pregnant clients as more difficult, they more often provided the advice to quit, set a quit date with clients who were motivated to quit smoking and provided arrangements for aftercare. Midwives in the experimental group reported to find 
implementation of the intervention in routine care feasible and a large najority plans to use the materials when they become available nationally.

Clients of midwives confirmed to great extent these results. Most wornen in the experimental group indicated to have received the video and self-help guide. However, only a small number $(16.7 \%)$ reported having received the post-delivery booklet. Women in the experimental group reported more often that their midwife discussed with them their smoking behavior, gave the advise to quit, discussed barriers which might hamper a successful quit attempt, set a quit date, regularly discussed smoking during pregnancy, discussed consequences of passive smoking and discussed smoking behavior postpartum. They also indicated to appreciate the advice received more compared to control women.

A majority of midwives reported to have distributed the partner booklet, which was confirmed by reports of their clients. However, only about half of the women who gave the booklet to their partner indicated that their partner also actually read the booklet. There were no differences with regard to discussing smoking behavior with the partner between groups.

Satisfaction with the intervention and feasibility of implementation are described in chapter 3. Results of the effectiveness of the intervention on quit attemprs and point prevalence abstinence up till six weeks postpartum are described in Chapter 4. Effects of the intervention on abstinence six months postpartum are described in Chapter 5.

\section{Continuation}

\section{Collaboration}

To improve the chances of structural national implementation of a successful intervention it is of great importance to collaborate with all actors who might be involved in the diffusion process. Therefore it was decided to create a steering group before the development of the intervention started. Since, in the Netherlands three professional groups of health care providers are involved in prenatal care we asked each group to send a representative to the steering group. Midwives are organized in 
the Royal Dutch Organization of Midwives (Koninklijke Nederlandse Organisatie van Verloskundigen, KNOV) and General Practitioners (GPs) are organized in the Dutch GPs Association (Landelijke Huisartsen Vereniging, LHV). Gynecologists are not organized in a special group. Therefore, we asked a well-known gynecologist who is also a professor at the University of Utrecht to become a member. The Dutch Foundation on Smoking and Health (Stivoro) was also an important member of the steering group. Stivoro is an organization, which is sponsored by the Dutch Cancer Society, the Dutch Heart Foundation, the Astma Fund and the Ministry of Health to provide smoking cessation materials free of charge to all interested Dutch citizens. They also provide training to intermediaries who want to learn how to provide effective smoking cessation counseling. The arrangement was made with Stivoro that they would take care of national implementation after the intervention had proven to be successful.

During the project the steering committee was consulted on several occasions. Issues, which were discussed were for instance goals and objectives of the materials, the development of the materials and implementation strategies.

\section{Diffusion Strategies}

Diffusion is described by Rogers (80) as a process, which takes place in four. phases. Parcel et al. (81) have also described which determinants are important to address in each phase. The target of the first phase, diffusion is to make people aware of the innovation. Important determinants in this phase are attention and knowledge. Second, people will have to decide whether they are going to adopt the innovation. It is important to create a favorable attitude towards the innovation and positive social influence. Third, people will actually start to implement the innovation. Therefore they will need positive self-efficacy and skills. Also they will need practical suggestions how to incorporate the innovation in their own practice. Finally, it is important that the innovation is incorporated in daily practice to improve the chance of continuation. People will need positive feedback to remain using the innovation.

Diffusion of a successful intervention is not a process, which takes place automatically. Therefore, effective diffusion strategies need to be developed in order to 
increase the likelihood of a successful distribution. Important factors which might stimulate the diffusion process are the advantages of the new intervention compared to existing ones, the compatibility of the intervention in current practice, the complexity, the feasibility of the effects, the possibility to experiment and the flexibility to adapt the intervention to personal or other preferences. (80).

\section{General conclusions and recommendations}

\section{Results}

Before the development of the intervention a study was conducted into predictors of providing smoking cessation advice to pregnant women by Dutch midwives. Results of this study indicated that midwives who have a more positive role definition regarding giving smoking cessation advice were more convinced of the advantages of giving advice, the positive health benefits for mother and child and perceived more support from their colleagues with regard to giving smoking cessation advice. Self-efficacy with regard to providing smoking cessation advice was low among both midwives with a positive as well as midwives with a less positive role definition regarding providing smoking cessation advice. Based on these results it was concluded that effective materials and training were needed to facilitate and stimulate midwives in their role as effective smoking cessation counselors.

The results of the effect evaluation of the intervention indicated that smoking cessation occurred more often in the experimental group, among less heavy smokers and among women with a non-smoking partner. Effects on smoking cessation were sustained up till six weeks postpartum. No effects were found long term on smoking behavior. Additionally no effects were found on smoking behavior of the partner at either time-point.

The results of the process evaluation indicated that midwives appreciated content and appearance of the materials. Experimental midwives indicated to find discussing smoking behavior with their clients somewhat more difficult compared to their colleagues in the control condition. However, they more often did advise their clients to quit, set a quit date with clients motivated to quit smoking and provided 
aftercare. These results were: confirmed by reports of their clients. However, only few women reported to have received the post delivery booklet or to have discussed postpartum smoking behavior with their midwife. With regard to partner smoking, more experimental midwives reported asking the partner if he wanted to quit but there were no differences for advising the partner to quit and not to smoke around his pregnant wife. A vast majority of midwives reported to find implementation of the intervention feasible and plan to use the materials when they become available nationally.

\section{Methodological conclusions (strengths and weaknesses)}

Strengths of the effectiveness study reported in this dissertation included the implementation of the intervention in routine care, high response rates of study parricipants up till six months postpartum and the application of the intention to treat procedure (including dropouts as smokicrs) for the effect analysis. Most studies, which have been included in reviews of effectiveness of smoking cessation interventions for pregnant women $(31,60,61)$ have been conducted with trained health educators/ counselors under optimal conditions to achieve optimal results. Only two studies have been reported which relied on usual care providers to provide smoking cessation counseling $(76,77)$. The study by Kendrick and colleagues (76) was unable to report an effect of the study on smoking cessation eight months gestation. The investigators speculated that implementation of the intervention may have been very low. Results of the study by Hjalmarsson and colleagues (77) indicated no effect of the intervention on smoking cessation rates in late pregnancy, but cessation rates were different by 8 weeks postpartum $(15.8 \%$ versus $9.1 \%)$.

Midwives asked their clients at the first consultation whether they smoked or had quit smoking in the previous six months. Women who indicated yes to one of these questions were asked to participate in a study about smoking and health. In total, midwives indicated to have approached about $80 \%$ of women eligible for the study, $72 \%$ of these women agreed to participate resulting in a study group of 556 women. Response rates were $94.6 \%$ six weeks post intervention, $88.7 \%$ six weeks postpartum and $84.4 \%$ six months postpartum. Posttest data wete collected by means of structured 
telephone interviews. There were no differences in dropout rates between groups.

Effects of the intervention on smoking cessation were analyzed in two ways. First, an intention-to-treat procedure was used including dropouts as smokers and second dropouts were excluded from the analysis. The first procedure has been recommended by various researchers as a protection against biased treatment effects due to patient selection (82-84). The intention-to-treat analysis should not be regarded as providing the ultimate answer, but as a check on the robustness against selection bias of the analysis without dropouts. Results of both analyses were almost similar.

Besides the reported strengths of the study, there were also some methodological weaknesses. Aithough the study used a pretest posttest randomized control design to test the effectiveness of the intervention, individuals were not randomized to one of both conditions, but women were nested within midwife practice and practices within four provinces, the latter being the unit of randomization to the experimental and control conditions. Such a nested design may lead to intraclass correlation, i.e. positive dependence between outcomes in the same practice, due to province and practice effect on the outcome. Ignoring such intra-class correlation will lead to underestimation of the standard error of the treatment effect, too narrow confidence intervals and possibly, Type 1 errors. $(85,86)$. Therefore, final models were re-analyzed with random effect logistic regression treating women as nested within practices and practices as random effect with province as fixed effect. A small significant effect of midwife practice was found on 7-day abstinence six weeks post intervention, six weeks postpartum, six months postpartum and continued abstinence, but size and significance of trearment and covariate effects was not seriously changed.

Additionally, province should also have been included in multi-level analysis as random effect, since province was the unit of randomization. However, since only four provinces were randomized such a random effect approach is not relevant. Therefore, a fixed effect approach was used correcting for province, implying a restriction of the results to the four provinces of the study. Only under the assumption of no (random) differences between provinices with respect to the outcomes the standard errors and $\mathrm{p}$ values were adequate for generalizing to other regions. Since the fixed effect of province was not predictive of any of the outcomes $(p>0.20)$ this assumption seems 
acceptable and so results can probably be generalized to other provinces in the Netherlands.

In this study it was impossible to reach women before entry into care at the midwife's office and to conduct a proper pretest. 'Therefore, women had to complete the pretest questionnaire at the midwife's office, during the first consultation before the start of the intervention. In interviews with midwives during the implementation phase of the intervention to monitor progress some midwives indicated that they asked the woman to fill in the questionnaire after the first consultation or to fill it in at home. As a consequence, some of the variables such as attitudes and intention towards smoking cessation were not used as predictors for the outcome variables, since intervention effects for these variables were already expected.

To study level of nondisclosure (women reporting non smoking who are actually smokers), midwives were asked to collect urine among a random sample of $30 \%$ of their clients reporting non-smoking at intake and six weeks postpartum. Midwives were asked to label the samples so results could be linked to the data file and mail them to a laboratory. At the beginning the laboratory reported receiving many broken samples. Therefore, midwives received different packaging material. Also many samples were not labeled properly and samples, which could be identified were sometimes collected among women indicating to be smokers. This resulted in only 47 $(14.8 \%)$ valid urine samples collected at intake and 7 six weeks postpartum. Results of the samples collected at intake indicated that overall $17 \%$ of self-reported non-smokers actually were smokers. There were no differences in level of nondisclosure between the experimental and control group. Results of the samples collected postpartum all confimed the self-reported non-smoking status.

\section{Implications for research}

Since the intervention did not show an effect on smoking six months postpartum and smoking behavior of partners of pregnant women more research is needed to develop effective interventions. 


\section{Women}

With regard to postpartum smoking behavior there have been a number of intervention studies, which have aimed to reduce relapse postpartum, but most studies have carried out the intervention during pregnancy and only reported smoking behavior postpartum $(34,64,78)$. These studies have been unable to report an effect of the intervention on postpartum smoking behavior. The only study, which did achieve a significant improvement in maintenance 12 months postpartum is the PANDA project (79). Interventions, which were carried out only postpartum $(36,38)$ have also been unable to show an effect on smoking behavior postpartum (at 12 months). Predictors of continued abstinence or postpartum relapse have been reported in several papers. Having a smoking partner is the most consistent predictor of postpartum relapse (33,36-38). Additional predictors are social support, decreases in self-efficacy formula feeding (87) and concern about weight gain, duration of breast feeding and being a heavier smoker before pregnancy $(38,88)$. These predictors must be taken into account when developing new postpartum relapse prevention interventions. Additionally, more research is needed into determinants of relapse postpartum among Dutch women. In this study both women should be included who quit smoking prior to becoming pregnant and women who quit smoking during pregnancy. Different access points need to be found to improve exposure to the postpartum non-smoking message.

\section{Midnives}

Since implementation of the postpartum component failed in this study more research is needed about the reasons for this failure. Before the development of the intervention predictors of providing smoking cessation advice were studied thoroughty among Dutch midwives, but not predictors of providing postpartum relapse prevention advice. Conducting such a study can provide important information for adapting the materials. Additionally, since women in the Netherlands are seen by their midwife for the last time six weeks postpartum, research is needed to explore which postpartum healthcare providers are willing to enforce the non-smoking message postpartum. However, since postpartum the focus of attention shifts from the woman 
to the newborn child, postpartum healthcare providers should become aware of the important role they can play in relapse prevention. A non smoking mother benefits the health of the baby.

\section{Partner}

With regard to smoking behavior of the partner more research is needed among partners themselves. The analysis phase we conducted for pregnant women should be redone for partners of pregnant women. Is partner smoking an individual or environmental problem, what are characteristics of partners of pregnant women who continue to smoke, what are the important determinants of cessation, how can they support their pregnant wife to not smoke both during pregnancy as well as postpartum, but also what are the access points. Before the development of the intervention we expected most fathers to at least attend the first consult which would enable the midwife to discuss also his smoking behavior. However, we have no data to confurm that partners actually were present at this first consult. If partners, were not present women were asked to give the partner booklet to their partners, but reinforcement of the smoking cessation message by a healthcare provider might be essential to persuade partners to quit. If this cannot be done face to face, computerized tailoring might be an effective way to give partners an individualized smoking cessation advice. Favorable results of tailored smoking cessation messages have been found among a general population of smokers in the Netherlands $(89,90)$.

\section{Implications for practice}

Since the program has proven its effectiveness on smoking cessation up till six weeks postpartum and process evaluation data have indicated the feasibility of implementing the program in routine care it is recommended to implement the intervention nationwide to at least reduce the number of smokers during pregnancy. The Dutch Organization on Smoking and Health (Stivoro) will take the leading role in the diffusion of the project and it is estimated that materials will become available to all people interested in the year 2001.

With regard to implementation of the intervention nationwide many 
experiences can be derived from the diffusion of a smoking cessation protocol for GPs in the Netherlands (59). Based on their experiences it is advised to structure the diffusion of the program. In the first phase it is important to distribute the materials to all midwives in the Netherlands. The package should contain the protocol for midwives, intervention materials for their clients (video, self-help guide, partner booklet and post delivery booklet), a letter preferably signed by the Durch Organization of Midwives and Stivoro to introduce the package and a form to order more copies. At the same time it is important to distribute articles about the effectiveness of the intervention in journals often read by midwives in the Netherlands. These articles should include the positive outcomes of the intervention and the results of the process evaluation, which show that it is possible to incorporate the intervention in daily practice. In the second phase it will be important to distribute the positive experiences of midwives who have worked with the intervention during the study period. Also, it will be essential to stress the importance of training to work with the intervention effectively. Training should be easily available at different times and places so all midwives who want to attend can do so. This information can for instance be distributed by newsletters to the regional netwotks of midwife practices. The third phase will incorporate the actual training of midwives to work with the intervention. Based on the results of the pilot study a training of three hours incorporating background information of the consequences of smoking pre- and postpartum, explanation of the different steps and skills training in applying the steps is sufficient for midwives to work effectively with the intervention materials. Since only few women indicated to have received the postpartum part of the intervention, the importance of stressing postpartum non smoking should receive more attention. Finally, it will be important to provide feedback on the diffusion of the intervention. If midwives learn of the increased number of colleagues who work with the intervention it can be a powerful tool to also persuade them to start working with the intervention. The materials of the intervention need to remain available. If diffusion is successful, it will be necessary to update the materials when new important findings with regard to for instance consequences of smoking during pregnancy are published or the design of the materials becomes out of date. 
In this pilot study effectiveness of the intervention was only tested among midwives. However, in the Netherlands pregrancies are also guided by general practitioners and gynecologists. It will be important to study whether the intervention under the same conditions can be distributed among general practitioners and gynecologists or whether some adaptations need to be made. Since general practitioners and gynecologists were involved in the development of the intervention contact should be sought with them to discuss guidelines for implementation of the intervention in their practices.

Structural measures and policies have the possibility to influence the continuation of a successful intervention. With regard to the continuation of the MIS for pregnant women there are multiple options. Health education is not yet a structural part of the education of new midwives in the Netheriands. Since the health counseling protocol can be adapted to many different behaviors such as smoking, nutrition, alcohol and exercise which are all important for pregnant women it would make a good addition to incorporate it in the standard curriculum. Furthermore, midwives are not reimbursed for health education activities. Therefore they can only address limited time to issues related to health education. Acknowledging the importance of health education by incorporating it in standard prenatal care will be a good start. There is a current debate in the Netherlands about: providing a standardized prenatal consult. Issues of importance during such a consultation would be inheritable diseases, which might influence the decision to become pregnant but also lifestyle behaviors which might influence the chance of becoming pregnant and the piositive outcomes of a pregnancy. Since smoking is the main lifestyle behavior, which influences a positive pregnancy outcome, smoking cessation should be an essential part of a prenatal consult. 


\section{References}

1. Verkerk PH, van Noord-Zaadstra BM.. Leefstijl, omgevingsfactoren, uitkomsten van zwangerschap en gezondheid. Fase 1. TNO-Gezondheidsonderzoek. Nederlands Instituut voor Praeventieve Gezondheidszorg TNO, 1991.

2. De Vries $H$. Prevention of cancer: Towards a national $A B C$ framework. European Journal of Cancer and Clinical Oncology. 1989;25:1025-33.

3. De Vries H, Kok G. Gezondheidsbevordering: een toepassing wan het $\mathrm{ABC}$ planningsmodel. Gedrag en Gezondheid. 1996;24:342-52.

4. De Vries $\mathrm{H}$, Willemsen MC. Planmatige gezondheidswoorlichting in de arbeidssituatie. In P Baart, G Roerink, M Selie (eds.), Gezondheidsbevordering op de werkplek. Amsterdam: NIA, 1996.

5. De Vries H.. Planning health promotion. In: R. Weston \& D.Scott. Evaluation of health promotion (pp. 92-108). Cheltenham: Stanley Thornes, 1998.

6. Green LW, Kreuter MW, Deeds SG, Partridge KB. Health education planning, a diagnostic approach. Palo Alto, Cal.: Mayfield, 1980.

7. Green LW, Kreuter MW. Health promotion planning, an educational and environmental approach. Toronto: Mayfield Publishing Co, 1991.

8. Kok GJ. Een model van gedragsverandering via voorlichting. Nederlands Tijdschrift voor Psychologie. 1985;40:71-6.

9. De Vries H, Mudde AN, Dijkstra A, Willemsen MC. Differential beliefs, perceived social influences, and self-efficacy expectations among smokers in various motivational phases. Prev Med. 1998;27:681-9.

10. De Vries $\mathrm{H}$, Mudde A. Predicting stage transitions for smoking cessation applying the Attitude - Social influence - Efficacy Model. Psychology \& Health. 1998;13:369-85.

11. Fishbein M, Ajzen I. Belief, attitude, intention and behavior: An introduction to theory and research. Reading (MA): Addison-Wesley, 1975.

12. Ajzen I, Fishbein M.. Understanding attitudes and predicting social behavior. Englewood Cliffs NJ: Prentice Hall, 1980.

13. Bandura A. Social Foundations of thought and action: a social cognitive theory. New York: Prentice-Hall, 1986. 
14. Ajzen I.. The theory of planned behavior. Organizational Behavior and Human Decision Processes. 1991;50:179-211.

15. Lechner L. Social psychological determinants of health risk behaviors related to cancer and CVD. Thesis Maastricht: University, Maastricht, 1998.

16. McGuire WJ. Attitudes and attitude change. In: G Lindzey, E Aronson (Eds.) Handbook of Social Psychology, Volume II, New York: Lawrence Erlbaum Associates, pp. 233-46, 1985.

17. Bartholomew LK, Parcel GS, Kok G. Intervention mapping: a process for designing theory- and evidence-based health education programs. Health Education \& Behavior. 1998;25:545-63.

18. Simpson WJ. A preliminary report on cigarette smoking and the incidental prematurity. Am J Obstet Gynecol. 1957;73:808-15.

19. Kramer MS. Determinants of low birthweight: methodological assessment and meta-analysis. WHO. 1987;65:663-737.

20. Wen SW, Goldenberg RL, Cutter GR, Hoffman HJ, Cliver SP. Intrauterine growth retardation and preterm delivery: risk factors in an indigent population. Am J Ob Gyn. 1989;162:213-8.

21. Goldenberg RL, Davis RO, Cliver SP, Cutter GR, Hoffman HJ, DuBard MA, Copper RL. Maternal risk factors and their influence on fetal anthropometric measurements. Am J Ob Gyn. 1993;168:1197-1203.

22. Cliver SP, Goldenberg RL, Cutter GR, Hoffman HJ, Davis RO, Nelson KG. The effect of cigarette smoking on neonatal anthopometric measurements. Obstet Gynecol. 1995;85:625-30.

23. Ahlborg G, Bodin L. Tobacco smoke exposure and pregnancy outcome among working women. A prospective study at prenatal care centers in Orebro County, Sweden. Am J Epidemiol. 1991;133:338-47.

24. Harlap S, Shiono PH. Alcohol, smoking, and incidence of spontaneous abortions in the first and second trimester. Lancet. 1980;2:173-6.

25. Windham GC, Swan SH, Fenster L. Parental smoking and the risk of spontaneous abortion. Am J Epidemiol. 1992;135:1394-1403. 
26. DiFranza JR, Lew RA. Effect of maternal cigarette smoking on pregnancy complications and sudden infant death syndrome. J Fam Pract. 1995;40:385-94.

27. Klonoff-Cohen HS, Edelstein SL, Lefkowitz ES, Srinivasan IP, Kaegi D, Chang JC, Wiley KJ. The effect of passive smoking and tobacco exposure through breast milk on sudden infant death syndrome. JAMA. 1995;273:795-8.

28. Blair PS, Fleming PJ, Bensley D, Smith I., Bacon C, Taylor E, Berry J, Golding J, Tripp J. Smoking and sudden infant death syndrome: results from 1993-5 case control study for confidential inquiry into stillbirths and deaths in infancy. BMJ. 1996;313:195-8.

29. DiFranza JR, Lew RA. Morbidity and mortality in children associated with the use of tobacco products by other people. Pediatrics. 1996;97:560-8.

30. Floyd RL, Rimer BK, Giovino GA, Mullen PD, Sullivan SE. A review of smoking in pregnancy: effects on pregnancy outcomes and cessation efforts. Annu Reru Publ Health. 1993;14:379-411.

31. Windsor RA, Boyd NR, Orleans CT. A meta-evaluation of smoking cessation intervention research among pregnant women: improving the science and art. Health Education Research. 1998;13:419-38.

32. Fingerhut LA, Kleinman,JC, Kendrick JS. Smoking before, during and after pregnancy. Am J Public Health. 1990;80:541-4.

33. McBride CM, Pirie PL, Curry SJ. Postpartum relapse to smoking: a prospective study. Health Education Research. 1992;7:381-390.

34. Mullen PD, Quinn VP, Ershoff DH. Maintenance of nonsmoking postpartum by women who stopped smoking during pregnancy. Public Health Briefs. 1990;80:992-4.

35. Sexton M, Hebel JR, Fox NL. Postpartum smoking. In: Rosenberg MJ (Ed) Smoking and reproductive health. Littleton, MA: PSG Publishing. (pp 222-6), 1987.

36. Severson HH, Andrews JA, Lichtenstein E, Wall M, Akers L. Reducing maternal smoking and relapse: Long-term evaluation of pediatric intervention. Prev Med. 1997;26:120-30.

37. Severson HH, Andrews JA, Lichtenstein E, Wall M, Zoref L. Predictors of 
smoking during and after pregnancy: A survey of mothers of newborns. Prev Med. $1995 ; 24: 23-8$.

38. Ratner PA, Johnson JL, Bottorff JL, Dahinten S, Hall W. Twelve-month follow-up of a smoking relapse intervention. for postpartum women. Addictive behaviors. 2000;25:81-92.

39. Aaronson L, Mural C, Pfoutz C. Seeking information, where do pregnant women go? Health Education Quarterly. 1988;15:335-45.

40. Dunckley J. Training midwives to help pregnant women stop smoking. Nursing times. 1997;93:64-6.

41. De Vries H, Backbier E. Self-efficacy as an important predictor of quitting among pregnant women who smoke: the $Ø$-pattern. Prev Med. 1994;23:167-74.

42. Cox HH. Een stoppen-met-roken interventie voor rokende zwangeren en kraamvrouwen. scriptie, Universiteit Maastricht, 1992.

43. Cnattingius S, Lindmark G, Meirik $O$. Who continues to smoke while pregnant? Journal of epidemiology and community health. 1992;46:218-21.

44. Gillies PA, Madely RJ, Power FL. Why do pregnant women smoke? Public Health. 1989;103:337-43.

45. Zimmer MH, Zimmer M. Socioeconomic Determinants of Smoking Behavior During Pregnancy. The Social Science Journal. 1998;35:133-42.

46. Dowsett SJ. Smoking attitudes and habits during pregnancy, Sheffield 1983. Health Education journal. 1985;44:83-6.

47. Panjari M, Bell RJ, Astbury J, Bishop SM, Dalais F, Rice GE. Women who spontaneously quit smoking in early pregnancy. Aust. and N.Z. Journal of Obstetrics and Gynaecology. 1997;37:3:271-8.

48. Wakefield M, Jones WR. Cognitive and Social Influences on Smoking Behaviour During Pregnancy. Aust NZ Obstet Gynaecol. 1991;31:235-9.

49. Haug K, Aaro LE, Fugelli P. Smoking habits in early pregnancy and attitudes towards smoking cessation among pregnant womers and their partners. Family Practice. 1992;9:494-9.

50. Prochaska JO, DiClemente CC. Stages and processes of self-change of smoking: toward an integrative model of change. J Consult Clin Psychol. 
$1983 ; 51: 390-5$.

51. Ockene JK. Smoking intervention: the expanding role of the physician. Am J Public Health. 1987;77:782-3.

52. Pederson LL. Compliance with physician advice to quit smoking: a review of the literature. Prev Med. 1982;11:71-84.

53. Anda RF, Remington PL, Sienko DG, Davis RM. Are physicians advising smokers to quit? The patient's perspective. JAMA. 1987;257:1916-9.

54. Frank E, Winkleby MA, Altman DG, Rockhill B, Fortmann SP. Predictors of physicians' smoking cessation advice. JAMA. 1991;266:3139-44.

55. Eiser C, Eiser J. Health education needs of primigravidae. Child Care Health Development. 1985;11:78-83.

56. Jaen CR, Stange KC, Nutting PA. Competing demandis of primary care: a model for the delivery of clinical preventive services. J Fam Prac. 1994;38:16671.

57. Mullen PD, Holcomb JD. Selected predictors of health promotion counseling by three groups of allied health professionals. Am J Prev Med. 1990;6:153-60.

58. Zapka JG, Pbert L, Stoddard AM, Ockene JK, Goins KV, Bonollo D. Smoking cessation counseling with pregnant and postpartum women: a survey of community health center providers. Am J Public Health. 2000;90:78-84.

59. Pieterse M. Stoppen met roken met hulp van de huisartspraktijk. Ontwikkeling, toetsing en implementatie van een minimale interventie strategie. Thesis, Twente University Press, Enschede, 1999.

60. Mullen PD, Ramirez G. Efforts to reduce tobacco use among women: Pregnant women and mothers. In: US Public Health Service: Office on Smoking and Health. The health consequences of smoking for women. A report of the Surgeon General. Rockville, MD: US Department of Health and Human Services, 1999.

61. Lumley J, Oliver $S$, Waters E. Interventions for promoting smoking cessation during pregnancy. Cochrane Database of Systematic Reviews, 2000.

62. Ershoff DH, Mullen PD, Quinn VP. A randomized trial of a serialized se]f-help smoking cessation program for pregnant women in an HMO. Am J Public 
Health. 1989;79:182-7.

63. Gebauer C, Kwo CY, Haynes EF, Wevers ME. A nurse-managed smoking cessation intervention during pregnancy. Journal of Obstetrics and Gynecology in Nursing. 1998;21:47-53.

64. McBride CM, Curry SJ, Lando HA, Pirie PL, Grothaus LC, Nelson JC. Prevention of relapse in women who quit smoking during pregnancy. Am J Public Health. 1999;89:706-11.

65. SIG. Jaarboek verloskunde 1991; gebaseerd op gegevens uit de landelijke verloskundige registratie, eerste en nweede lijn. Utrecht: Van Nieuwenhuis BV, 1992.

66. Mullen PD. Maternal smoking during pregnancy and evidence-based intervention to promote cessation. In Spangler JG (Ed). Primary care: clinics in office practice. Philadelphia: WB Saunders, 2000.

67. Dijkstra A, De Vries $H$, Bakker $M$. The pros and cons of quiting, self-efficacy and the stages of change in smoking cessation. Journal of Consulting and Clinical Psychology. 1996;4:758-65.

68. Prochaska JO. Strong and weak principles for progressing from precontemplation to action on the base of twelve problem behaviors. Health Psychology. 1994;3:1-5.

69. De Vries H. Determinanten van gedrag. In: V Damoiseaux, HT van der Molen, GJ Kok. (Eds.). Gezondheidsvoorlichting en gedragsverandering (pp. 109-132). Assen: Van Gorcum, 1993.

70. De Vries $\mathrm{H}$, Dijkstra M, Kok G. A Dutch smoking prevention project: an overview. Hygie. 1992;11:14-8.

71. Schaalma HP, Kok G, Poelman J, Reinders J. The development of Aidseducation for Dutch secondary schools; a systematic approach based on theory research and cooperation. In: Th. Rutter and L. Quine Social psychology and heath: European perspectives (pp. 175-194). Aldershot: Avebury, 1993.

72. De Vries H. Smoking Prevention and Smoking Cessation. In: NJ Smelser, PB Baltes (Eds.), The Intemational Encyclopedia of the Social \& Behavioral Sciences. Chapter 108. Pergamon: Oxford, 2000. 
73. Bolman C, De Vries H, van Breukelen G. Evaluation of a nurse-managed minimal-contact smoking cessation intervention for cardiac inpacients. (submitted)

74. Bolman C, De Vries H, van Breukelen G. A minimal-contact intervention for cardiac inpatients: long-term effects on smoking cessation. (submitted).

75. Bracht N. Health promotion at the community level. Newbury Park: Sage Publications, 1990.

76. Kendrick JS, Zahniser SC, Miller N, Salas N, Stine J, Gargiullo PM, Floyd RL, Spierto FW, Sexton M, Metzger RW, Stockbauer JW, Hannon WH, Dalmut ME. Integrating smoking cessation into routine public health prenatal care: The smoking cessation in pregnancy project. Am J Public Health. 1995;85:217-22.

77. Hjalmarson AIM, Hahn L, Svanberg B. Stopping smoking in pregnancy: effect of a self-help manual in a controlled trial. Br J Obst Gyn. 1991;98:260-4.

78. Secker-Walker RH, Solomon LJ, Flynn BS, Skelly JM, Lepage SS, Goodwin MS, Mead PB. Individualized smoking cessation counseling during prenatal and early postnatal care. Am J Obstet Gynecol. 1994;171:1347-55.

79. Mullen PD, DiClemente CC, Carbonari JP, et al. Project PANDA: Effectiveness in maintaining prenatal abstinence 12 months postpartum. (in preparation)

80. Rogers EM. Diffusion of innovations. New York: The Free Press, 1983.

81. Parcel GS, Perry CL, Taylor WC. Beyond demonstration: diffusion of health promotion innovations. In: $\mathrm{N}$ Bracht (Ed.), Health promotion at the community level (pp. 229-251). Newbury Park: Sage Publications, 1990.

82. The Tobacco Use and Dependence Clinical Practice Guideline Panel, Staff, and Consortium Representatives. A clinical practice guideline for treating tobacco use and dependence. A US public health service report. JAMA. 2000;283:324454.

83. Dignan M. Power analysis: a useful tool for designing health education and health promotion research. Health Val. 1993;17:55-7.

84. Rossi PH, Freeman HE. Evaluation: a systematic approach, 5th ed. Newbury Park: Sage, 1993. 
85. Bryk AS, Raudenbusch SW. Hierarchical linear models. Newbury Park (Calif): Sage, 1993.

86. Goldstein H. Multilevel statistical models. London: Edward Arnold, 1995.

87. O'Campo P, Faden RR, Brown $\mathrm{H}$, Gielen AC. The impact of pregnancy on women's prenatal and postpartum smoking behaviour. Am J Prev Med. 1992;8:81-92.

88. McBride CM, Pirie PL. Postpartum smoking relapse. Addict Behav. $1990 ; 15: 165-8$.

89. Dijkstra A, De Vries H, Roijackers J, Van Breukelen G. Tailored interventions to communicate stage-matched information to smokers in different motivational stages. Journal of Consulting and Clinical Psychology. 1998;3:54957.

90. Dijkstra A, De Vries H, Roijackers J. Long-term effectiveness of computergenerated tailored feed-back in smoking cessation. Health Education Research. 1998;13:207-214. 


\section{Chapter 2}

Predictors of perceiving smoking cessation counseling as a midwife's role: a survey of Dutch midwives ${ }^{1}$

' Submitted for publication to Midwifery as: Bakker MJ, de Vries H, Dolan Mullen P \& Kok GJ. Predictors of perceiving smoking cessation counselling as a midwife's role: a survey of Dutch midwives 


\section{Abstract}

Objective. Smoking during pregnancy can have many serious consequences. As the usual providers of pregnancy care in the Netherlands, midwives could serve as effective counselors to pregnant women about cigarette smoking. The aim of the present study was to identify relevant factors that hamper or promote the provision of effective smoking cessation advice and counseling.

Design. Questionnaires were mailed to midwives; 237 (64.4\%) were returned. Questions were asked about advantages and disadvantages of giving smoking cessation advice, perceived health benefits for mother and child, smoking behavior and normative beliefs of colleagues, self-efficacy and role definition of midwives with regard to giving smoking cessation advice.

Findings. Midwives who have a more positive role definition regarding giving smoking cessation advice are more convinced of the advantages of giving advice, the advantages of quitting for their clients and perceive more support from their colleagues with regard to giving advice.

Key conclusions and implications for practice. In general, midwives were motivated to provide their elients with smoking cessation advice. They were less comfortable with guiding women through the cessation process. Therefore, effective materials and training should be developed to facilitate and stimulate midwives in their role as effective counselors. 


\section{Introduction}

Pregnant women are considered a special targer group for smoking cessation because smoking cessation during pregnancy significantly reduces the risks of growth retardation, fetal death, Sudden Infant Death Syndrome, and other problems (1-5), women can be more readily motivated to quit smoking because of the harmful effects for their baby (6) and women are in regular contact with a health care professional. Health care professionals are a potential source of health information, and their attitudes and counseling practices can have an important impact on the health habits of thcir clients (7).

In the Netherlands, several sources and channels can be used to reach pregnant women, such as mass media approaches and more interpersonal approaches. Although mass media approaches may have a more agenda-setting function, interpersonal contacts may present a better strategy for realizing behavioral change. Consequently, those who provide pregnancy care can be potential sources of anti-smoking information. In the Netherlands, pregnancy care is provided through midwives, general practitioners and gynecologists. Uncomplicated pregnancies are usually guided by midwives who work independently in private practices, organized into regional networks (8).

Although midwives may be potential sources of smoking cessation education, a precondicion is that they consider providing smoking cessation to be part of their job. In the Netherlands no information about this was available. Moreover, only a few international studies have addressed this issue. An English snudy by McGreal (9) revealed that midwives were anxious to encourage pregnant women to give up smoking, but arguably lacked certain skills in this area and thus felt ill equipped for the task. Although little has been written about attitudes regarding providing smoking: cessation advice by midwives, more general studies about attitudes of health professionals have listed several reasons for failing to raise the issue of smoking. Lack of time, insufficient knowledge, personal atritudes and feat of endangering the relationship with the client have all been frequently cited $(10)$.

Studies conducted among nurses indicate that nurses perceive health education to be an important part of their role but that there are various factors, which either 
facilitate or constrain this role. Nurses feel for instance that it is essential that their health education role is valued by other health care professionals (11). With regard to providing smoking health risk education few actually provide this care due to perceived ineffectiveness of health risk education, belief that smoking is not a health risk, and lack of knowledge base to provide care (12).

Several behavioral science models suggest: that behavior is determined by three types of cognitions or ideas that people hold about a particular behavior: attitudes, perceived social influences and self-efficacy expectations, although the description of these cognitions differ from model to model (13-17). The present study uses the Attitude- Social influences- Efficacy model, or ASE-model (18-20). Attitude is conceptualized as the result of weighing the perceived advantages and disadvantages of: a behavior. Perceived social influence is conceptualized as the result of social norms (21), modeling (14) and social support encountered in favor of the behavior or pressure against the behavior (22). Self-efficacy, a concept derived from Bandura's Social. Learning Theory (14,23), measures an individual's perceived capacity to perform a particular behavior. The ASE model has been used to explain various health behaviors, nutrition (24), exercise $(25,26)$, alcohol consumption (27), child safety (28) and smoking $(19,29-30)$.

To assess the degree to which midwives see themselves as appropriate intermediaries to give smoking cessation advice to pregnant women and their partners, a survey was conducted with a sample of members of the Dutch Organization of Midwives.

It was hypothesized that midwives who have: a positive role definition of giving smoking cessation advice to their clients would be more convinced of the advantages of providing smoking cessation advice, including the perceived health benefits for pregnant women, experience more social support from their colleagues to provide smoking cessation advice, and have higher levels of self efficacy for this task than midwives with a less positive role definition. 


\section{Methods}

\section{Design}

In January 1995, 368 questionnaires were mailed to all members of the Dutch Organization of Midwives in the Middle and Southern part of the Netherlands (provinces: Gelderland, Utrecht, Zeeland, Noord-Brabant and Limburg). Enclosed with the questionnaire was a cover letter explaining the purpose of the study and the co-operation of the Dutch Organization of Midwives and a post-paid pre-addressed envelope. Midwives who returned the questionnaire were offered the opportunity to win a gift certificate of 100 Dutch guilders.

\section{Measures}

- outcome expectations

Attitude toward providing smoking cessation advice was assessed with eight advantages ("When I provide smoking cessation advice to my clients ... there is less chance of young children becoming ill, they are better able to weigh the pros and cons of quitting, they will they appreciate me more, I am a better midwife, I fulfill an important preventive task, I show interest in the health of my client, there is less chance that the woman will start smoking again postpartum") answered on a 7-point scale, with 6 indicating total agreement and 0 total disagreement $(\alpha=0.75)$ and nine disadvantages ("When I provide smoking cessation advice to my clients this takes a lot of time, I am hindered by the presence of others, I notice that I am not trained to provide preventive tasks, I lack specific knowledge of the subject, I create evasive reactions, I intrude the privacy of my clients, I patronize my clients, I have to break my usual routine, it is difficult when there is no immediate reason") answered on a 7-point scale, with -6 indicating total agreement and 0 total disagreement $(\alpha=0.71)$.

\section{- perceived health benefits}

Perceived health benefits of quitting for the pregnant client was assessed with eight advantages ("When my client quits smoking she will improve her health, she will improve her physical condition, she will improve the health of the fetus, she will reduce her risk of heart disease, cancer and lung problems, she shows a feeling of 
responsibility for her pregnancy, she sets a positive example for other pregnant women"') answered on a 7-point scale, with 6 indicating total agreement and 0 total disagreement $(\alpha=0.80)$ and three disadvantages ("When rny client quits smoking she will gain more weight than usual, she will be less able to relax, she will eat less healthfully (eat more sweets)) answered on a 7-point scale, with -6 indicaring total agreement and 0 total disagreement $(\alpha=0.65)$.

\section{- social norms}

Social notms about giving smoking cessation advice were assessed using three items representing different groups of important colleagues ("My colleague midwives/general practitioners/gynecologists think that providing smoking cessation advice is part of my job) answered on a 5-point scale with -2 indicating total disagreement and 2 total agreement $(\alpha=0.72)$. Additionally midwives were asked to indicate how many of their colleague midwives/general practitioners/gynecologists smoke, using a 5-point scale, with 1 indicating none and 5 all.

- self-efficacy

Self efficacy for giving smoking cessation advice was assessed by 15 items ("Are you able to give smoking cessarion advice when you are running out of time, you have little time per client, you feel rushed, you feel sick, you are not convinced of the negative consequences of smoking during pregnancy, your client is not interested, your client shows resistance, your client is accompanied by her partner, children, mother or acquaintance, your colleagues do not talk about smoking cessation, your client has little time available, you do not have sufficient background information, you are not specifically trained to provide smoking cessation information) answered on a 7-point scale, with -3 indicating total disagreement and 3 total agreement $(\alpha=0.72)$.

- role definition

Role definition of midwives with regard to giving smoking cessation advice was assessed using two items (Do you think advising pregnant women to quit is part of your job?" and "Do you think helping pregnant women to quit is part of your job?") answered on a 6 -point scale, with 1 indicating total disagreement and 6 total agreement. 
- behavior

Behavior was assessed by asking the midwife how much time she actually spent, per client, giving smoking cessation advice during the first consultation (in minutes).

\section{- backeground variables}

Three sets of variables were sociodemographic (sex (female, male) and age (in years), midwife and practice characteristics (years working as a midwife, type of practice (solo, duo, group or health center), having a practice assistant (yes/no), location of midwife practice (Utrecht, Gelderland, Zeeland, Noord-Brabant, Limburg) duration in minutes of a first consult and follow-up consultations) and smoking status (smoker, exsmoker, never smoked) and about how many of your clients smoke at intake (in percentages).

Analysis

Chi-square for categorical variables and t-tests for continuous variables) were used for sociodemographic, midwife and practice characteristics and smoking items to check for any between group differences. Cronbach's $\alpha$ 's were computed to evaluate the internal consistency of the outcome expectations, perceived health benefits, social norms and self-efficacy items. Analysis of variance was performed to study differences between the two groups with regard to total scores on the scales (positive outcome expectations, negative outcome expectations, positive perceived health benefits, negative perceived health benefits, social support and self-efficacy) and also on individual items per scale.

Logistic regression was used to assess the predictive power of outcome expectations, perceived health benefits, social norms and self-efficacy for role definition with regard to giving smoking cessation advice. For the analysis, midwives wete divided into two subgroups using a median split of their combined scores on the two role definition items. All analyses were performed using the SPSS-x statistical analysis program (31). 


\section{Results}

\section{Recruitment and participant characteristics}

A total of $237(64.4 \%)$ midwives returned their questionnaire. Respondents could be characterized as non-smokers, having worked as a midwife more than 10 years, and working in duo or group practices without a practice assistant. An average first consult lasts about 30 minutes and follow-up consultations last approximately 10 minutes each. Midwives estimate that about $30 \%$ of their clients still smoke at intake. They reported spending on average 3.5 minutes discussing smoking with their client during intake. There were no differences between groups on any of these items (table 2.1).

\section{Ontcame expectations}

There are no differences between the two groups on the total score of disadvantages of providing smoking cessation advice. On individual items a difference was found only for believing that providing smoking cessation advice intrudes the privacy of clients (table 2.2). Midwives with a less positive role definition with regard to providing smoking cessation advice were more convinced that this intrudes on their clients' privacy (table 2.3).

With regard to advantages of providing smoking cessation advice, a difference was found between the two groups on the total score. Midwives with a more positive role definition were more convinced of the advantages (table 2.2).

In-depth analysis showed that midwives with a more positive role definition regarding providing smoking cessation advice were more convinced that providing smoking cessation advice reduces the risk of young children becoming ill, helps women to quit smoking, helps women to weigh the pros and cons, makes them a better midwife, helps them fulfill a preventive task, they show interest in their client's health and they help women to not start smoking again postpartum compared to midwives with a less positive role definition. 


\begin{tabular}{|c|c|c|c|c|}
\hline & $\begin{array}{l}\text { Positive role definition } \\
(\mathrm{n}=129)\end{array}$ & missing & $\begin{array}{l}\text { Negative role definition } \\
(\mathrm{n}=104)\end{array}$ & missing \\
\hline Sex (female) & $97.7 \%$ & & 98.0 & 2 \\
\hline Age (in years) & $37.7(9.65)$ & & $36.7(8.51)$ & 1 \\
\hline Smoker & $20.9 \%$ & & 25.2 & 1 \\
\hline Ex-smoker & 35.7 & & 35.0 & \\
\hline Never smoker & 43.3 & & 39.8 & \\
\hline $\begin{array}{l}\text { Number of years } \\
\text { working as a midwife }\end{array}$ & $12.4(9.41)$ & & $11.1(7.33)$ & 1 \\
\hline \multicolumn{5}{|l|}{ Type of practice } \\
\hline Solo & 20.9 & & 9.6 & \\
\hline Duo & 28.7 & & 32.7 & \\
\hline Group & 49.6 & & 57.7 & \\
\hline Health center & 0.8 & & & \\
\hline $\begin{array}{l}\text { Practice assistant } \\
\text { (yes) }\end{array}$ & 23.3 & & 23.1 & \\
\hline \multicolumn{5}{|l|}{ Province } \\
\hline Utrecht & $16.7 \%$ & & 17.3 & \\
\hline Gelderland & 28.6 & & 32.7 & \\
\hline Zeeland & 4.0 & & 1.0 & \\
\hline Noord-Brabant & 38.9 & & 32.7 & \\
\hline Limburg & 11.9 & & 16.3 & \\
\hline $\begin{array}{l}\text { Duration first consult } \\
\text { (minutes) }\end{array}$ & $30.5(9.01)$ & & $28.9(8.65)$ & 1 \\
\hline $\begin{array}{l}\text { Duration follow-up } \\
\text { consultation } \\
\text { (minutes) }\end{array}$ & $11.1(2.87)$ & & $10.6(1.97)$ & 1 \\
\hline $\begin{array}{l}\text { Percentage of clients } \\
\text { who smoke at intake }\end{array}$ & $31.4 \%$ & 2 & $31.2 \%$ & 3 \\
\hline $\begin{array}{l}\text { Time discussing } \\
\text { smoking first consult } \\
\text { (minutes) }\end{array}$ & $3.76(2.00)$ & 6 & $3.38(1.80)$ & 1 \\
\hline
\end{tabular}

\section{Perceived bealth benefits}

No differences were found between the two groups with regard to the total score of negative perceived health benefits of quitting for the pregnant woman (table 2.2). Additionally, no differences were found on individual items (table 2.3).

A difference was found between the two groups on the total score of positive perceived health benefits. Midwives with a more positive role definition were more convinced of the advantages of quitting for pregnant women (table 2). Additionally, women with a more positive role definition were more convinced that when pregnant women quit smoking they improve their health, they improve the health of the fetus, they decrease their risk of heart disease and lung problems and they set a positive example for other pregnant women (table 2.3). 


\begin{tabular}{|c|c|c|c|}
\hline Sum scores & $\begin{array}{l}\text { Positive role definition } \\
\text { (129) }\end{array}$ & Negative role definition (104) & \\
\hline $\begin{array}{l}\text { Negative outcome } \\
\text { expectations }\end{array}$ & $-15.3(7.31)$ & $-15.6(7.22)$ & ns \\
\hline $\begin{array}{l}\text { Positive outcome } \\
\text { expectations }\end{array}$ & $34.4(5.50)$ & $31.2(6.13)$ & $F(1,231)=17.3 ; p<0.001$ \\
\hline $\begin{array}{l}\text { Negative } \\
\text { perceived health } \\
\text { benefits }\end{array}$ & $-10.5(3.17)$ & $-9.88(3.14)$ & ns \\
\hline $\begin{array}{l}\text { Positive perceived } \\
\text { health benefits }\end{array}$ & $41.6(4.28)$ & $39.4(4.69)$ & $F(1,231)=14.2 ; \mathrm{P}<0.001$ \\
\hline Social norms & $3.32(2.00)$ & $2.64(1.94)$ & $F(1,228)=6.80 ; p<0.05$ \\
\hline Self-efficacy & $9.51(12.2)$ & $7.17(11.5)$ & ns \\
\hline
\end{tabular}

\section{Social support}

Midwives with a more positive role definition were more convinced that their colleagues are more positive about them providing this task (table 2.2). On individual items a difference was found for believing that general practitioners and gynecologists consider providing smoking cessation advice to be part of the midwife's job. (table 2.3).

\section{Self-efficacy}

There were no differences between the two groups with regard to total score on self-efficacy items (table 2.2). On individual items only a difference was found for being able to provide smoking cessation advice when you are running out of time or you have little time per client. Midwives with a more positive role definition are more convinced that they are able to provide smoking cessation advice in the situations described on this scale. 


\begin{tabular}{|c|c|c|c|}
\hline Outcome expectations & Positive $(n=129)$ & Negative $(n=104)$ & \\
\hline Cons Takes a lot of time & $.2 .50(1.75)$ & $-2.20(1.57)$ & \\
\hline Hindered by presence of others & $-1.22(1.44)$ & $-1.31(1.50)$ & \\
\hline Nor educated for preventive tasks & $-1.26(1.44)$ & $-1.19(1.25)$ & \\
\hline No specific knowledge & $-1.22(1.31)$ & $-1.34(1.32)$ & \\
\hline Evasive reactions & $-2.42(1.58)$ & $-2.54(1.42)$ & \\
\hline Intrusion of privacy & $-1.73(1.34)$ & $-2.09(1.38)$ & $F(1,231)=4.00 ; p<0.05$ \\
\hline Patronizing & $-1.88(1.40)$ & $-2.10(1.33)$ & \\
\hline Breaks usual routine & $-1.67(1.67)$ & $-1.34(1.44)$ & \\
\hline Difficult without immediate cause & $-1.40(1.50)$ & $-1.54(1.49)$ & \\
\hline Pros Less risk of young children becoming ill & $4.46(1.34)$ & $3.89(1.51)$ & $F(1,231)=9.09 ; \mathrm{p}<0.01$ \\
\hline Helping women to quit sinoking & $4.60(0.98)$ & $4.14(1.33)$ & $\mathrm{F}(1,231)=8.97 ; \mathrm{p}<0.01$ \\
\hline Weighing up pros and cons & $4.94(0.91)$ & $4.49(1.32)$ & $F(1,231)=9.33 ; p<0.01$ \\
\hline Being more appreciated & $2.88(1.14)$ & $2.86(1.07)$ & \\
\hline Being a better midwife & $4.71(1.29)$ & $4.27(1.35)$ & $F(1,231) 6.54 ; p<0.05$ \\
\hline Fulfilling a preventive task & $5.05(0.91)$ & $4.57(1.09)$ & $F(1,231)=1.3 .4 ; p<0.001$ \\
\hline Showing interest in clients health & $4.71(1.17)$ & $4.34(1.14)$ & $F(1,231)=5.88 ; p<0.05$ \\
\hline Relapse prevention & $3.03(1.45)$ & $2.63(1.56)$ & $\mathrm{F}(1,231)=4.04 ; \mathrm{p}<0.05$ \\
\hline \multicolumn{4}{|l|}{ Perceived health benefits } \\
\hline Cons Gaining more weight than usual & $-4.19(.124)$ & $-3.89(1.42)$ & \\
\hline Less able to relax & $-3.12(1.47)$ & $-3.08(1.40)$ & \\
\hline Less healthy eating habits & $-3.22(1.29)$ & $-2.91(1.34)$ & \\
\hline Pros improving health & $5.05(0.77)$ & $4.76(0.93)$ & $F(1,231)=6.97 ; p<0.01$ \\
\hline Improving physical condition & $5.18(0.68)$ & $5.03(0.65)$ & \\
\hline Better health of fetus & $5.60(0.54)$ & $5.31(0.76)$ & $F(1,23,1)=12.1 ; p<0.01$ \\
\hline Decreased risk heart disease & $5.36(0.66)$ & $5.06(0.71)$ & $F(1,231)=11.6 ; p<0.01$ \\
\hline Decreased risk cancer & $5.15(0.86)$ & $4.92(0.91)$ & \\
\hline Decreased risk lung problems & $5.35(0.68)$ & $5.05(0.81)$ & $F(1,231)=9.54, p<0.01$ \\
\hline Being responsible & $5.13(1.01)$ & $4.99(1.03)$ & \\
\hline Setting an example & $4.78(1.18)$ & $4.28(1.52)$ & $\mathrm{F}(1,231)=8.15 ; \mathrm{p}<0.01$ \\
\hline \multicolumn{4}{|l|}{ Social norms and smoking behavior } \\
\hline Smoking behavior of midwives & $1.61(0.84)$ & $1.63(0.98)$ & \\
\hline Smoking behavior of GPs & $2.00(0.72)$ & $1.95(0.73)$ & \\
\hline Smoking behavior of gynecologists & $2.04(0.93)$ & $1.96(0.94)$ & \\
\hline $\mathrm{nb}$ of colleague midwives & $1.47(0.73)$ & $1.31(0.77)$ & \\
\hline nb of colleague GPs & $0.83(0.88)$ & $0.55(0.79)$ & $F(1,228)=0.37 ; p<0.05$ \\
\hline nb of colleague gynecologists & $1.02(0.87)$ & $0.78(0.87)$ & $F(1,229)=4.29 ; \mathrm{p}<0.05$ \\
\hline \multicolumn{4}{|l|}{ Self-efficacy } \\
\hline Overrun office hours & $0.83(1.35)$ & $0.37(1.51)$ & $\mathrm{F}(1,231)=6.12 ; \mathrm{p}<0.05$ \\
\hline Insufficient time per client & $0.43(1.46)$ & $0.005(1.37)$ & $F(1,231)=4.25 ; p<0.05$ \\
\hline Feeling rushed & $-0.22(1.35)$ & $-0.24(1.36)$ & \\
\hline Feeling sick & $-0.006(1.45)$ & $0(1.39)$ & \\
\hline Not convinced of disadvantages & $-0.33(1.72)$ & $-0.57(1.60)$ & \\
\hline Client shows no interest & $0.26(1.52)$ & $0.006(1.39)$ & \\
\hline Client shows resistance & $0.31(.135)$ & $0.006(1.41)$ & \\
\hline Partnet present & $1.61(1.13)$ & $1.56(0.91)$ & \\
\hline Children present & $1.40(1.22)$ & $1.21(1.17)$ & \\
\hline Morher present & $1.38(1.19)$ & $1.28(1.20)$ & \\
\hline Acquaintance present & $1.36(1.18)$ & $1.25(1.16)$ & \\
\hline Collcagues do not provide information & $1.57(1.18)$ & $1.58(0.87)$ & \\
\hline $\begin{array}{l}\text { Client has insufficient time } \\
\text { Not enough backgtound information }\end{array}$ & $\begin{array}{l}0.41(1.34) \\
-0.22(1.35)\end{array}$ & $\begin{array}{l}0.22(1.37) \\
-0.29(1.17)\end{array}$ & \\
\hline Not educated & $0.80(1.33)$ & $0.64(1.04)$ & \\
\hline
\end{tabular}




\section{Correlations among scales}

Significant correlations between factors are presented in table 2.4. Logistic regression indicated that midwives who were more convinced of the advantages of giving smoking cessation advice $(B=0.07, S E=0.03, O R=1.07, p<0.05)$ and midwives who were more convinced of the advantages of quitting for pregnant women $(B=0.08$, $\mathrm{SE}=0.03, \mathrm{OR}=1.08, \mathrm{p}<0.05$ ) were more likely to have a positive role definition with regard to providing smoking cessation advice.

\begin{tabular}{|c|c|c|c|c|c|c|c|}
\hline & $\begin{array}{l}\text { Positive } \\
\text { outcome } \\
\text { expectations }\end{array}$ & $\begin{array}{l}\text { Negative } \\
\text { outcome } \\
\text { expectations }\end{array}$ & $\begin{array}{l}\text { Positive } \\
\text { perceived } \\
\text { health } \\
\text { benefits }\end{array}$ & $\begin{array}{l}\text { Negative } \\
\text { perceived } \\
\text { health } \\
\text { benefits }\end{array}$ & $\begin{array}{l}\text { Social } \\
\text { norms }\end{array}$ & $\begin{array}{l}\text { Self- } \\
\text { efficacy }\end{array}$ & $\begin{array}{l}\text { Role } \\
\text { definition }\end{array}$ \\
\hline $\begin{array}{l}\text { Negative } \\
\text { perceived } \\
\text { health } \\
\text { benefits }\end{array}$ & $0.41^{* *}$ & & $-0.16^{*}$ & & & & \\
\hline $\begin{array}{l}\text { Social } \\
\text { norms }\end{array}$ & $0.28 *$ & $0.15^{*}$ & & $0.14^{*}$ & & & \\
\hline $\begin{array}{l}\text { Self- } \\
\text { efficacy }\end{array}$ & & $0.26^{* *}$ & & & $0.23^{* *}$ & & \\
\hline $\begin{array}{l}\text { Role } \\
\text { definition }\end{array}$ & $0.35^{* *}$ & & $0.31^{* *}$ & & $0.24^{* *}$ & $0.17^{*}$ & \\
\hline Behavior & $0.13^{*}$ & & & & & $0.18^{* * *}$ & $0.19^{* *}$ \\
\hline
\end{tabular}

* significant correlation $\mathrm{p}<0.05$

** significant 


\section{Conclusions}

The present study investigated a set of psychosocial motives that were thought to determine whether a midwife has a positive or negative role definition with regard to giving smoking cessation advice to their clients. The framework used in the study was the ASE-model, which states that behavior is determined by attitude, social influences and self-efficacy.

There were no differences between midwives who expressed a more positive role definition and those who were less positive with regard to any of the background characteristics. Respondents with a more positive role definition were more convinced of the advantages of providing smoking cessation advice, the advantages of quitting smoking for their clients and perceived more support from their colleagues to provide smoking cessation advice. Examples of important items, which accounted for the difference between the two groups were that midwives with a more positive role definition regarding providing smoking cessation advice were more convinced that by providing advice they would perform their job as midwives better and would help more women to quit smoking and prevent relapse postpartum. An important finding of this study is that both groups had very low scores on the individual self-efficacy items.

The data from our self-administered questionnaire of smoking behavior indicated a relatively small percentage of smoking midwives in this survey; between $20.9 \%$ and $25.2 \%$. This means that the smoking rate among midwives is lower compared to the gencral population of Dutch adult females $(33.8 \%)$. Research of smoking habits among nurses and general practitioners has shown that these health professionals tend to smoke more than the general population. However, a study conducted in the United Kingdom (32) found that only $9.5 \%$ of midwives smoked, indicating that the relatively low smoking rates in our study group might be correct or attributed to response bias (fewer smoking midwrives responded to the questionnaire).

The results of the present study suggest that to foster a more positive attitude of midwives towards providing smoking cessation education to pregnant women who smoke, they need to receive information about the advantages such as helping more women quit smoking, women can be enabled to weigh up the pros and cons of nonsmoking, and more women can be helped to avoid relapse after delivery. Furthermore; 
it may be helpful for midwives to receive information about the positive health benefits of smoking cessation during pregnancy for mother and child. Additionally, publicizing the midwives, general practitioners and gynecologists who view smoking cessation as normal and good practice may increase positive role definition. Finally, training including enactment, persuasion, and role modeling to increase self-efficacy, even under adverse conditions, would seem to be helpful.

Moreover, some structural problems may also cause perceptions of low selfeffieacy, such as time constraints and lack of knowledge. The latter issue implies that changes at the organizational level may be needed in order to facilitate smoking cessation advice by midwives. An example of such changes can be training midwives systematically to provide effective stage-matched smoking cessation advice so information can be given in a short period of time. Another option would be the development of materials ro provide midwives with enough background information to make them feel comfortable in talking about the subject. Also, materials should be developed for smoking clients, so midwives can refer to these materials when women need more information. 


\section{References}

1. Avoidable losses: effects of smoking on reproductive health. US Department of Health and Social Services. State of Wisconsin;1988. Publication No (POH) $5086(10-88)$.

2. Windham GC, Swan SH, Ficster L. Parcntal cigarette smoking and the risk of spontaneous abortion. Am J Epidemiol. 1992;135:1394-403.

3. Shino PH, Klebanoff MA, Rhoads GG. Smoking and drinking during pregnancy; their effects on preterm birth. JAMA.1986;225:82-84.

4. Hanrahan JP. The effect of maternal smoking during pregnancy on early infant lung function. Am Rev Respir Dis.1992;145:1129-11.35.

5. DiFranza JR, Lew RA. Effect of maternal cigarette smoking on pregnancy complications and sudden infant death syndrome. J Fam Pract.1995; 40:385. 394.1 .

6. Hill AE. Considerations for smoking advice in pregnancy. The Llster Medical Journal 1988; 57(1): 22-27.

7. Laitakari J, Milunpalo S, Vuori I. The process and methods of health counseling by primary health care personnel in Finland: a national strategy. Patient Education and Counseling 1997;30:61-70.

8. SCP, Geboorte en Zorgvernieuwing (Birth and care innovation). Chapter 2:Verloskunde [Obstetrics]. Rijswijk: SCP/'s Gravenhage: VUGA 1991, teport.

9. McGreal IE. Smoking and the pregnant women. Midwives 1995; (108)1290: 218-221.

10. Devonport C. Support for pregnant women who wish to stop smoking. Nursing times 1996; $92(10) 36-7$.

11. Cantrell J. District nurses' perceptions of health education. J Clin Nurs 1998; 7 : $89-96$

12. Aitken A. Recognition of a major role: district nurses and health education. Prof Nurse 1994; 9: 574-6.

13. Ajzen I. The Theory of Planned Behavior. Organizational Behavior and Human Decision Processes 1991; 50: 179-211.

14. Bandura A. Social Foundation of thought and actions: a social cognitive theory. 
Englewood Cliffs, HJ, Prentice Hall, 1986.

15. De Vries H, Kok GJ. From determinants of smoking behavior to the implications for a prevention programme. Health Education Research 1986; 1 (2):85-94.

16. Prochaska JO, DiClemente CC. Stages and Processes of self-change of smoking: Toward an integrative model of change. Journal of Consulting and Clinical Psychology 1983; 51: 390-395.

17. Janz NK, Becker MH. The Health Belief Model: A Decade later. Health Education Quarterly 1984; 11: 1-47.

18. De Vries H, Mudde AN, Dijkstra A, Willemsen MC. Differential beliefs, perceived social influences, and self-efficacy expectations among smokers in various motivational phases. Prev Med. 1998;27:681-9.

19. De Vries H, Mudde AN 1998 Predicting stage transitions for smoking cessation applying the Attitude-Social influence-Efficacy model. Psychology and Health 13:369-385

20. De Vries H, Backbier E. Self-efficacy as an important predictor of quitting among pregnant women who smoke: the Ø-partem. Prev Med, 1994;23:167174.

21. Ajzen I, Fishbein M. Understanding attitudes and predicting; social beharior. Prentice Hall, Englewood Cliffs, 1980.

22. De Vries H, Backbier E, Kok GJ, Dijkstra M. The impact of social influences in the context of attitude, self-efficacy, intention, and previous behavior as predictors of smoking onset. Journal of Applied Social Psychology 1995; 25: $237-257$.

23. Bandura A. The exercise of control. New York: Freeman, 1997.

24. Brug J, Lechner L, De Vries H. Psychosocial determinants of fruit and vegetable consumption. Appetite 1995; 25: 285-196.

25. Lechner L, Vries de H. Participation in an employee fitness program: determinants of high adherence, low adherence, and dropout. Journal of Occupational and Environmental Medicine 1995; 37: 429-436.

26. Lechner L, De Vries H. Starting participation in an employee fitness program: 
Attitudes, social influence, and self-efficacy. Preventive Medicine 1995; 24: 6276.33.

27. Oostveen T, Knibbe RA, De Vries H. Social influences on young adults alcohol consumption; norms, modeling, pressure, socializing and conformity. Addictive Bchaviors 1996; 21: 187-197.

28. Wortcl E, De Vries H, Gcus de GH. Icssons learned from a Community Campaign on child safety in the Nitherlands. Family and Community Health 1995; 18 (3): 60-77.

29. De Vries $H$, Mudde A, Dijkstra A \& Willemsen M. Differential beliefs , perceived social influences and self-efficacy expectations among smokers in various motivational phases. Preventive Medicine 1998; 27: 681-689.

30. Willemsen M, De Vrics $H$. Evaluation of a smoking cessation intervention for Dutch employecs consisting of self-help methods and a group programma. Tobacco Control 1996; 4: 351-354.

31. SPSS Inc. SPSS-X User's guide. Chicago: SPSS Inc. 1988.

32. Sacker A. Smoking habits of nurses and midwives. Journal of Advanced Nursing 1990:1341-1346. 


\section{Chapter 3}

Use and appreciation of midwives of a Dutch smoking cessation and relapse prevention protucol for pregnant women ${ }^{1}$

I Submitted for publication to Patient education and counseling as: Bakker MJ, Dolan Mullen $\mathrm{P}$, de Vries $\mathrm{H}$ and van Breukelen G. Use and appreciation of midwives of a Dutch smoking cessation and relapse prevention protocol for pregnant women 


\begin{abstract}
Objective. To assess whether Dutch midwives trained to use a snoking cessation counseling protocol appreciated it and could implement it in routine care.
\end{abstract}

Methods. Pretest-posttest controlled design, with 118 midwives from 42 practices from 4 provinces; provinces were randomized. Data were collected from 69 midwives $(58.5 \%)$ after implementation.

Results. Although experimental group midwives indicated discussion of smoking, motivation to quit, and barriers as more difficult than control group midwives, they more often advised quitting, set a quit date, and provided aftercare. Clients reported midwives did not often discuss smoking postpartum or give post delivery booklets. More experimental midwives reported asking the partner if he wanted to quit, but there were no differences between study groups on advising the partner to quit and not smoke around his wife.

Conclusions. This effective, easy-to-implement program is recommended for broad dissemination. Further investigation is needed to improve the partner and pustpartum component. 


\section{Introduction}

Health care professionals are a potential source of health information, and their atritudes and counseling practices can have an important impact on the health habits of their clients (1). For pregnant women, health care professionals can play a major part in adapting health behavior, because during pregnancy regular contacts enable the professional to discuss adapting behavior on a regular basis and to provide aftercare. Since 1957, when Simpson found an average loss of birth weight of $200 \mathrm{~g}$ in babies of smoking women compared to babies of non-smoking women (2), it has become increasingly clear that smoking cessation is one of the most important factors which can reduce negative pregnancy outcomes (3). It is therefore essential to develop programs which enable women to quit smoking effectively early in pregnancy.

Several recent systematic reviews of studies evaluating the effectiveness of smoking cessation interventions for pregnant women (4-6) indicate that self-help plus minimal contact smoking cessation interventions have produced behavioral impact in public health maternity clinics and in obstetrical care in the U.S. and other industrialized countries (4). Important aspects of these effective interventions are to tailor the intervention to pregnancy and to use multiple methods (counseling, written materials, follow-up) (5). Most of the trials, which are incorporated in these reviews made use of specifically trained health care professionals; only two trials were noted with interventions delivered by usual prenatal care practitioners (7-8). Delivery in routine care has been less successful and represents an important aspect for future study (7-8).

The aim of the study described here was to study the feasibility of implementing a tailored smoking cessation and relapse prevention program for pregnant women and their partners in regular midwife prenatal care in the Netherlands. In the Netherlands uncomplicated pregnancies are usually guided by midwives who work independently in private practices, organized into regional networks.

The content of the midwife advice and materials was designed using a counseling approach, previously tested in the Netherlands for other groups of smokers (9-11) and known as the minimal intervention strategy (MIS). MIS combines elements of the Atritude-Social influences-Efficacy model (12-14) and the stages of change 
construct of the Transtheoretical model (15), and it helps intermediaries to select the information relevant to their clients. The main goal of the MIS is to promote a structured way of working, not to spent more time discussing smoking cessation but to use time available in regular care more efficiently. MIS for pregnant smokers consists of 7 steps, which are presented in figure 3.1 . These steps are similar to the steps developed by Glynn and Manley (16) for the U.S. National Cancer Institute and adopted by the Clinical Guideline Panel (17) and updated in the new guideline (18) by making an implicit step explicit by the insertion of "assess" before "arrange".

We expected that midwives in the experimental condition would find it easier to discuss smoking behavior, the consequences of smoking, advise women to quit, discuss barriers, set a quit date with motivated clients and provide aftercare, and would also perform these behaviors more often. 


\section{Methods}

\section{Derign}

The study used a pretest posttest randomized control design, where women were nested within midwife practice and practices within four provinces, the latter being the unit of randomization to the experimental and comparison condition (Figure 3.2). At intake at the midwife's office, both smokers as well as recent quitters (quit smoking in the previous six months) were included in the study. Details of the study and participant characteristics have been described elsewhere (19).

All midwives in participating practices received a questionnaire after the implementation period of the effectiveness study was finished in March, 1998. Enclosed with the questionnaire was a letter thanking them for their participation in the study, a small gift and a post-paid pre-addressed envelope. Reminders, another questionnaire and reply envelope, were mailed to non-responders one month later. At the end of that month non-responders were also contacted by telephone. To illuminate the reports of midwives, data collected among study participants were used.

\section{Intervention}

Midwives in the experimental condition received a brief manual and intervention card on the MIS. The manual describes seven steps, based on the health counseling model described by Gerards (20) which incorporates several different psychological concepts, including the stage of change, goal setting and relapse prevention. The health counseling model has been applied previously to smoking cessation by Mudde and colleagues (9) for the general population of smokers in the Netherlands.

Step 1 consisted of identifying smoking behavior by the woman and her partner (Figure 3.1). The number of cigarettes smoked per day and the motivation to quit were also assessed to classify her stage of change, adapted from the Transtheoretical model (21). Women who indicated that they wanted to quit smoking in the next 30 days were identified as in preparation, women who indicated that they want to quit smoking during this pregnancy but not within the next 30 days were identified as contemplators 
and women who indicated that they did not want to quit smoking were identified as precontemplators. In step 2 , the midwife tried to enhance the motivation to quit for precontemplators and contemplators by giving information about mainly short term advantages of not smoking. Step 3, for those in the preparation stage, the midwife discussed barriers that might hamper a successful quit attempt and midwives were to help mobilize social support by asking whether someone in the wornan's environment would help her during the quitring process. Also for women in preparation a quit date was set and noted by the midwife (step 4). Step 5 was to give additional self-help materials to women in all stages. Step 6 was to ask what kind of aftercare she preferred (telephone contacts, during the next consultation, on initiative of the woman herself). And, step 7 at about eight months gestation, the midwife handed out a booklet about smoking after delivery to all who had been smokers, regardless of quitting status. Information about the consequences of passive smoking for young children was discussed, and for quitters, a commitment to stay a non-smoker was invited. An intervention card was designed for midwives to be able to write down progress and commitments of their clients.

We offered all midwives in the experimental condition 3 hours of training about how to talk about smoking and smoking cessation with their clients during the first consultation based on the MIS. During pregnancy the midwife was advised to talk about smoking with her client on a regular basis. At least two contacts were encouraged during the first consultation (three months pregnant) to enhance quitting behavior and at eight months pregnant to talk about relapse prevention.

For clients of midwives in the experimental condition a video, self-help guide and post delivery booklet were developed. The video was especially directed to precontemplators, women who were not giving any thought to stopping smoking and who probabily would not put any effort in reading materials about smoking cessation. The self-help guide is stage-matched and based on a self-help smoking cessation. guide used by general pracritioners in the Netherlands (9-10). The guide was adapted for pregnant women, by changing the definitions of stage (defining precontemplators as those not serious about quitting in the next 30 days), adding pregnancy specific information and changing the illustrations. To make women aware of the danger of 
relapse after delivery, a booklet was written about the positive effects of not smoking after delivery and the consequences of environmental tobacco smoke for young children.

Step 1 Assessing smoking behavior from woman and partner and motivation to quit $\downarrow$

Step 2 Enhancing motivation to quit (precontemplation and contemplation)<smiles>C1CC1</smiles>

Step 3 Discussing barriers and motilizing social support (preparation)

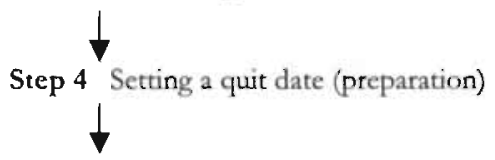

Step 5 Provision of written materials (video self-help guide and partner booklet)

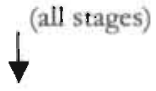

Step 6 Aftercare (actors)

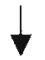

Step 7 Discussing postpartum relapse prevention and smoking behavior (post delivery booklet) (all stages)

Figure 3.1 Smoking cessation and relapse prevention protocol for pregnant women and their partners

Because pregnant women who want to quit smoking indicate that it is very difficult for them to quit when their partner smokes, a special booklet was made for this partner. The partner booklet did not follow the MIS, because there was no counseling element in place; it was directed to precontemplators. It stressed the importance of the commitment of the expectant father to the pregnancy, and it explained that quitting together with his partner would make a substantial difference for the health of their baby and for the parents themselves.

Midwives in the comparison condition were asked to provide smoking cessation counseling as they used to do and hand out a folder about smoking cessation during pregnancy developed by the Dutch Foundation on Smoking and Health. 


\section{Measures}

- midwives

outcomes. Six questions were asked to assess performance of smoking cessation counseling steps with pregnant clients. Did you discuss your clients' smoking behavior, did you discuss consequences of smoking during pregnancy, did you advise your client to quit. smoking, did you discuss barriers which might hamper a quit attempt, did you. set a quit date with your client and did you discuss what type of aftercare your client would prefer ( $1-5$ scale with $1=$ never and $5=$ always). Additionally, midwives were asked to indicate how difficult it was to apply each individual step ( $1-5$ scale with $1=$ very difficult and $5=$ very easy).

With regard to partner smoking, midwives were: asked whether they assessed partner smoking behavior, advised the partner to quit and advised the partner not to smoke around his pregnant wife $(1-5$ scale with $1=$ never and $5=$ always $)$.

background variables. We measured one sociodemographic characteristic, age: in years; professional and practice characteristics, including years working as a midwife and type of practice (solo, duo, group or health center), having a practice assistant: (yes/no), duration in minutes of a first consult and follow-up consultations) and location of midwife practice (East/ West); personal. smoking behavior, are you a smoker (never, not anymore, yes) and smoking in the professional environment (no, minority, half, majority, all).

implementation variables. Midwives indicated whether they participated in the. training (yes/no) and what they thought of the duration (1-5 scale with $1=$ too long and $5=$ too short) and the content (good/bad). They also reported the amount of time: spent discussing smoking cessation at the first consult and during pregrancy (before the start of the study and during the study period). With regard to the video, self-help guide, post delivery booklet and partner bookiet, midwives indicated whether they distributed them to their clients (1-5 scale, with $1=$ never and $5=$ always) and watched of read them (yes/no). Those who watched the video rated its readability, understandability, interest, attractiveness and length (1-5 scale, with $1=$ the lowest score and $5=$ the highest. The same aspects of the manual, the self-help guide, postdelivery booklet and partner booklet were rated, using the same rating scale. Lastly, 
they were asked to give a global rating for the intervention (1-10 scale, with $10=$ highest.

- clients

implementation variables. Participants indicated whether or not their midwife discussed smoking at intake, advised to quit, discussed barriers for a quit attempt, set a quit date, regularly discussed smoking during pregnancy, discussed consequences of passive smoking postpartum and discussed smoking behavior postpartum. Additionally, they were asked to indicate their opinion of receiving smoking cessation advice from their midwife (1-7 scale, with $1=$ very bad and $7=$ very good) and to give an overall rating of the smoking cessation advice received at the first consult and during pregnancy (1-10 scale, with 10=highest). With regard to the video, self-help guide, post delivery booklet and partner booklet, women indicated whether or not they received them.

\section{Anatysis}

Chi-square (for categorical variables) and t-tests (for continuous variables) were used to test for any differences between the study conditions in descriptive variables. Non-response was analyzed using logistic regression analysis, with response as the dependent variable and study condition $(0=$ control, $1=$ experimental $)$ and location of midwife practice ( $0=$ East, $1=W e s t)$ as independent variables.

To determine whether midwives in the experimental condition were more effecrive in applying the MIS steps, we used linear regression, with applying the MIS steps and difficulty of applying the steps as outcomes and the following covariates as independent variables: study condition and location of midwife practice. Linear regression analysis was conducted with participant data to explore differences on advice received from the midwife regarding smoking cessation pre- and postpartum as outcomes. Independent variables included study condition $(0=$ control, $1=$ (xperimental), intake smoking status $(0=$ smoker, $1=$ recent quitter $)$ and location of practice (1): East, $1=W^{\prime}$ cst). Additionally, linear regression with outcomes indicating satisfaction with advice reccived and the same independent variables also were conductcd. To keep tcsults comparable with data gathered from midwives, client data 
were aggregated to the midwife level.

Traditional linear regression analysis is based on the assumption that the outcomes of the study are statistically independent. However, ours is a nested design with midwives nested within practices (on average approximately, two midwives per practice), which may lead to intra-class correlation, i.e. positive dependence between outcomes in the same practice, due to province and practice effect on the outcome. Ignoring such intra-class correlation would lead to underestimation of the standard error of the treatment effect, overly narrow confidence intervals, and possibly Type I errors (22-23). Therefore, we also aggregated data to the practice level and conducted the same linear regression analyses with practices as unit of analysis.

\section{Results}

\section{Recruitment and drop-out}

\section{- midnives}

In total, 118 midwives representing 42 practices were assigned to participate in the study, 57 in the experimental condition and 61 in the control condition, and approximately $65 \%$ and $52 \%$ of the two groups respectively, returned the follow-up questionnaire (Figure 3.2). Reasons for not returning the questionnaire were retirement. $(4.1 \%)$, on holiday $(2 \%)$, no longer working in the practice $(10.2 \%)$, and not interested. or no time $(83.7 \%)$. Non-response was not related to study condition $(p>0.20)$ nor location of midwife practice $(\mathrm{p}>0.10)$.

- clients

A total of 556 women were included in the study, 253 in the experimental condition (clients of 44 midwives out of 20 practices) and 303 in the control condition. (clients of 51 midwives out of 20 practices) (Figure 3.2). By the second posttest approximately $88 \%$ remained eligible for the study. 
Characteristics

- miduives

Midwives participating in the study can be characterized as having a mean age of: about 37 years and having worked as a midwife for a mean of 12 years (Table 3.1). Most were members of a group practice and did not have a practice assistant. The reported mean length of the first consultation was about 30 minutes, with follow-up consultations of about 10 minutes. About $8 \%$ of midwives indicated to be smokers themselves and most reported that none of their colleagues smoked.

Study groups differed on number of minutes used for a first consultation and location of midwife practice (Table 3.1). Midwives in the experimental group used less time for a first consultation and practices were more often located in the Eastem part of the Netherlands.

Figure 3.2 Design, sampling procedure, sizes of samples and participation rates (\%)

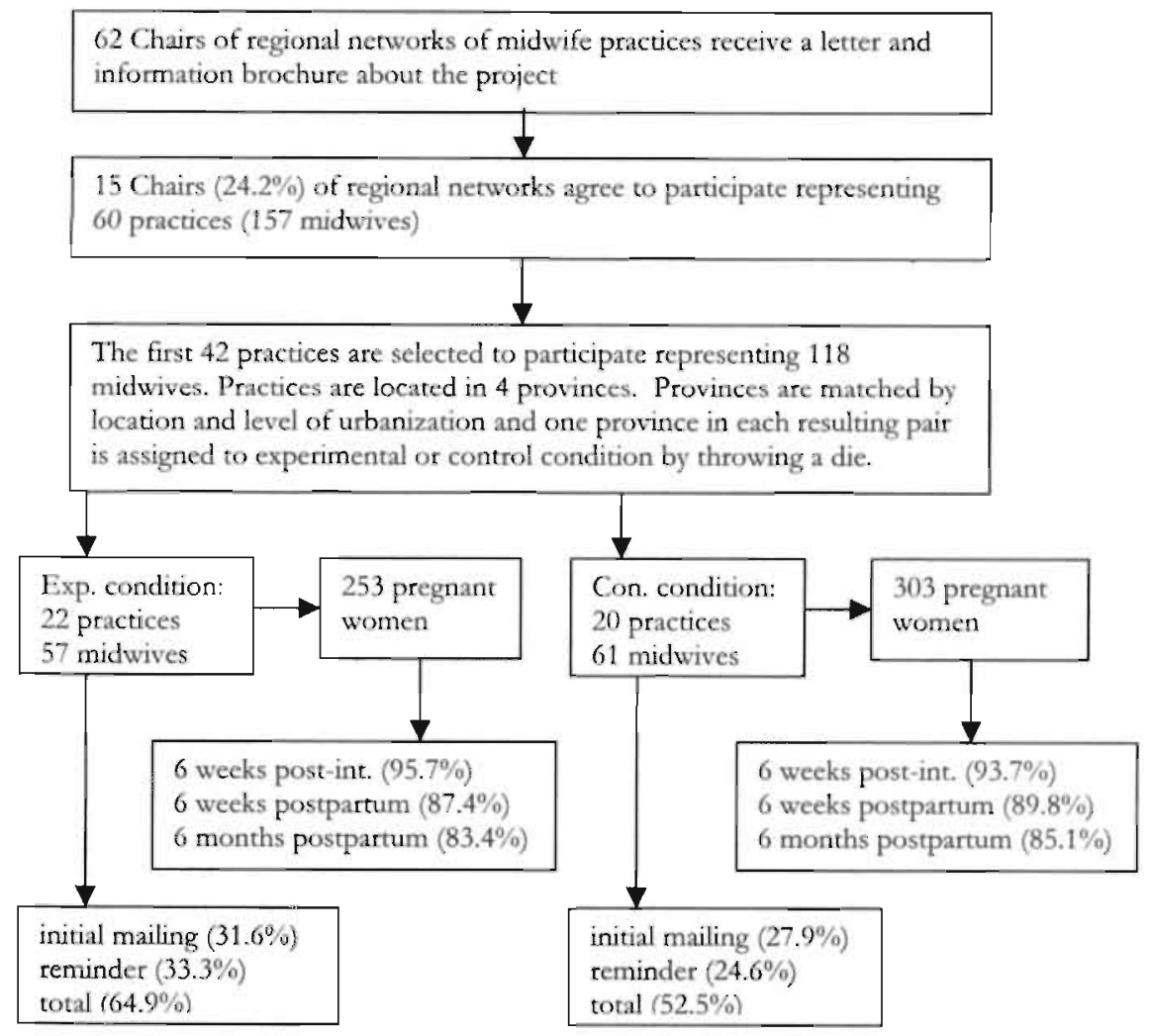




\begin{tabular}{|c|c|c|c|c|}
\hline \multicolumn{5}{|c|}{$\begin{array}{l}\text { Table } 3.1 \text { Sociodemographic, midwife and practice and smoking characteristics in } \\
\text { percentages or mean (SD) by study group }\end{array}$} \\
\hline $\operatorname{Age}\left(\mathrm{M}_{2} \mathrm{SD}\right)$ & $38.4(9.39)$ & & $36.7(8.16)$ & \\
\hline $\begin{array}{l}\text { Years working as a midwife } \\
(\mathrm{M}, \mathrm{SD})\end{array}$ & $12.5(8.70)$ & & $11.7(8.03)$ & \\
\hline Type of practice & & 2 & & \\
\hline Solo & $5.7 \%$ & & 3.1 & \\
\hline Duo & 20.0 & & 6.3 & \\
\hline Group practice & 74.3 & & 87.5 & \\
\hline Health center & & & 3.1 & \\
\hline Practice assistant (yes) & $37.8 \%$ & & 18.8 & \\
\hline $\begin{array}{l}\text { Minutes first consultation } \\
(\mathrm{M}, \mathrm{SD}) \\
(\mathrm{F}(1)=4.95 ; \mathrm{p}<.05)\end{array}$ & $29.8(7.74)$ & 1 & $34.1(8.48)$ & \\
\hline $\begin{array}{l}\text { Minutes follow-up } \\
\text { consultations (M,SD) }\end{array}$ & $11.2(2.44)$ & & $10.3(1.33)$ & \\
\hline $\begin{array}{l}\text { Minutes discussing smoking } \\
\text { cessation first consultation } \\
(\mathrm{M}, \mathrm{SD})\end{array}$ & $3.4(5.01)$ & 4 & $4.8(8.26)$ & 4 \\
\hline $\begin{array}{l}\text { Minutes discussing smoking } \\
\text { cessation during pregnancy } \\
(\mathrm{M}, \mathrm{SD})\end{array}$ & $8.2(9.08)$ & 11 & $6.9(4.07)$ & 11 \\
\hline Smoker (yes) & $10.8 \%$ & & 6.3 & \\
\hline \multicolumn{5}{|l|}{ Do colleagues smoke } \\
\hline No & 81.1 & & 90.6 & \\
\hline Minority & 16.2 & & 9.4 & \\
\hline All & 2.7 & & & \\
\hline $\begin{array}{l}\text { Location midwife practice } \\
(\text { West })\left(\chi^{2}(1)=5.28 ; p<.05\right)\end{array}$ & $35.1 \%$ & & $63.3 \%$ & 2 \\
\hline
\end{tabular}

\section{Satisfaction with training and content of materials}

- midwives in the experimental group

$\Lambda t$ least one midwife was trained in using the MIS in every participating practice, $71 \%$ of all midwives in the experimental condition. Of midwives who returned the questionnaire $44.6 \%$ participated in the training. Participants of the training found the length sufficient, with an average of $2.86(1-5$ scale, $\mathrm{SD}=0.36)$ and $74.3 \%$ appreciated the content.

In total $86 \%$ of the midwives watched the video, $97 \%$ read the self-help guide, and $89 \%$, the post delivery booklet. Participant ratings of the length of the video, and written materials were lower than ratings of other attributes (Table 3.2). In general midwives rated the materials as credible, understandable, interesting and attractive (Table 3.2). The self-help guide, however, was perceived as too long. The overall rating for the intervention was $7(\mathrm{SD}=0.85)$, on a scale from 1 to 10 .

In total, $83.8 \%$ of midwives in the experimental group indicated that they found 
the health counseling protocol and accompanying materials implementable in routine care, $78.4 \%$ of experimental midwives also plan to use the materials when they become available nationally.

\begin{tabular}{llllll}
\hline \multicolumn{5}{l}{ Table 3.2 Evaluation of manual, video, self-help guide and post delivery booklet (M,SD) } \\
\hline & Manual & Video & Self-help guide & $\begin{array}{l}\text { Post } \\
\text { delivery }\end{array}$ & Partner booklet \\
& & & & booklet & \\
Credible* & $4.31(0.58)$ & $4.15(0.76)$ & $4.29(0.52)$ & $4.12(0.74)$ & $4.18(0.68)$ \\
Understandable & $4.20(0.63)$ & $4.21(0.65)$ & $4.26(0.56)$ & $4.09(0.68)$ & $4.18(0.63)$ \\
Interesting & $3.91(0.56)$ & $3.79(0.82)$ & $3.97(0.82)$ & $3.85(0.62)$ & $3.85(0.62)$ \\
Attractive & $3.50(0.71)$ & $3.68(0.79)$ & $3.88(0.73)$ & $3.84(0.68)$ & $3.88(0.61)$ \\
Length & $2.56(0.70)$ & $2.91(0.82)$ & $2.32(0.68)$ & $2.66(0.55)$ & $2.50(0.57)$ \\
\hline
\end{tabular}

* Scale of $1-5,1=$ lowest rating

Performance of smoking cessation counseling steps - midwives

Midwives in the experimental group indicated they had distributed the video $(M=4.43, S D=0.92)$, self-help guide $(M=4.43, S D=0.92)$ and post-delivery booklet $(\mathrm{M}=3.49, \mathrm{SD}=1.36)$. During the implementation period, the experimental group reported discussing smoking cessation with their clients at the first consultation a mean of 6.5 minutes $(\mathrm{SD}=3.01)$ and in the control condition during $4.2(\mathrm{SD}=2.78)$ minutes $(F(1)=9.57$; $<.01)$. During the entire pregnancy smoking cessation was discussed a mean of $14.2(\mathrm{SD}=8.71)$ and $7.5(\mathrm{SD}=5.25)$ minutes, respectively $(\mathrm{F}(1)=8.62 ; \mathrm{p}<.01)$.

Study groups differed on providing the advice to quit, setting a quit date and discussing aftercare (Table 3.3). The experimental group more often reported giving the advice to quit, setring a quit date with women who indicated they were motivated to quit and discussing aftercare. With data aggregated to the practice level, similar results were found. The difference between the two groups with regard to providing the advice to quit was no longer statistically significant, however. 


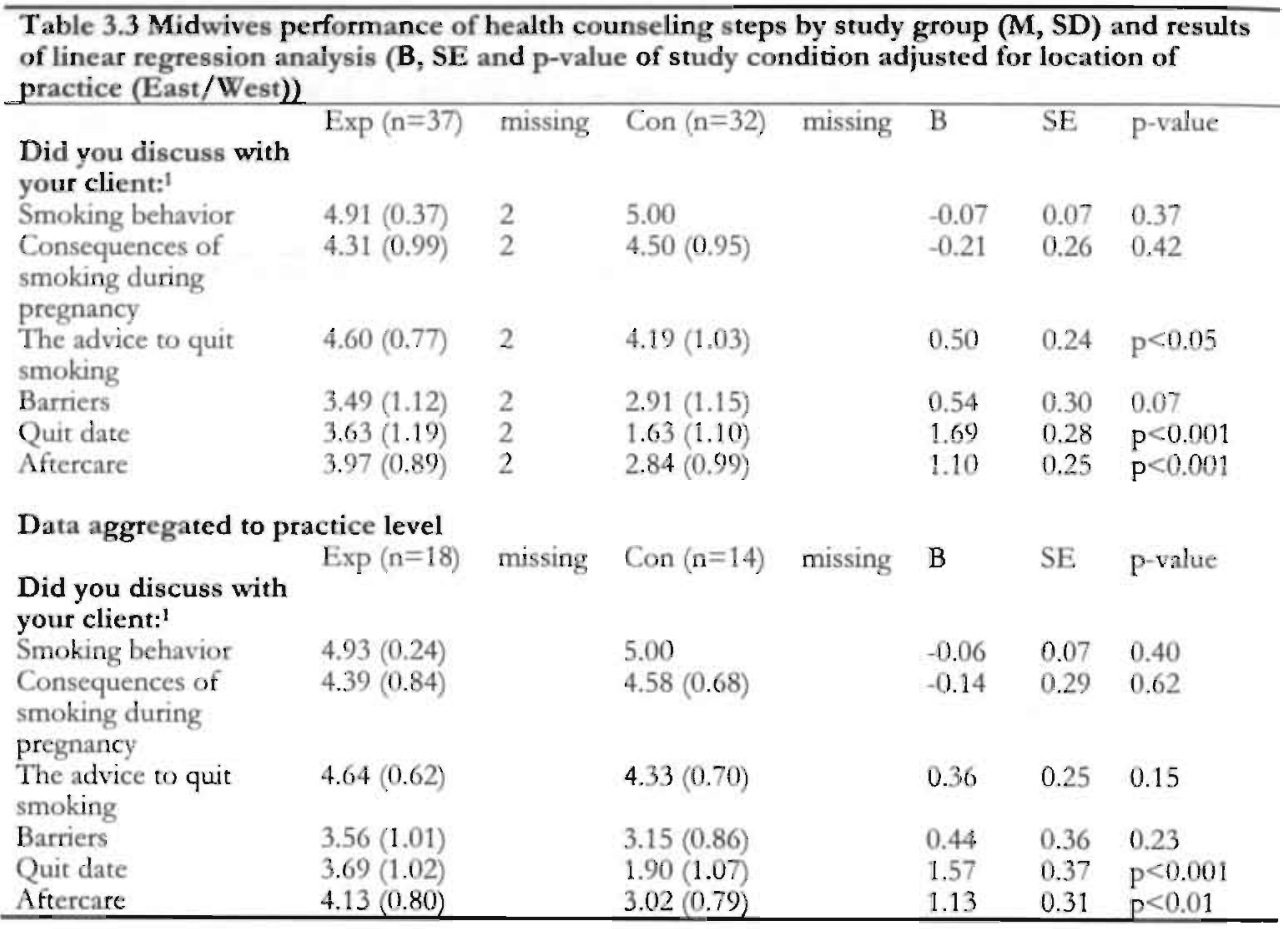

${ }^{1}$ Scale of $1-5(1=$ never, $5=$ always $)$

Midwives in the comparison condition reported greater ease in discussing smoking, motivation to quit and barriers to a successful quit attempt (Table 3.4). Similar results were found for data aggregated to the practice level.

\section{- study participants}

In total $84 \%$ of experimental group women reported having received the video, $80 \%$, the self-help guide and $17 \%$, the post delivery booklet. More women in the experimental condition reported that their midwife discussed with them their smoking behavior, gave the advice to quit, discussed barriers which might hamper a successful quit: attempt, set a quit date, regularly discussed smoking during pregnancy, discussed consequences of passive smoking and discussed smoking behavior postpartum (Table 3.5). Identical results were found with data aggregated to the practice level. 
Table 3.4 Difficulty of applying the steps of the health counseling model by study group (M,SD) and results of linear regression analysis $(B, S E$ and $p$-value of study condition adjusted for location of practice (East/West))

Do you find it $\operatorname{Exp}(\mathrm{n}=37)$ missing $\operatorname{Con}(\mathrm{n}=32)$ missing $\mathrm{B} \quad$ SE $\mathrm{p}$-value

difficult or easy to

discuss: ${ }^{1}$

Smoking behavior

Consequences of

$3.74(0.61) \quad 1$

$4.03(0.62) \quad 2$

$4.63(0.55)$

$4.06(0.77)$

$-0.90$

$0.16 p<0.001$

smoking during

pregnancy

motivation to quit

$3.06(0.89) \quad 3$

Barriers

Quit date

$2.71(0.79) \quad 2$

$4.03(0.78)$

$-0.15$

$0.17 \quad 0.40$

Aftercare

$3.00(0.94) \quad 2$

$3.42(0.81)$

$\begin{array}{ll}2 & 2.58(0.85) \\ 2 & 3.84(0.81)\end{array}$

$3.57(0.81)$

$\begin{array}{ll}2 & 2.58(0.85) \\ 2 & 3.84(0.81)\end{array}$

\section{$-0.94$}

$\begin{array}{lll}-0.62 & 0.22 & \mathrm{p}<0.01\end{array}$

0.31

0.23

0.19

$\begin{array}{lll}-0.20 & 0.21 & 0.37\end{array}$

Data aggregated to practice level

Do you find it

$\operatorname{Exp}(n=18)$ missing $\operatorname{Con}(n=14)$ missing $B \quad$ SE $p$-value

difficult or easy to

discuss: ${ }^{1}$

Smoking behavior

Consequences of

smoking during

pregnancy

motivation to quit

Barriers

Quit date

Afrercare

$3.65(0.61)$
$4.12(0.48)$

$2.92(0.81)$
$2.75(0.68)$
$2.88(0.85)$
$3.67(0.67)$

\section{$4.65(0.41)$}

$4.05(0.55)$

$4.04(0.70)$

$3.50(0.82)$

$2.60(0.74)$

$3.75(0.68)$
$-1.00$

0.09

0.20

0.20

$\mathrm{p}<0.001$

0.66

$-0.95$

$-0.67$

0.27

0.29

0.29

$-0.06$ $p<0.01$

$p<0.05$

0.64

0.83

IScale of 1-5 (1=very difficult, $5=$ very easy $)$

Experimental group clients give higher mean ratings on a scale of $1-7$, with 7 the highest rating, of advice about smoking cessation from their midwife $(M=6.5$, $\mathrm{SD}=0.29)$ than control group clients $(\mathrm{M}=6.1, \mathrm{SD}=0.61)(\mathrm{B}=0.33, \mathrm{SE}=0.09, \mathrm{P}<0.001)$.

On a scale from $1-10$, with 10 the highest, the overall rating for the advice received from the midwife at intake was $7.3(\mathrm{SD}=0.69)$ and $6.8(\mathrm{SD}=1.00)$ for experimental and control group women $(B=0.12, \mathrm{SE}=0.06, \mathrm{p}<0.05)$. For the advice received from the midwife during pregnancy the ratings were $6.7(\mathrm{SD}=0.90)$ and $5.8(\mathrm{SD}=1.86)$, respectively $(B=0.008, S E=0.03, p<0.05)$. Similar results were found with data aggregated to the practice level. 


\begin{tabular}{|c|c|c|c|c|c|c|c|}
\hline & $\operatorname{Exp}(n=44)$ & missing & $\operatorname{Con}(n=51)$ & missing & B & SE & p-value \\
\hline \multicolumn{8}{|l|}{$\begin{array}{l}\text { Did your midwife } \\
\text { discuss: }\end{array}$} \\
\hline Smoking at intake & $0.91(0.18)$ & & $0.72(0.29)$ & & 0.17 & 0.05 & $\mathrm{p}<0.01$ \\
\hline Advice to quit & $0.85(0.25)$ & 1 & $0.64(0.36)$ & 6 & 0.22 & 0.07 & $\mathrm{p}<0.01$ \\
\hline Discuss barriers & $0.38(0.29)$ & & $0.11(0.18)$ & & 0.25 & 0.05 & $\mathrm{p}<0.001$ \\
\hline Set a quit date & $0.33(0.34)$ & 1 & $0.03(0.16)$ & 6 & 0.22 & 0.06 & $p<0.001$ \\
\hline $\begin{array}{l}\text { Regularly discuss } \\
\text { smoking during } \\
\text { pregnancy }\end{array}$ & $0.55(0.29)$ & & $0.21(0.27)$ & & 0.35 & 0.06 & $\mathrm{p}<0.001$ \\
\hline $\begin{array}{l}\text { Discuss consequences } \\
\text { of passive smoking } \\
\text { postpartum }\end{array}$ & $0.51(0.32)$ & & $0.26(0.26)$ & & 0.29 & 0.06 & $p<0.001$ \\
\hline $\begin{array}{l}\text { Discuss smoking } \\
\text { behavior postpartum }\end{array}$ & $0.21(0.25)$ & & $0.04(0.08)$ & & 0.17 & 0.04 & $\mathrm{p}<0.001$ \\
\hline \multicolumn{8}{|c|}{ Data aggregated to practice level } \\
\hline \multicolumn{8}{|l|}{$\begin{array}{l}\text { Did your midwife } \\
\text { discuss: }\end{array}$} \\
\hline Smoking at intake & $0.94(0.08)$ & & $0.74(0.16)$ & & 0.19 & 0,04 & $\mathrm{P}<0.001$ \\
\hline Advice to quit & $0.87(0.14)$ & & $0.61(0.24)$ & & 0.26 & 0.07 & $p<0.01$ \\
\hline Discuss barriers & $0.39(0.23)$ & & $0.11(0.10)$ & & 0.28 & 0.06 & $\mathrm{p}<0.001$ \\
\hline Set a quit date & $0.33(0.29)$ & & $0.02(0.05)$ & & 0,25 & 0.07 & $\mathrm{p}<0.01$ \\
\hline $\begin{array}{l}\text { Regularly discuss } \\
\text { smoking during } \\
\text { pregnancy }\end{array}$ & $0.57(0.21$ & & $0.20(0.15)$ & & 0.37 & 0.06 & $p<0.001$ \\
\hline $\begin{array}{l}\text { Discuss consequences } \\
\text { of passive smoking } \\
\text { postpartum }\end{array}$ & $0.52(0.29)$ & & $0.30(0.13)$ & & 0.26 & 0.08 & $\mathrm{p}<0.01$ \\
\hline $\begin{array}{l}\text { Discuss smoking } \\
\text { behavior postpartum }\end{array}$ & $0.17(0.14)$ & & $0.05(0.07)$ & & 0.11 & 0.04 & $\mathrm{p}<0.01$ \\
\hline
\end{tabular}

'Scale of 0-1 $(0=$ no, $1=$ yes $)$ at the patient level, continuous from $0-1$ at the midwife or practice level.

\section{Partner smoking}

- midwives

Midwives indicated on a scale from 1 to 5 to have distribured the partner. booklet $(M=4, S D=1.16)$. In total, $89.2 \%$ of midwives indicated having read the booklet. They rated the partner booklet as credible, understandable, interesting, attractive, and sufficient in length (Table 3.2).

There was no difference berween experimental and control midwives with regard to asking the partner if he wanted to quit $(M=3.82$ (1.49) vs. $M=3.08(1.35)$, $\mathrm{B}=0.78, \mathrm{SE}=0.40, \mathrm{p}=0.06)$ advising the partner to quit $(\mathrm{M}=4.03$ (1.33) vs. $\mathrm{M}=3.58$ 
(1.42), $\mathrm{B}=0.42, \mathrm{SE}=0.38, \mathrm{p}=0.28$ ) and advising the partner not to smoke in the presence of his pregnant wife ( $M=3.45$ (1.35) vs. $M=3.85$ (1.32), $B=-0.28, S E=0.39$, $\mathrm{p}=0.46$ ). Similar results were found with data aggregated to the practice level.

- study participants

In total $86.1 \%$ of women in the experimental group reported having given the partner booklet to their smoking partner. 


\section{Discussion}

The vast majority of midwives in the experimental group who returned the follow-up questionnaire in the study of the effectiveness of a multi media smoking cessation and relapse prevention program for pregnant women and their partners in routine Dutch prenatal care indicated that the program is easy to implement within their practice and that they plan to use the program when it becomes available nationally. They reported distributing the different materials (video, self-help guide and post delivery booklet) to a large majority of their clients and those midwives who also watched and read the materials themselves appreciated content and appearance.

After a three-hour training session and supported by a manual and intervention card describing the 7 steps, midwives were able to implement the steps of the counseling strategy effectively. Though they indicated that applying some of the steps was more difficult compared to their colleagues in the control group, midwives in the experimental group more often advised their clients to quit smoking, set a quit date with women who are motivated to quit smoking and discussed and provided arrangements for aftercare.

Similar data collected among the participants of the study largely confirmed the reports of midwives. Most women indicated they received the video and self-help guide. Adjusted for location of midwife practice and intake smoking status, women in the experimental group reported more often receiving the advice to quit and counseling about quitting compared to women in the control group. Although midwives in the experimental group indicated that they found applying some of the steps more difficult, women were more positive about the advice received from their midwife, both during intake as well as during the entire pregnancy.

With regard to receiving advice about non-smoking postpartum, however, data collected among midwives and women were contradictory. Responding midwives indicated they distributed the post delivery booklet to the majority of their clients, whereas only $17 \%$ of clients indicated they received it. Additionally, although women in the experimental group indicated they received more advice regarding their smoking behavior postpartum compared to control group clients, the percentage who said they received advice was very low. 
With regard to smoking behavior of the partner, most midwives distributed the partner booklet to their clients, which was confirmed by reports of their clients. However, there were no differences between the two groups with regard to discussing smoking behavior of the partner.

From the above it can be concluded that the implementation of the smoking cessation component of the program for pregnant women during pregnancy was successful. However, implementation of the relapse prevention component postpartum and partner smoking cessation was not successful. This is also confirmed by the results of the study which are reported in detail elsewhere. Until six weeks postpartum, abstinence rates are significantly larger among women in the experimental group $(21.3 \%$ and $12.0 \%$ in the experimental and contral group, respectively) (24). However, this effect is not sustained. Results collected six months postpartum show no differences between groups with regard to abstinence (19). At no single time point, partner smoking rates differ between the two groups.

How can this be explained? Perhaps, prenatal carc providurs are not the right intermediaries for interventions aimed at continued smoking cessation pustpartum. This seems to be confirmed by the fact that although several studies, which focuscd on prenatal smoking cessation but also included a post delivery relapse component were unable to report effects postpartum (25-26). Even though these interventions were not implemented in routine care, but made use of specially trained personnel.

Furthermore, it might be that interventions aimed at smoking cessation during pregnancy do not make use of the right arguments to sustain non-smoking postpartum. By trying to convince pregnant women to quit smoking, most emphasis is put on the harmful effects of smoking for the fetus. This is also one of the recommendations of the AHCPR regarding smoking cessation interventions for pregnant women (17). However, by laying the emphasis on the consequences for the fetus, women might draw the conclusion that cessation will only be temporary. As soon as the baby is born these consequences disappear and the woman is free to start again. The decision to quit might therefore not be a decision to refrain from smoking for life but only while pregnant. This seems to be confirmed by Stotrs et al. (27-28), who reported that during pregnancy the baby is an 'external' motivation for quitting, there is no 'internal' 
intention to change.

Since this study has shown that it is feasible to implement the program in routine midwifery care in the Netherlands and has shown to be effective in increasing cessation both during pregnancy as well as early postpartum, we recommend further investigation of the possibilities and requirements of implementation. Besides implementation of the intervention in midwife practices, it will be important to study preconditions for implementation of the intervention in general practitioners and gynecologist practices, since they are also providers of prenatal care.

As for the partner and the post delivery component of the intervention, further work on an appealing and efficacious intervention is required. It may be that other access points to communicate with partners about smoking cessation during pregnancy and the positive role they can play in helping their wife to stop should be found. As for the post delivery component it might be most effective to study possibilities to continue the non-smoking message postpartum at for instance well baby visits, although this will be very difficult to implement in routine care. So far, the few studies $(25,29-30)$ which have aimed specifically at non-smoking postpartum have not been able to reduce relapse rates. 


\section{References}

1. Laitakari J, Miilunpalo S, Vuori I. The process and methods of health counseling by primary health care personnel in Finland: a national strategy. Patient Education and Counseling 1997;30:61-70.

2. Simpson WJ. A preliminary report on cigarette smoking and the incidental prematurity, Am J Obstet Gynecol. 1957;73:808-815.

3. Centers for Disease Control and Prevention. Women and smoking. A repont of the Surgeon General, 2001.

4. Windsor RA, Boyd NR, Orleans CT. A meta-evaluation of smoking cessation intervention research among pregnant women: improving the science and art. Health Education Research. 1998;13:419-438.

5. Mullen PD, Ramirez G. Efforts to reduce tobacco use among women: Pregnant women and mothers. In: US Public Health Service: Office on Smoking and Health. The health consequences of smoking for women. A report of the Surgeon General. Rockville, MD: US Department of Health and Human Services, 1999.

6. Lumley J, Oliver S, Waters E. Interventions for promoting smoking cessation during pregnancy. Cochrane Database of Systematic Reviews, 2000.

7. Kendrick JS, Zahniser SC, Miller N, Salas N, Stine J, Gargiullo PM, Floyd RL, Spierto FW, Sexton M, Metzger RW, Stockbauer JW, Hannon WH, Dalmut ME. Integrating smoking cessation into routine public health prenatal care: The smoking cessation in pregnancy project. Am J Public Health. 1995;85:217-222.

8. Hjalmarson AIM, Hahn L, Svanberg B. Stopping smoking in pregnancy: effect: of a self-help manual in a controlled trial. Br J Obst Gyn. 1991;98:260-264.

9. Mudde AN, De Vries H, Willemsen MC, van Assema P. Development and utilization of a self-help manual for community smoking cessation interventions. In R. Richmond (E.d.), Interventions for smokers: an international perspective. New York: Williams \& Wilkins, 1994:293-322.

10. Pieterse ME, Seydel ER, De Vries H, Mudde AN \& Kok GJ. Effectiveness of a minimal contact smoking cessation progran for Dutch general practitioners: a. randomized controlled trial. Prev Med. 2001;32:182-90. 
11. Bolman CA, De Vries H, Van Breukelen G. Evaluation of a nurse-managed minimal-contact smoking-cessation intervention for cardiac patients. (submitted).

12. De Vries H, Mudde AN, Dijkstra A, Willemsen MC. Differential beliefs, perceived social influences, and self-efficacy expectations among smokers in various motivational phases. Prev Med. 1998;27:681-9.

13. De Vries H, Mudde AN. Predicting stage transitions for smoking cessation applying the Attitude-Social influence-Efficacy model. Psych Health $1998 ; 13,369-385$.

14. De Vries H, Backbier E. Self-efficacy as an important predictor of quitting among pregnant women who smoke: the Ø-pattern. Prev Med. 1994;23:167174.

15. Prochaska JO, DiClemente CC. Stages and processes of self-change of smoking: toward and integrative model of change. J Consult Clin Psychol. 1983;51:390395.

16. Glynn TJ \& Manley MW. How to help your patients stop smoking: a National Cancer Institute manual for physicians. Bethesda MD: NIH Publication No. 893064. 1989.

17. Fiore MC, Bailey WC, Cohen SJ et al. Smoking cessation. Clinical Practice Guideline. US Department of Health and Human Services. AHCPR Publication No 96-0692. 1996.

18. Tobacco Use and Dependence Clinical Practice Guideline Panel, Staff, and Consortium Representatives. A Clinical Practice Guideline for treating tobacco use and dependence. JAMA 2000;283:3244-3254.

19. Bakker MJ, De Vries H, Mullen PD, Van Breukelen G. Effects six months postpartum of a Dutch smoking cessation and relapse prevention program for pregnant women and their partners. (submitted).

20. Gerards FM, Hospers H. Health counseling. Een strategie voor het individueel begeleiden van adviezen (Health counseling. A strategy for individually guiding advice). Nederlands Tijdschrift voor Dietisten 1991; 46:132-137.

21. Prochaska JO, DiClemente CC. Stages and Processes of self-change of smoking: 
Toward an integrative model of change. Journal of Consulting and Clinical Psychology 1983;51: 390-395.

22. Bryk AS, Raudenbusch SW. Hierarchical linear models.Newbury Park (Calif): Sage , 1993 .

23. Goldstein H. Multilevel statistical models. London: Edward Arnold, 1995.

24. Bakker M], De Vries H, Mullen PD, Van Breukelen G. Smoking cessation by participants in a Dutch multi-media smoking cessation program for pregnant. women and their partners. (submitted).

25. McBride CM, Curry SJ, Lando HA, Pirie PL, Grothaus LC, Nelson JC. Prevention of relapse in women who quit smoking during pregnancy. Am J Public Health. 1999;89:706-711.

26. Secker-Walker RH, Solomon LJ, Flynn BS, Skelly JM, Lepage SS, Goodwin MS, Mead PB. Individualized smoking cessation counseling during prenatal and early postnatal care. Am J Obstet Gynecol. 1994;171:1347-1355.

27. Stotts AL, DiClemente CC, Carbonari JB, Mullen PD. Pregnancy smoking cessation: a case of mistaken identity. Addictive Behaviors 1996; 21: 459-471.

28. Stotts AL, DiClemente CC, Carbonari JP \& Mullen PD. Postpartum return to smoking: staging a "suspended" behavior. Health Psychol. 2000; 19: 324-332.

29. Ratner PA, Johnson JL, Bottorff JL, Dahinten S, Hall W. Twelve-month followup of a smoking relapse intervention for postpartum women. Addictive Behaviors 2000 25: 81-92.

30. Van ' $t$ Hof SM, Wall MA, Dowler DW \& Stark MJ. Randomised controlled trial of a postpartum relapse prevention intervention. Tobacco Control 2000; 9 (Suppl III): iii64-iii66. 


\section{Chapter 4}

Smoking cessation by participants in a Dutch multi-media smoking cessation program for pregnant women and their partners'

' Submitted for publication to American Journal of Public Health as: Bakker MJ, de Vries H, Dolan Mullen P \& van Breukelen G. Smoking cessation by participants in a Dutch multimedia smoking cessation program for pregnant women and their partners 


\section{Abstract}

Objectives. This study assessed the effects of brief counseling by midwives and self-help materials on smoking cessation during pregnancy and early postpartum. Additionally, the effects of a partner booklet on smoking cessation were analyzed.

Methods. The study used a pretest posttest randomized control group design with 318 daily smokers $(72.1 \%$ response) nested within midwife practice and practices nested within 4 provinces (province=unit of assignment). Posttest data were collected 6 weeks after intake and 6 weeks postpartum.

Results. In total $95.6 \%$ of women received the video and $91.2 \%$, the self-help guide. Of experimental women $18.7 \%$ reported not smoking in the past 7 days 6 weeks after the intervention versus $7.4 \%$ of the controls. Postpartum, these percentages were $21.3 \%$ and $12.0 \%$, respectively. Predictors were receiving the intervention $(\mathrm{OR}=3.63$, $95 \% \mathrm{CI}=1.50-8.83$ six weeks post intervention; $\mathrm{OR}=2.40 ; 95 \% \mathrm{CI}=1.03-5.58$ six weeks postpartum), being a lighter smoker $(\mathrm{OR}=0.84 ; 95 \% \mathrm{CI}=0.76-0.93$ and $\mathrm{OR}=0.87 ; 95 \%$ $\mathrm{CI}=0.79-0.95)$ and having a non-smoking partner $(\mathrm{OR}=0.42 ; 95 \% \mathrm{CI}=0.19-0.92$ and $\mathrm{OR}=0.21 ; 95 \% \mathrm{CI}=0.10-0.47)$. Only $48.4 \%$ of smoking partners read the booklet. Partner smoking was not different between study groups at either time point.

Conclusions. The intervention is effective in reducing smoking by women early in pregnancy and early postpartum. The booklet for partners was not successful. Women indicated that they appreciated the intervention. 


\section{Introduction}

Smoking cessation during pregnancy significantly reduces the risks of growth retardation, fetal death, Sudden Infant Death Syndrome, and other problems (1-5). Continued abstinence postpartum also reduces children's exposure to environmental tobacco smoke and its associated health risks $(6,7)$. Moreover, sustained abstinence postpartum reduces women's lifetime risk for smoking related-diseases (8). Therefore, it is essential to develop programs which enable women to quit smoking effectively early in pregnancy and reduce the high relapse rates which occur in the first few months after delivery (9-11).

Systematic reviews of prenatal smoking cessation trials have noted few trials with interventions delivered by usual prenatal care practitioners (12-14). Favorable results have been found for interventions used by specifically trained health care professionals, but delivery in routine care has been less successful and represents an important aspect for future study. An additional finding of these reviews and research priority is that partner smoking is a chief predictor of postpartum relapse $(12,13)$.

The aim of the study was to develop, implement and evaluate a tailored smoking cessation and relapse prevention program for pregnant women and their pareners which could be easily implemented in regular midwife prenatal care in the Netherlands. In the Netherlands uncomplicated pregnancies are usually guided by midwives who work independently in private practices, organized into regional networks. Therefore midwives were chosen as intermediaries for delivering the program.

The content of the midwife advice and materials for women was designed using a counseling approach, previously tested in the Netherlands for other groups of smokers (15-17) and known as the minimal intervention strategy (MIS). MIS combines elcments of the Atritude-Social influences-Efficacy model (18-20) and the stages of change construct of the Transtheoretical Model, (21) and it helps intermediaries select the infomation relevant to their clients. 


\section{Methods}

\section{Design}

The study used a pretest posttest randomized control design, where women were nested within midwife practice and practices within four provinces, the latter being the unit of randomization to the experimental and control conditions.

\section{Recruitment and assignment method}

At the end of 1995, we sent letters and an information brochure to the 62 chairs of regional networks of midwife practices (members of the Dutch Organization of Midwives) to inform them about the project and to ask them to inquire among their members whether they were willing to participate in the study. After one week the chairs were also contacted by telephone. Fifteen chairs $(24.2 \%)$ agreed to ask their members to participate. Reasons for refusal included no extra time available, already participating in another study, the midwife was a smoker and the midwife was pregnant. The 15 regional networks represented 60 practices (157 midwives), which were all willing to participate. The first 42 practices (118 midwives) were selected, because our power calculation indicated that by 7 clients per midwife approximately 100 midwives were needed for the study. Selected practices were located in 4 provinces, which were representative of the Netherlands with regard to geographic distribution (east-west) and level of urbanization. Provinces were matched by location and level of urbanization, and one province in each of the resulting pairs was assigned to experimental or control group condition by throwing a die.

\section{Identification of pregnant smokers}

Women were eligible for the study if they had not been pregnant more than iwice, were able to speak and understand spoken and written Dutch and indicated to smoke at least one cigarette a day. Women were included in the study from February 1995 to December 1995. Participating midwives asked their clients at the first consultation whether they smoked. Clients reporting smoking were given a letter asking whether they wanted to participate in a study about smoking and health. The letter also 
explained the study requirements, including the possibility of having urine tested for cotinine, an indicator of cigarette: use. If the woman consented, she filled out the baseline questionnaire and was then included in the study. Although midwives were asked to have nonconsenters fill out a form with reasons for refusal, only 12 were returned. Therefore, we asked the midwives to estimate the percentage of women who refused.

\section{Intomention}

We offered all midwives in the experimental condition 3 hours of training about how to talk about smoking and smoking cessation with their clients during the first consultation. The training was based on the MIS (15-17), a guideline developed for health counselors to help them give short, effective, stage-matched information about smoking cessation. For the application of the MIS protocol for: pregnant women, special materials were developed for three groups: midwives, pregnant women who smoke or quit smoking recently and smoking partners.

For women in the experimental condition a video, self-help guide and postdelivery booklet were developed. The video was especially directed to precontemplators, women who were not giving any thought to stopping smoking and who probably would not put any effort in reading materials about smoking cessation. The self-help guide is stage-matched and based on a self-help smoking cessation guide used by general practitioners in the Netherlands (15-16). The guide was adapted for pregnant women, by changing the definitions of stage (defining precontemplators. as those not serious about quitting in the next 30 days), adding pregnancy specific information and changing the illustrations. To make women aware of the danger of relapse after delivery, a booklet was written about the positive effects of not smoking after delivery and the consequences of environmental tobacco smoke for young children.

Since pregnant women who want to quit smoking indicate that it is very difficalt for them to quit when they have a smoking parmer, a special booklet was made for ail smoking partners of women in the experimental group. The partner booklet did not follow the MIS because there was no counseling element in place but was directed to 
precontemplators. It was written to stress the importance of the commitment of the expectant father to the pregnancy and to explain that quirting together with his partner would make a substantial difference for the health of their baby and for themselves.

For midwives to be able to work with the MIS, a brief manual and intervention card were developed. The manual describes the seven steps midwives need to follow to provide effective counseling. These steps are based on the health-counseling model described by Gerards (22), which incorporates several different psychological concepts, including the stages of change, goal setting and relapse prevention. The healthcounseling model has been applied to smoking cessation before by Mudde (15) for the general population of smokers in the Netherlands.

The first step of the MIS consisted of identifying smoking behavior from both woman and partner. The number of cigarettes smoked per day and the motivation to quit were also assessed to group women by stage of change. Women who indicated that they want to quit smoking within the next 30 days were identified as in preparation, women who indicated that they want to quit smoking during this pregnancy but not within the next 30 days were identified as contemplators; and women who indicated that they did not want to quit smoking were identified as precontemplators. Second, when a woman indicated she did not intend to quit within the next 30 days (precontemplators and contemplators) the midwife tried to enhance the motivation to quit by giving information about mainly short term advantages of not smoking. Third, when women indicated that they wanted to quit smoking within the next 30 days (preparation. stage) the midwife discussed barriers that might hamper a successful quit attempt. During the preparation stage mobilizing social support was also discussed by asking the woman whether someone in her environment would help her during the quitting process. Fourth, if a woman actually wanted to stop smoking a quit date was set and noted by the midwife. Fifth, additional self-help materials were given. Sixth, the midwife also discussed with the woman what kind of aftercare she preferred (telephone contacts, during the next consultation, on initiative of the woman herselff. Seventh, at about eight months pregnant the midwife handed out a booklet about smoking after delivery. Information about the consequences of passive smoking for young children was discussed and for quitters a commitment to stay a non-smoker was invited. An 
intervention card was designed for midwives to be able to write down progress and commitments of their clients.

During pregnancy the midwife was advised to talk about smoking with her client on a regular basis. At least two contacts were scheduled: during the first consultation (three months pregnant) to enhance quitting behavior and at eight months pregnant to talk about relapse prevention.

Midwives in the control condition were asked to provide smoking cessation. counseling as they used to do and hand out a folder about smoking cessation during pregnancy developed by the Durch Foundation on Smoking and Health.

\section{Measures}

Data presented here are from 3 measurement occasions: a written questionnaire completed at intake at the midwife's office and two telephone interviews conducted six weeks after the intervention and six weeks postpartum. Since the pretest questionnaire was completed at the midwife's office, it had to be very brief. Therefore, some additional demographic and smoking history questions were asked in the first posttest measurement. Questions related to satisfaction with content and appearance of materials were also asked in the first posttest measurement. Questionnaire development was based on earlier work on smoking cessation in general (23-24) and pregnant women (20).

\section{- outcomes}

Three outcomes were assessed at both follow-ups based on self-reports. First, women were asked whether they had one or more quit attempts of at least 24 -hours since the last measurement contact. Second, to assess point prevalence abstinence they were asked whether they had smoked a cigarette (even if it: was just one puff) in the past 7 days. Third, women were asked to indicate whether their parmer smoked and how many cigarettes per day. To increase the reliability of self-reports a bogus pipeline procedure was used (25).

\section{- biochemical validation}

Midwives were asked to collect urine during the first consultation and 6 weeks after pregnancy for cotinine analyses among a randomly selected sub sample of women 
reporting not smoking. Urine-cotinine was measured by gas chromatography/ mass spectrometry. The cut off point was set at $25 \mathrm{mg} / 1$ (26).

\section{- predictor and control variables}

Three sets of variables were sociodemographic characteristics (age in years, highest educational level, having a steady partner, and having a paid job), pregnancy (parity and number of weeks gestation at entry into care), and smoking items (number of cigarettes per day before pregnancy and at entry into care, number of minutes to first cigarette, age when they became a regular smoker, and whether they anticipated help from their partner for quitting, "a lot", "average", "a little", "none"). Glasses of alcohol per week was measured at all time points.

\section{- implementation variables}

Women indicated whether they received the video (yes/ no) and watched it (yes/ no). With regard to the self-help guide they were asked whether they received it (yes/ no), read it (yes/ no) and if yes, to what extent (on a scale from 0 to 4 with 0 indicating nothing and 4 everything). Those who watched the video rated credibility, understandability, interest, attractiveness and length on a scale from 1 to 7 with 1 indicating the lowest score and 7 the highest. The same rating applies for those who read the self-help guide. Both the video and guide were given an overall rating on a scale from 1 to 10 with 10 as the highest mark.

\section{Analysis}

Chi-square (for categorical variables) and t-tests (for continuous variables) were used for sociodemographic, pregnancy and smoking characteristics to check for any baseline differences between the study conditions.

Numbers of participants who dropped out and reasons for dropout were described by study group, but in all outcome analyses dropouts (except for women who miscarried or could not participate due to language difficulties) are treated as smokers. Attrition was analyzed as additional outcome with logistic regression analysis according to the same procedure as used for the outcome analysis. For the attrition analysis of posttest 1 dropout at posttest 1 was the outcome. For the attrition analysis of posttest 2 dropout at posttest 1 and/ or 2 was the outcome. 
To determine whether the intervention had an effect, we used logistic regression analysis, with quit attempt and 7-day abstinence as dependent variables, and study condition (experimental versus control group) and the following covariates as independent variables: age, educational level, number of weeks pregnant at intake, parity, the age at onset of smoking, number of cigarettes smoked on average a day at intake, having a smoking partner, number of glasses of alcohol on average per day and location of midwife practice. Interactions between study condition and baseline characteristics were entered first as one block. Interaction terms were then removed one by one, using a backward elimination procedure. If a significant interaction term remained, the logistic regression was done within strata defined by the covariate interacting with condition. Covarates were removed from the model unless they satisfied at least one of the following criteria: interacting with the treatment condition, differing between the 2 study groups and/ or being a significant predictor of the dependent variable. All analyses were performed using the SPSS 8 for Windows statistical program (27). All tests were 2 -tailed and $\alpha=0.10$ was used to keep main effects in the model, but $\alpha=0.05$ for conclusions. To test the effect of the intervention on smoking behavior of the partner, we used the same procedure with smoking behavior of the partner as dependent variable and study condition, educational level of the partner, number of weeks pregnant at intake, parity, smoking behavior of the partner at intake, number of cigarettes smoked on average a day at intake by the pregnant woman and location of midwife practice as independent variables.

Traditional logistic regression analysis is based on the assumption that the outcomes of all study participants are statistically independent. However, ours is a nested design, which may lead to intra-class correlation, i.e. positive dependence between outcomes in the same practice, due to province and practice effect on the outcome. Ignoring such intra-class correlation will lead to underestimation of the standard error of the treatment effect, too narrow confidence intervals and possibly, Type I errors (28-29). Therefore, we re-ran our models with random effect logistic regression (using EGRET version 1.02.10) (30) treating women as nested within practices and practices as random effect, and type of province (East/ West) as fixed effect. 


\section{Results}

\section{Recruitment}

Participating midwives in both conditions estimated that they approached $80 \%$ of women eligible for the study and $72 \%$ agreed to participate. Reasons for refusal were described as women did not want to quit, feared the confrontation with their smoking behavior, intrusion of privacy, feelings of guilt and shame and the burden of participating in a research study (e.g. filling out questionnaires).

A total of 318 intake smokers were included in the study, 141 in the experimental condition and 177 in the control condition. By the time of the second posttest $85.1 \%$ and $88.7 \%$ of the two groups respectively, remained eligible for the study (Figure 4.1). Neither study condition nor any of the baseline characteristics was predictive of dropout at posttest 1 ( $p>.20)$ or posttest 2 ( $p>.08)$.

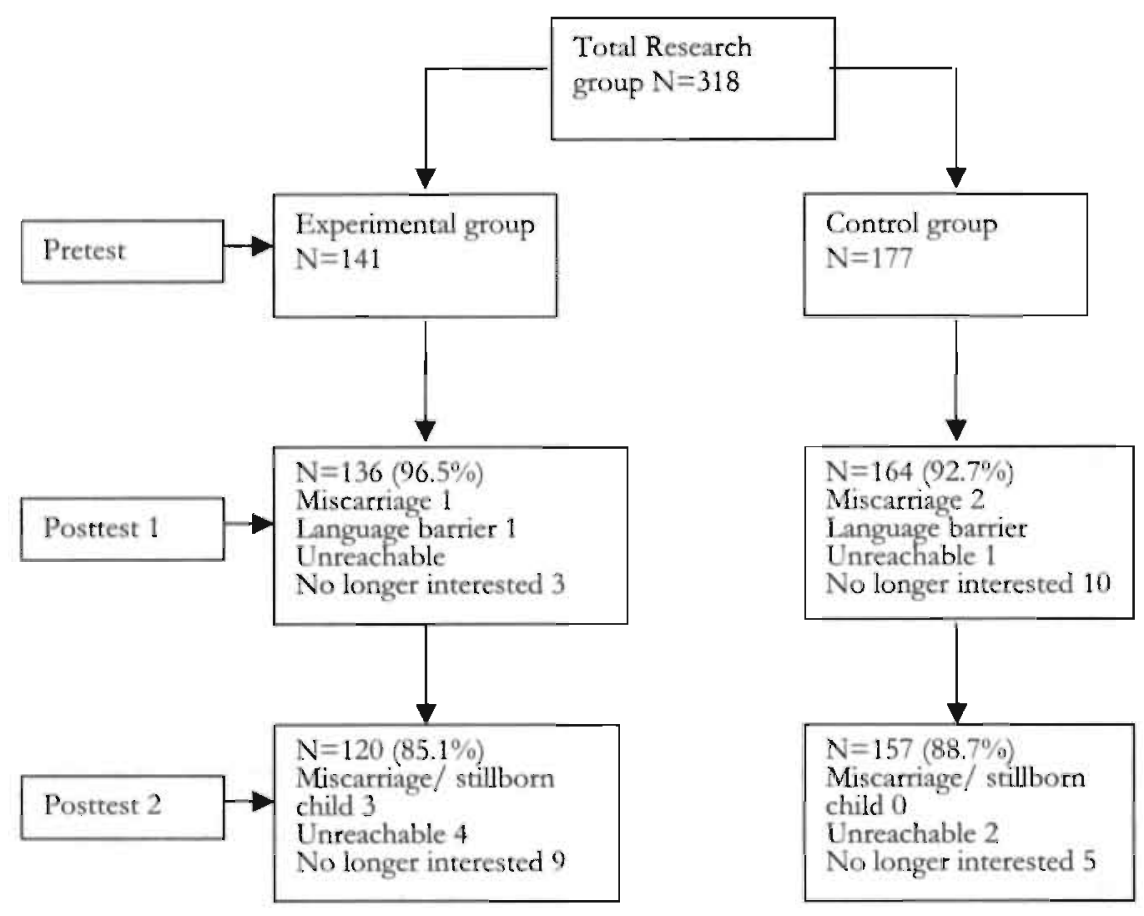

Figure 4.1 Reasons for dropout by study group and point of measurement 


\section{Participant characteristics}

Study groups differed at baseline on educational level, number of weeks gestation at intake, the number of cigarettes women smoked on average per day when they visited their midwife for the first time and the location of the midwife practice (Table 4.1). Women in the experimental group were more highly educated, began pregnancy care earlier, were heavier smokers and their midwife practice was more often located in the Eastern part of the Netherlands.

\begin{tabular}{|c|c|c|c|c|}
\hline & $\operatorname{Exp}(n=14 i)$ & missing & $\operatorname{Con}(n=177)$ & missing \\
\hline Age (M, SD) & $28.6(4.32)$ & 9 & $28.4(4.39)$ & \\
\hline Level of education $\left(\chi^{2}(2)=7.97 ; p<.05\right)$ & & 5 & & 13 \\
\hline Low & $47.1 \%$ & & 61.6 & \\
\hline Mediun & 38.2 & & 23.8 & \\
\hline High & 14.7 & & 14.6 & \\
\hline Steady partner (yes) & ร) $3 \%$ & 2 & 97.2 & 1 \\
\hline Paid job woman (yes) & $68.4 \%$ & 5 & 65.2 & 13 \\
\hline Number of prior pregnancies & & 5 & & 13 \\
\hline 0 & $55.1 \%$ & & 51.8 & \\
\hline 1 & 29.4 & & 30.5 & \\
\hline $2+$ & 15.4 & & 17.7 & \\
\hline $\begin{array}{l}\text { Number of weeks pregnant at intake }(\mathrm{M}, \mathrm{SD}) \\
(\mathrm{F}(1,312)=10 ; \mathrm{p}<.01)\end{array}$ & $12.4(1.91)$ & $\hat{\imath}$ & $13.5(3.60)$ & 3 \\
\hline $\begin{array}{l}\text { Number of cigarettes a day before pregnancy } \\
(\mathrm{M}, \mathrm{SD})\end{array}$ & $17.4(8.46)$ & 1 & $18.4(8.51)$ & 0 \\
\hline $\begin{array}{l}\text { Number of cigarettes a day at first visit with } \\
\text { midwife } \\
(M, S D)(F(1,316)=4.69 ; p<.05)\end{array}$ & $9.1(6.83)$ & 0 & $7.7(5.01)$ & 0 \\
\hline Age began smoking (M, SD) & $14.9(2.28)$ & 5 & $15.4(2.51)$ & 13 \\
\hline Minutes to first cigarette & & 5 & & 13 \\
\hline$<5$ & $8.8 \%$ & & 6.7 & \\
\hline $6-30$ & 18.4 & & 22.0 & \\
\hline $31-60$ & 19.9 & & 13.4 & \\
\hline$>60$ & 52.2 & & 56.1 & \\
\hline Glasses of alcohol per week (M, SD) & $0.38(1.29)$ & 5 & $0.28(1.11)$ & 13 \\
\hline Partner smoking (yes) & $71.2 \%$ & 10 & 72.5 & 18 \\
\hline Anricipated help in effort to quit from partner & & 0 & & 3 \\
\hline a lot & $29.8 \%$ & & 27.0 & \\
\hline average & 31.2 & & 30.5 & \\
\hline little & 13.5 & & 15.5 & \\
\hline none & $2 ; 1.3$ & & 21.8 & \\
\hline Province (West) $\left(\chi^{2}(1)=72.8 ; p<.001\right)$ & $28.4 \%$ & 0 & 76.3 & 0 \\
\hline
\end{tabular}




\section{Implementation}

At least one midwife was trained in using the MIS in every participating practice, resulting in $71 \%$ of all midwives in the experimental condition.

In total $95.6 \%$ of treatment group women reported having received the video and $91.2 \%$, the self-help guide. Of those who received the video $67.5 \%$ watched and of those who received the guide $82.4 \%$ read at least part of it, with an average of 2.82 on a scale from 0 to $4(\mathrm{SD}=1.40)$. In general women rated the materials as credible, understandable, interesting, and attractive and gave them a good overall rating (Table 4.2). The self-help guide, however, was perceived as too long.

\begin{tabular}{lll}
\hline \multicolumn{3}{l}{ Table 4.2 Evaluation of video, self-help guide and relapse } \\
booklet by experimental intake smoking group \\
\hline & Video $(\mathrm{n}=92)$ & Self-help guide $(\mathrm{n}=112)$ \\
& Mean (SD) & Mean (SD) \\
credible* $_{\text {understandable** }}^{*}$ & $5.76(1.30)$ & $5.91(1.03)$ \\
interesting** & $5.30(0.87)$ & $6.32(0.54)$ \\
attractive* & $4.08(1.66)$ & $5.78(1.10)$ \\
length* & $5.20(1.81)$ & $5.35(1.41)$ \\
overall** $^{* *}$ & $6.66(1.36)$ & $3.19(1.65)$ \\
\hline
\end{tabular}

* Scale of $1-7,1=$ lowest rating

** Scale of $1-10,1=$ lowest rating

\section{Differences in quit attempts and point-prevalence abstinence}

Six weeks post intervention, $36.7 \%$ of the experimental group, reported a quit attempt versus $24.0 \%$ of controls $\left(\chi^{2}(1)=5.99 ; p<.05\right)$. Seven day abstinence was reported by $18.7 \%$ of experimental group members versus $7.4 \%$ of controls $\left(\chi^{2}(1)=9.06 ; \mathrm{p}<.01\right)$. Percentages without including dropouts as smokers were $37.5 \%$ versus $25.6 \%$ for quit attempts $\left(\chi^{2}(1)=4.91 ; \mathrm{p}<.05\right)$ and $19.1 \%$ versus $7.9 \%$ for 7 -day abstinence $\left(\boldsymbol{\chi}^{2}(1)=8.23 ; \mathrm{p}<.01\right)$, respectively. Logistic regression indicated that women in the experimental group were more likely to attempt to quit and to be quitters (Table 4.3). Further, women with a smoking partner and heavier smokers were less likely to be abstinent. The same conclusions were drawn with logistic regression excluding dropouts. In multilevel analyses, no significant effect of practice with respect to quit attempt was shown. However, there was a significant effect of practice on 7-day 
abstinence ( $\mathrm{p}$ near 0.05), but this did not seriously change size or significance of treatment or covariate effects.

\begin{tabular}{|c|c|c|c|c|c|}
\hline Quit attempt after first consult & B & SE & OR & $\begin{array}{l}95 \% \text { CI for } \\
\text { the odds ratio }\end{array}$ & $\mathrm{p}$-value \\
\hline Study condition' & 0.66 & 0.32 & 1.94 & $1.04-3.63$ & $<0.05$ \\
\hline Number of cigarettes at first visit & -0.05 & 0.03 & 0.95 & $0.90-1.00$ & 0.05 \\
\hline Educational level & & & & & 0.20 \\
\hline Low vs high & -0.35 & 0.40 & 0.71 & $0.32-1.56$ & 0.39 \\
\hline Medium vs high & 0.20 & 0.42 & 1.22 & $0.54-2.77$ & 0.63 \\
\hline Number of weeks pregnant & -0.01 & 0.05 & 0.99 & $0.90-1.09$ & 0.91 \\
\hline Age onset of smoking & 0.11 & 0.06 & 1.11 & $1.00-1.24$ & 0.06 \\
\hline Province & 0.23 & 0.31 & 1.26 & $0.69-2.31$ & 0.46 \\
\hline Constant & -2.29 & 1.24 & & & 0.07 \\
\hline $\begin{array}{l}\text { Quitters six weeks after first } \\
\text { consult }\end{array}$ & B & SE & OR & $\begin{array}{l}95 \% \text { CI for } \\
\text { the odds ratio }\end{array}$ & $\mathrm{P}$-value \\
\hline Study condition & 1.29 & 0.45 & 3.63 & $1.50-8.83$ & $<0.01$ \\
\hline Number of cigarettes at first visit & -0.17 & 0.05 & 0.84 & $0.76-0.93$ & $<0.01$ \\
\hline Educational level & & & & & 0.75 \\
\hline Low vs high & 0.03 & 0.59 & 1.03 & $0.33-3.24$ & 0.96 \\
\hline Medium vs high & 0.33 & 0.58 & 1.39 & $0.44-4.37$ & 0.57 \\
\hline Number of weeks pregnant & -0.08 & 0.09 & 0.92 & $0.78-1.09$ & 0.35 \\
\hline Smoking partner & -0.88 & 0.40 & 0.42 & $0.19-0.92$ & $<0.05$ \\
\hline Province & -0.49 & 0.44 & 1.64 & $0.69-3.89$ & 0.27 \\
\hline Constant & -0.25 & 1.36 & & & 0.86 \\
\hline
\end{tabular}

1 Coding of variables: study condition (experimental $=1$; control $=0$ ); number of cigarettes at first visit (continuous); educational level ( $0 / 1$ dummy indicators with high as reference category); number of weeks pregnant at intake (continuous); age onset of smoking (continuous, in years); smoking partner $(\mathrm{no}=0$; yes $=1$ ); province $($ East $=0$, West $=1$ )

Six weeks postpartum $38.2 \%$ of women in the experimental condition attempted to quit versus $23.4 \%$ of controls $\left(\chi^{2}(1)=8.00 ; p<.01\right)$. Seven day abstinence was reported by $21.3 \%$ of experimental women and $12.0^{\mathrm{D}} \%$ of controls $\left(\boldsymbol{x}^{2}(1)=4.93\right.$; $p<.05)$. Excluding dropouts, percentages were $43 \%$ versus $25.5 \%\left(\chi^{2}(1)=9.58 ; p<.01\right.$ ) and $24.2 \%$ versus $13.2 \%\left(\chi^{2}(1)=5.58 ; \mathrm{p}<.05\right)$, respectively. Logistic regression indicated that women in the experimental group, lighter smokers, women with higher education and women without a smoking partner were more likely to attempt to quit and to be 7 day abstinent (Table 4.4). Further, women who began pregnancy care early were more likely to attempt to quit and women who started smoking at a later age were more likely to be 7-day abstinent. Logistic regression excluding dropouts revealed almost identical 
results. Women in the experimental group were more likely to attempt to quit $(\mathrm{OR}=3.02, \mathrm{p}<0.01 ; 95 \% \mathrm{CI}=1.47-6.18)$ and to be 7 -day abstinent $(\mathrm{OR}=2.58, \mathrm{p}<0.05$; $95 \% \quad C I=1.07-6.20)$. With regard to attempting to quit an additional predictor was found. Women who started smoking at a later age were more likely to quit $(\mathrm{OR}=1.14$, $\mathrm{p}=0.05 ; 95 \% \mathrm{CI}=1.01-1.30)$. Multilevel analyses showed no significant random effect of practice on quit attempt but did show a significant random effect of practice on 7 day abstinence. However, size and significance of treatment or covariate effects were not seriously changed.

\begin{tabular}{|c|c|c|c|c|c|}
\hline Quit attempt during pregnancy & B & SE & OR & $\begin{array}{l}95 \% \text { CI for } \\
\text { the odds ratio }\end{array}$ & $\mathrm{p}$-value \\
\hline Srudy condition ${ }^{1}$ & 0.92 & 0.34 & 2.51 & $1.28-4.91$ & $<0.01$ \\
\hline Number of cigarettes at first visit & -0.11 & 0.03 & 0.89 & $0.84-0.95$ & $<0.001$ \\
\hline Educational level & & & & & $<0.05$ \\
\hline Low vs high & -1.11 & 0.44 & 0.33 & $0.14-0.77$ & $<0.05$ \\
\hline Medium rs high & -0.43 & 0.45 & 0.65 & $0.27-1.56$ & 0.33 \\
\hline Number of weeks pregnant & -0.16 & 0.07 & 0.85 & $0.75-0.97$ & $<0.05$ \\
\hline Age onset of smoking & 0.12 & 0.06 & 1.12 & $0.99-1.27$ & 0.06 \\
\hline Smoking partner & -0.73 & 0.32 & 0.48 & $0.26-0.90$ & $<0.05$ \\
\hline Province & 0.18 & 0.34 & 1.19 & $0.62-2.30$ & 0.60 \\
\hline Constant & 1.03 & 1.47 & & & 0.49 \\
\hline Quitters six weeks postpartum & B & $S E$ & OR & $\begin{array}{l}95 \% \text { CI for } \\
\text { the odds ratio }\end{array}$ & $\mathrm{p}$-value \\
\hline Study condition & 0.88 & 0.43 & 2.40 & $1.03-5.58$ & $<0.05$ \\
\hline Number of cigarettes at first visit & -0.14 & 0.05 & 0.87 & 0.79 .0 .95 & $<0.01$ \\
\hline Educational level & & & & & $\begin{array}{l}<0.01 \\
<0.01\end{array}$ \\
\hline $\begin{array}{l}\text { Low vs high } \\
\text { Medium vs high }\end{array}$ & $\begin{array}{l}-1.77 \\
-0.51\end{array}$ & $\begin{array}{l}0.58 \\
0.53\end{array}$ & $\begin{array}{l}0.17 \\
0.60\end{array}$ & $\begin{array}{l}0.05-0.53 \\
0.21-1.70\end{array}$ & $\begin{array}{l}<0.01 \\
0.34\end{array}$ \\
\hline Number of weeks pregnant & -0.08 & 0.08 & 0.93 & $0.79-1.09$ & 0.34 \\
\hline Age onser of smoking & 0.16 & 0.08 & 1.18 & $1.00-1.39$ & $<0.05$ \\
\hline Age & -0.09 & 0.05 & 0.92 & $0.83-1.01$ & 0.09 \\
\hline Smoking partner & -1.56 & 0.41 & 0.21 & $0.10-0.47$ & $<0.001$ \\
\hline Province & -0.46 & 0.42 & 0.63 & $0.28-0.47$ & 0.28 \\
\hline Constant & 2.04 & 2.19 & & & 0.35 \\
\hline
\end{tabular}

1 Coding of variables: study condition $(\exp =1$; $\operatorname{con}=0)$; number of cigarettes at first visit (continuous); educational level $(0 / 1$ dummy indicators with high as reference category); number of weeks pregnant at intake (continuous); age onset of smoking (continuous, in years); age (continuous, in years); smoking partner $(n o=0$; yes $=1)$; province (East $=0$, West $=1$ )

Tables 4.3 and 4.4 are the final regression models (after dropping nonsignificant interactions and covariates eligible for deletion according to the modeling 
procedure outlined in the method section), no interactions were found.

\section{Biochemical validation}

At intake $47(14.8 \%)$ urine samples were collected from a random sample of women. Results indicated that overall $17 \%$ of self-reported non-smokers actually were smokers (17.6\% and $16.7 \%$ for the experimental and control condition, respectively). Six weeks postpartum only 7 urine samples were collected. These samples all confirmed the self-reported non-smoking status.

\section{Partner smoking}

In total $76.2 \%$ of women in the experimental group reported having given the partner booklet to their smoking partner. Of those who received the booklet $48.4 \%$ read it. At intake $71.2 \%$ of experimental group partners and $72.5 \%$ of controls were described by the women as smoking. Six weeks post intervention these percentages were $70.1 \%$ for experimental group parmers and $69.6 \%$ for controls. Six weeks postpartum a further decrease was reported, $68.1 \%$ and $65.8 \%$ respectively. None of these differences was statistically significant. None of the included covariates predicted partner smoking 6 weeks post intervention, excepting pretest partner smoking $(\mathrm{OR}=42.3, \mathrm{p}=<0.0001)$. Study condition had no effect on partner smoking during pregnancy or early postpartum. 


\section{Discussion}

Findings from this study indicate that a smoking cessation intervention consisting of brief counseling by a midwife, a video and self-help guide was effective in assisting pregnant women to quit smoking. Implementation of the intervention in routine Dutch prenatal midwifery care was successful. A large majority of daily intake smokers reported receiving the materials. Materials were watched and read by most women, and they reported liking both the content and appearance. The program raised quit rates 6 weeks after the intervention and early postpartum. Consistent predictors of smoking behavior were the number of cigarettes smoked on average at intake, the age at onset of smoking and having a smoking partner. Comparison of the logistic regression output with re-analyses of the final models using random effect logistic regression showed a small effect of midwife practice on 7-day abstinence 6 weeks post intervention and six weeks postpartum and no significant effect on quit attempt at both time points. However, this small effect did not substantially change the effect of study condition on abstinence.

The partner component of the intervention, consisting of a partner booklet was not successful. Approximately $75 \%$ of the women reported having given the booklet to their smoking partner, but they indicated that only about half of the partners also read it. Partner smoking rates were not different between study groups at either time point. Furthermore, logistic regression indicated no effect of study condition on partner smoking behavior.

Previous studies (31-32) that also relied on usual health care providers to provide counseling did have comparable assessment periods. Kendrick and colleagues (31) conducted 3 statewide trials with public maternity clinics and Women, Infants, and Children's Supplemental Feeding Programs ("WIC") clinics, and their cotininevalidared results at the $8^{\text {th }}$ month of pregnancy showed no effect of the intervention. These investigators speculated that implementation of the intervention may have been very low. Hjalmarson's trial with Swedish obstetricians (32) did not really involve counseling, but consisted primarily of distribution of a self-help manual. This intervention achieved a non-significant increase in verified cessation in late pregnancy $(12.6 \%$ of the experimental group versus $8.6 \%$ of controls), but by 8 weeks 
postpartum, these percentages had increased to $15.8 \%$ and $9.1 \%$, respectively.

There were some methodological weaknesses to this study. One of the problems of conducting research in routine care is that, as a researcher, one should not disrupt standard practice. Therefore, women had to complete the pretest at the midwife's office, during the first consultation before the start of the intervention. However, in practice many women completed the questionnaire after the first consultation was finished. As a consequence, some of the variables such as attitudes and intention towards becoming a non-smoker were not used as predictors for the outcome variables, since intervention effects for these variables were already expected.

Furthermore, although we tried to conduct cotinine analyses on $30 \%$ of women claiming to be non-smokers at intake and six weeks postpartum we only received a fraction of this number. Results of the cotinine analyses at intake indicated that in total $17 \%$ of self-reported non-smokers actually were: smokers. Percentages did not differ between study groups. Six wecks postpartum all samples confirmed the self-reported non-smoking status. The level of nondisclosure at intake was similar to at least one other study at a comparable time in a U.S. health maintenance organization (33). The major difficulty with nondisclosure has occurred in several U.S. trials at the late pregnancy measurement, when the overall level was above $25 \%$ and when there were: also large differences between study groups (31-34). Postpartum self-report would seem to remove at least some of the social demand of pregnamcy, but there is little literature regarding this period.

To be able to generalize the present results to other regions in the Netherlands, region should have been included into the analysis as a random effect, as was midwife practice. The small number of regions renders such an approach impossible, however. The present correction for region (Fiast/ West dummy) is a fixed effect approach, implying a restriction of the results to the present 4 regions. Only under the assumption of no (random) differences between regions with respect to the outcomes are the present standard errors and $\mathrm{p}^{-v a l u e s}$ adequate for generalizing to other regions. The fact that the fixed effect of East versus West was not predictive of any outcome $(p>0.20)$ gives tentative support for this assumption.

Since the intervention can be implemented in routine prenatal midwifery care in 
the Netherlands and has shown to be effective in increasing cessation both during pregnancy as well as early postpartum, we recommend further investigation of the possibilities and requirements of implementation. Besides implementation of the intervention in midwife practices, it will be important to study preconditions for implementation of the intervention in general practitioners and gynecologist practices, since they are too providers of prenatal care in the Netherlands.

As for the partner component of the intervention, further work on an appealing and efficacious intervention is required. It may be that other access points to communicate with partners about smoking cessation during pregnancy and the positive role they can play in helping their wife to stop smoking should be found. 


\section{References}

1. US Department of Health and Social Services. Avoidable losses: effects of smoking on reproductive health State of Wisconsin, Publication No (POH) 5086 (10-88), 1988.

2. Windham GC, Swan SH, Fester L. Parental cigatette smoking and the risk of spontaneous abortion. Am J Epidemiol. 1992;135:1394-403.

3. Shino PH, Klebanoff MA, Rhoads GG. Smoking and drinking during pregnancy; their effects on preterm birth. JAMA.1986;225:82-84.

4. Hantahan JP. The effect of maternal smoking during pregnancy on early infant lung function. Am Rev Respir Dis.1992;145:1129-1135.

5. Difranza JR, Lew RA. Effect of maternal cigarette smoking on pregnancy complications and sudden infant death syndrome. J Fam Pract.1995; 40:385394.

6. Jedrychowski W, Flak E. Maternal smoking during pregnancy and postnatal exposure to environmental tobacco smoke as predisposition factors to acute respiratory infections. Environ Health Perspect. 1997;105:302-306.

7. Schlaud M, Kleemann WJ, Poets CF, Sens B. Smoking during pregnancy and poor antenatal care: two major preventable risk factors for sudden infant death syndrome. Int J Epidemiol. 1996;25:959-965.

8. Albrecht SA, Rosella JD, Patrick T. Smoking among low-income, pregnant women: prevalence rates, cessation interventions, and clinical implications. Birth. 1994:21:155-62.

9. McBride $\mathrm{CM}$, Pirie PL. Postpartum smoking relapse. Addict Behav. 1990;15:165-168.

10. Fingerhut LA, Kleinman JC, Kendrick JS. Smoking before, during and after pregnancy. Am J Public Health. 1990;80:541-544.

11. Mullen PD, Quinn VP, Ershoff DH. Maintenance of non smoking postpartum by women who stopped smoking during pregnancy. Am J Public Health. 1990;80:992-994.

12. Windsor RA, Boyd NR, Orleans CT. A meta-evaluation of smoking cessation intervention research among pregnant women: improving the science and art. 
Health Education Research. 1998;13:419-438.

13. Mullen PD, Ramirez G. Efforts to reduce tobacco use among women: Pregnant women and mothers. In: US Public Health Service: Office on Smoking and Health. The health consequences of smoking for women. A report of the Surgeon General. Rockville, MD: US Department of Health and Human Services, 1999.

14. Lumley J, Oliver S, Waters E. Interventions for promoting smoking cessation during pregnancy. Cochrane Database of Systematic Reviews, 2000.

15. Mudde AN, De Vries H, Willemsen MC, van Assema P. Development and utilization of a self-help manual for community smoking cessation interventions. In R. Richmond (Ed.), Interventions for smokers: an international perspective. New York: Williams \& Wilkins.1994:293-322.

16. Pieterse ME, Seydel ER, De Vries H, Mudde AN \& Kok GrJ. Effectiveness of a minimal contact smoking cessation program for Dutch general practitioners: a randomized controlled trial. Prev Med. 2001;32:182-90.17. Bolman CA, De Vries H, Van Breukelen G. Evaluation of a nurse-managed minimal-contact smoking-cessation intervention for cardiac patients. (submitted).

17. De Vries H, Mudde AN, Dijkstra A, Willemsen MC. Differential beliefs, perceived social influences, and self-efficacy expectations among smokers in various motivational phases. Prev Med. 1998;27:681-9.

18. De Vries H, Mudde AN. Predicting stage transitions for smoking cessation applying the Artitude-Social influence-Efficacy model. Psych Health. 1998;13,369-385.

19. De Vries H, Backbier E. Self-efficacy as an important predictor of quirting among pregnant women who smoke: the O-pattern. Prev Med. 1994;23:167174.

20. Prochaska JO, DiClemente CC. Stages and processes of self-change of smoking: toward an integrative model of change. J Consult Clin Psychol. 1983;51:390395.

21. Gerards FM, Hospers $H$. Health counseling. Een strategie voor het individueel begeleiden van adviezen (Health counseling. A strategy for individually guiding 
advice). Nederlands Tijdschrift voor Diëtisten. 1991; 46:132-137.

22. Mudde AN, de Vries H, Dolders MG. Evaluation of a Dutch community-based smoking cessation intervention. Prev Med. 1995;24:61-70.

23. Willemsen MC, de Vries $H$, van Breukelen G, Genders R. Long-term effectiveness of two Dutch worksite smoking cessation programs. Health Educ Beh. 1998;25:418-35.

24. Roese NJ, Jamieson. W. Twenty years of bogus pipeline research: A critical review and meta-analysis. Psych Bull. 1993;114:363-375.

25. James H, Tizabi Y, Taylor R. Rapid method for the simultaneous measurement of nicotine and cotinine in urine and serum by gas chromatography-mass spectrometry. J Chromatogr B. 1998;708:87-93.

26. SPSS Inc. SPSS-X User's guide. Chicago: SPSS Inc;1988.

27. Bryk AS, Raudenbusch SW. Hierarchical linear models. Newbury Park, Calif: Sage; 1993.

28. Goldstein H. Multilevel statistical models. London: Edward Amold; 1995.

29. Statistic and Epidemiology Research Corporation. EGRET reference manual. Seattle, Washington; 1993.

30. Kendrick JS, Zahniser SC, Miller N, et al. Integrating smoking cessation into routine public health prenatal care: The smoking cessation in pregnancy project. Am J Public Health. 1995;85:217-222.

31. Hjalmarson AIM, Hahn L, Svanberg B. Stopping smoking in pregnancy: effect of a self-help manual in a controlled trial. Br J Obst Gyn. 1991;98:260-264

32. Mullen PD, Carbonari JP, Tabak ER, et al. Improving disclosure of smoking by pregnant women. Am J Obstet Gynecol. 1991;165:409-13.

33. Windsor RA, Lowe, JB, Perkins LL, Smith DY, Artz L, Contrezas L, Amburgy K, Crawford M, Boyd NR. Health education methods for pregnant smoker: Its behavioral impact and cost benefit. Am J Public Health. 1993;83:201-206. 


\section{Chapter 5}

Effects six months postpartum of a Dutch multi-media smoking cessation and relapse prevention program for pregnant women and their partners 


\section{Abstract}

Background. This study assessed the effects of brief counseling by midwives and self-help materials on 7-day abstinence six months postpartum and continued abstinence. Additionally, the effects of a partner booklet on smoking cessation were analyzed.

Methods. The study used a pretest posttest randomized control group design with 556 daily smokers and spontaneous quitters (72\% response) nested within midwife practice and practices nested within 4 provinces (province=unit of assignment). Posttest data were collected six weeks and six months postpartum.

Results. In total $83.8 \%$ of women reported receiving the video, $79.8 \%$, the guide and $16.7 \%$ the post delivery booklet. Of experimental women $27.4 \%$ reported not smoking in the past 7 -days versus $30.6 \%$ of the controls. For continued abstinence percentages were $24.6 \%$ and $25.3 \%$. Consistent predictors of abstinence were being a lighter smoker and starting smoking at a later age. Additionally, women with a smoking partner and intake smokers were less likely to be 7-day abstinent. Women who began pregnancy care later were less likely to be continued abstinent. Only $46.3 \%$ of smoking partners read the booklet. Partner smoking was not different between study groups.

Conclusions. The short-term effects on smoking cessation during pregnancy and early postpartum were not sustained. The booklet for partners was also not successful. Since only few women received the post delivery booklet, different methods and access points should be tested. 


\section{Introduction}

Smoking cessation during pregnancy significantly reduces the risks of growth retardation, fetal death, Sudden Infant Death Syndrorne, and other problems (1-5). Continued abstinence postpartum also reduces children's exposure to environmental tobacco smoke and its associated health risks $(6,7)$. Moreover, sustained abstinence postpartum reduces women's lifetime risk for smoking related-diseases (8),

In the Netherlands, about $35 \%$ of all pregnant women are estimated to be pre pregnancy smokers. At the time of their first prenatal consult $70 \%$ of then will report smoking and $30 \%$ will report recent quitting, resulting in a smoking prevalence among pregnant women of $24.5 \%$ (9). US studies report $25 \%$ of women who become pregnant to be smokers at the time they learn they are pregnant (10). Approximately $23 \%$ to $40 \%$ of these women spontaneously quit: after learning they are pregnant $(11,12)$. Although women who quit during pregnancy usually abstain from smoking for five months or more, approximately $65 \%$ to $70 \%$ return to smoking within six months after delivery and half do so in the first six weeks (12-15). Considering the harmful consequences of smoking pre- and postpartum and the substantial number of women who remain smokers during pregnancy or relapse after delivery, it is essential to develop programs which enable women to quit smoking effectively early in pregnancy and will reduce the high relapse rates which occur in the first few months after delivery $(12,14,16)$.

Favorable results have been found for interventions used by specifically trained health care professionals on prenatal smoking cessation, but delivery in routine care has been less successful and represents an important aspect for future study (17-19). Furthermore, although some studies have incorporated a post delivery relapse prevention component, only one study, which started the intervention in prenatal care, achieved a significant improvement in maintenance up till 12 months postpartum (20). This intervention also produced a significant reduction in the proportion of fathers who smoked, suggesting that this was a helpful strategy to reduce mothers' return to smoking.

The aim of the study described in this article was to develop, implement and evaluate a tailored smoking cessation and relapse prevention program for pregnant 
women and their partners which could be easily implemented in regular midwife prenatal care in the Netherlands. In the Netherlands uncomplicated pregnancies are usually guided by midwives who work independently in private practices, organized into regional networks. Therefore midwives were chosen as intermediaries for delivering the program.

The content of the midwife advice and materials for women was designed using a counseling approach, previously tested in the Netherlands for other groups of smokers (21-23) and known as the minimal intervention strategy (MIS). MIS combines elements of the Attitude-Social influences-Efficacy model (24-26) and the stages of change concept of the Transtheoretical Model (27), and it helps intermediaries to select the information relevant to their clients.

Short-term effects of the intervention which have been described elsewhere have indicated a positive effect on smoking cessation up till 6 weeks postpartum. In total $21.3 \%$ of experimental women indicated to be 7 -day abstinent compared to $12 \%$ of control women (28). This paper reports the effects of the intervention on 7-day abstinence six months postpartum and continued point prevalence abstinence (reporting 7-day abstinence at six weeks and six months postpartum) among intake smokers and spontaneous quitters and the main predictors of non-smoking. Additionally, the effects of the intervention on partner smoking behavior are presented. Satisfaction with content and appearance of the materials is also reported here. 


\section{Methods}

\section{Design}

The study used a pretest posttest randomized control design, where women were nested within midwife practice and practices within four provinces, the latter being the unit: of randomization to the experimental and control condition.

\section{Number of practices and assignment method}

In total 42 midwife practices (118 midwives) were selected to participate in the study. Selected practices were located in 4 provinces, which were representative of the Netherlands with regard to geographic distribution (east-west) and level of urbanization. Provinces were matched by location and level of urbanization, and one province in each of the resulting pairs was assigned to experimental or control group condition by throwing a die. Details about the identification of practices are reported elsewhere (28).

\section{Identification of pregnant intake smokers and spontaneous quitters}

Women were eligible for the study if they had not been pregnant more then two times, were able to speak. and understand Dutch and indicated to smoke at least one cigarette a day (intake smokers) or to have quit smoking in the previous six months (spontaneous quitters). Women were included in the study from February 1995 to December 1995. Participating midwives asked their clients at the first consultation whether they smoked or had quit smoking. Clients reporting smoking of to have stopped smoking were given a letter asking whether they wanted to participate in a study about smoking and health. The letter also explained the study requirements, including the possibility of having urine tested for cotinine, an indicator of cigarette use. If the woman consented, she filled out the baseline questionnaire at the midwife's office and was then included in the study. Although midwives were asked to have women who refused to participate fill out a form with reasons for refusal, only 12 were returned. Therefore, we also asked the midwives to estimate the percentage of women who refused. 


\section{Intervention}

During the first consultation, the midwives in the experimental condition were trained to talk about-smoking and smoking cessation with their clients based on the MIS (21-23). For the application of the MIS, special materials were developed.

For pregnant women who smoked or quit smoking recently, a video, self-help guide and post delivery booklet were developed. Furthermore, since pregnant: women who want to quit smoking indicate: that it is very difficult for them to quit when they have a. smoking partner, a special booklet was made for this partner.

For midwives to be able to work with the MIS, a brief manual and intervention card were developed. The manual describes the seven steps midwives need to follow to provide effective counseling. A schematic overview of the steps is provided in figure 5.1. Details about the materials and steps of the MIS are described elsewhere (28).

During pregnancy the midwife was advised to talk about smoking with her client on a regular basis. At least two contacts were scheduled: during the first consultation (three months pregnant) to enhance quiting behavior and at eight months pregnant to talk about postpartum relapse prevention.

Midwives in the control condition were asked to provide smoking cessation counseling as they used to do and hand out a folder about smoking cessation during pregnancy developed by the Dutch Foundation on Smoking and Health.

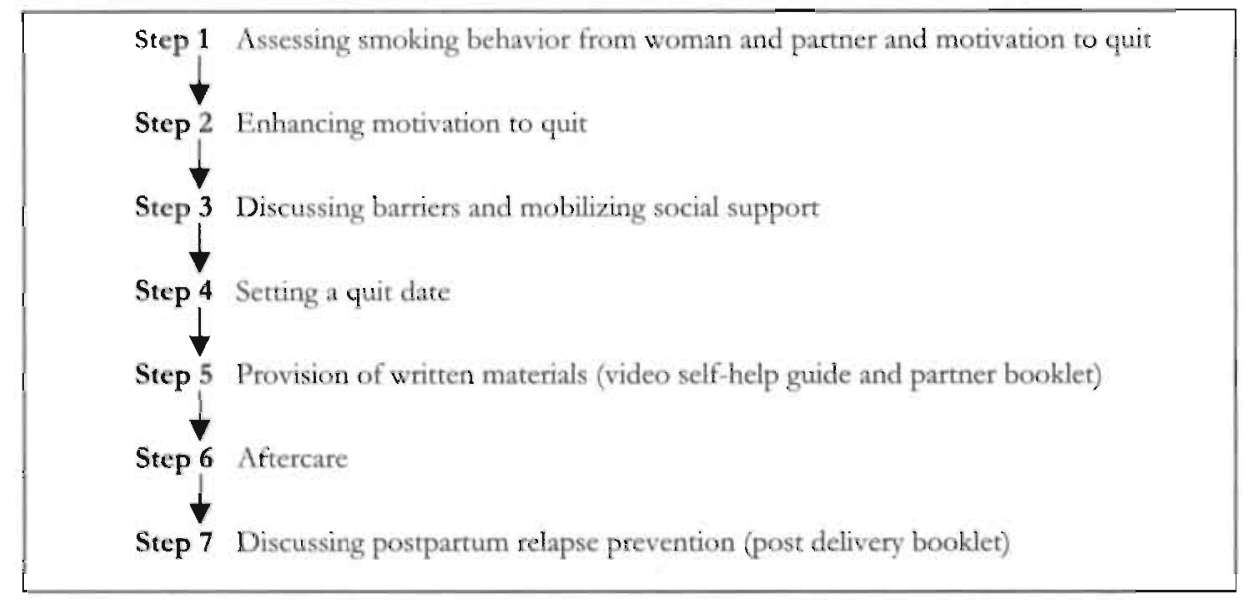

Figure 5.1 Smoking cessation and relapse prevention protocol for pregnant women and their partners 
Measures

Data presented here are from 4 measurement occasions: a written questionnaire completed at intake at the midwife's office and three telephone interviews conducted six weeks after the start of the intervention, six weeks postpartum and six months postpartum. Since the pretest questionnaire was completed at the midwife's office, it had to be very brief. Therefore, some additional demographic and smoking history questions were asked in the first posttest measurement. Questions related to satisfaction with content and appearance of materials were asked in the first posttest measurement with regard to the video and self-help guide and in the second posttest measurement with regard to the post delivery booklet. Questionnaire development was based on earlier work on smoking cessation in general $(29,30)$ and pregnant women (26).

\section{- outcomes}

Three outcomes were assessed based on self-reports. To increase the validity of self-reports a bogus pipeline procedure was used (31). First, to assess point prevalence abstinence women were asked whether they had smoked a cigarette (even if it was just one puff) in the past 7 days. Second, to assess continued point prevalence abstinence a new variable was computed by combining the answers on the point prevalence abstinence question six weeks and six months postpartum. Third, women were asked to indicate whether their partner smoked and how many cigarettes per day.

\section{- biochemical validation}

Midwives were asked to collect urine during the first consultation and 6 weeks after pregnancy for cotinine analyses among a randomly selected sub sample of women reporting not smoking. Urine-cotinine was measured by gas chromatography/ mass spectrometry. The cut off point was set at $25 \mathrm{mg} / \mathrm{l}$ (32).

\section{- predictor and control variables}

Three sets of variables were sociodemographic characteristics (age in years, highest educational level, having a steady partner, and having a paid job), pre and post pregnancy (parity, number of weeks gestation at entry into care and still breastfeeding the baby 6 months postpartum), and smoking items (intake smoking status, "daily smoker", "spontaneous quitter", number of cigarettes per day before pregnancy and at 
entry into care, number of minutes to first cigarette, age when they became a regular smoker, and whether they anticipated help from their partner for quitting, "a lot", "average", "a little", "none”). Glasses of alcohol per week was measured at all time points.

\section{- implementation variables}

Women indicated whether they received the video (yes/ no) and watched it (yes/ no). With regard to the self-help guide they were asked whether they received it (yes/no), read it (yes/no) and if yes, to what extent (on a scale from 0 to 4 with 0 indicating nothing and 4 everything). For the post delivery booklet, women indicated whether they received it (yes/ no) and read it (yes/ no). Those who watched the video rated credibility, understandability, interest, attractiveness and length on a scale from 1 to 7 with 1 indicating the lowest score and 7 the highest. The same rating applies for those who read the self-help guide and post delivery booklet. The video, guide and post delivery booklet were given an overall rating on a scale from 1 to 10 with 10 as the highest mark.

\section{Analysis}

Chi-square (for categorical variables) and t-tests (for continuous variables) were used for sociodemographic, pregnancy and smoking characteristics to check for any baseline differences between the study conditions.

Numbers of participants who dropped out and reasons for dropout were described by study group, but in all outcome analyses dropouts (except for women who miscarried or lost the baby) are treated as smokers. Attrition was analyzed as additional outcome according to the same procedure as used for the outcome analysis. For the attrition analysis of posttest 1 dropout at posttest 1 was the outcome. For the attrition analysis of posttest 2 dropout at posttest 1 and/ or 2 was the outcome and for dropout at posttest 3 dropout at posttest 1 and/or 2 and/or 3.

To determine whether the intervention had an effect, logistic regression analyses were carried out with 7-day abstinence and continued point prevalence abstinence as dependent variables, and study condition (experimental versus control group) and the following covariates as independent variables: age, educational level, number of weeks 
pregnant at: intake, parity, the age at onset of smoking, number of cigarettes smoked a day before intake and at intake, intake smoking status, having a smoking partner, number of glasses of alcohol on average a day, still breastfeeding the baby at six months postpartum and location of midwife practice as independent variables.

Interactions between study condition and baseline characteristics were entered first as one block. Interaction terms were then removed one by one, using a backward elimination procedure. If a significant interaction term remained, the logistic regression was done within strata defined by the covariate interacting with condition. Furthermore, covariates were removed from the model unless they satisfied at least one of the following criteria: interacting with the treatment condition, showing a difference between the two treatment conditions and/ or being a significant predictor of the dependent variable. All analyses were performed using the SPSS 8 for Windows statistical program (33). An $\alpha=0.05$ was used for all 2-tailed tests of main effects ( $\alpha=0.01$ for interactions). To test the effect of the intervention on smoking behavior of the partner, we used the same procedure with smoking behavior of the partner as dependent variable and study condition, educational level of the partner, number of weeks pregnant at intake, parity, smoking behavior of the partner at intake, number of cigaretres smoked on average a day at intake by the pregnant woman and location of midwife practice as independent variables.

To check which factors determined whether a woman in the experimental group received the post delivery booklet, we conducted a logistic regression analysis only on women in the experimental group with receiving the post delivery booklet as outcome and baseline characteristics and abstinence six weeks post-intervention as predictors. Additionally, we also tested whether receiving the post delivery booklet influenced the outcomes of the study. However, distribution of the post delivery booklet might itself be influenced by the woman's smoking behavior at, or before, the time of distribution. This might induce a spurious correlation between receiving the booklet and smoking postpartum. Therefore, the effect of receiving the booklet on abstinence postpartum was tested with the same regression procedure as for the intervention effect on abstinence, but with as additional predictors: receiving the booklet, abstinence six 
weeks post-intervention, and the interaction berween study condition and abstinence six weeks post-intervention.

Traditional logistic regression analysis is based on the assumption that the outcomes of all study participants are statistically independent. However, ours is a nested design, which may lead to intra-class correlation, i.e. positive dependence between outcomes in the same practice, due to province and practice effect on the outcome. Ignoring such intra-class correlation will lead to underestimation of the standard error of the treatment effect, too narrow confidence intervals and possibly, Type I errors (34-35). Therefore, we re-ran our models with random effect logistic regression (using EGRET version 1.02.10) (36) treating women as nested within practices and practices as random effect, and type of province (East/ West) as fixed effect.

\section{Results}

\section{Recruitment}

Participating midwives in both conditions estimated that they approached $80 \%$ of women eligible for the study and $72 \%$ agreed to participate. Reasons for refusal werc described, as women did not want to quit, feared the confrontation with their smoking behavior, intrusion of privacy, feelings of guilt and shame and the side-effects of participating in a research study (e.g. filling out questionnaires).

A total of 556 women were included in the study, 253 in the experimental condition and 303 in the control condition. By the third posttest $83.4 \%$ and $85.1 \%$ of the two groups respectively, remained eligible for the study (Figure 5.2). Study condition was not predictive of dropout at posttest 1 , posttest 2 or posttest 3 . However, heavier smokers $(\mathrm{OR}=1.05 ; 95 \% \mathrm{CI}=1.01-1.09)$ were more likely to dropout at posttest. 2. and heavier smokers $(\mathrm{OR}=1.04 ; 95 \% \mathrm{CI}=1.01-1.08)$ and younger women $(\mathrm{OR}=0.93 ; 95 \% \mathrm{CI}=0.88-0.99)$ were more likely to dropout at posttest 3 .

\section{Participant characteristics}

Study groups differed at baseline on having a steady partner, number of weeks 
pregnant at intake, the number of cigarettes women smoked on average per day when they visited their midwife for the first time (only intake smokers) and location of midwife practice (Table 5.1). Women in the experimental group were more likely to have a steady partner, to begin pregnancy care early, intake smokers were heavier smokers and the midwife practice was more often located in the Eastern part of the Netherlands.

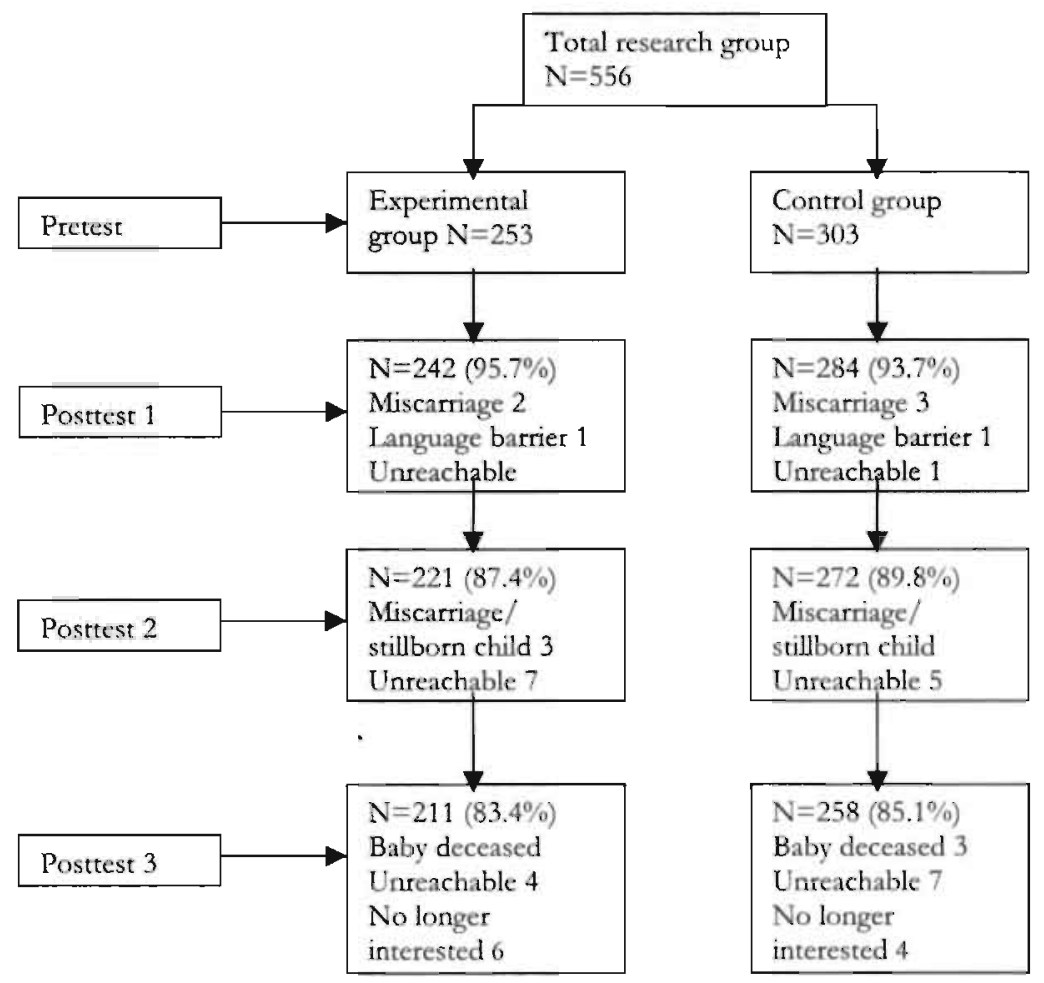

Figure 5.2. Reasons for dropout by study group and point of measurement

\section{Implementation}

At least one midwife was trained in using the MIS in every participating practice, resulting in $71 \%$ of all midwives in the experimental condition.

In total $83.8 \%$ of experimental group women reported having received the video, $79.8 \%$, the self-help guide and $16.7 \%$, the post delivery booklet. Of those who 
received the video $70.8 \%$ watched it, of those who received the guide $87.1 \%$ read at least part of it, with an average of 2.76 on a scale from 0 to $4(\mathrm{SD}=1.48)$ and of those who received the post delivery booklet $75.7 \%$ read it. In general women rated the materials as credible, understandable, interesting, and attractive and gave them a good overall rating (Table 5.2). The self-help guide, however, was perceived as too long.

\begin{tabular}{|c|c|c|c|c|}
\hline \multicolumn{5}{|c|}{$\begin{array}{l}\text { Table } 5.1 \text { Baseline characteristics in percentages or mean (SD) by study group (sociodemographic, } \\
\text { pregnancy, smoking history and smoking networks) }\end{array}$} \\
\hline & $\operatorname{Exp}(n=253)$ & missing & $\operatorname{Con}(n=303)$ & missing \\
\hline Age $(\mathrm{M}, \mathrm{SD})$ & $28.5(4.21)$ & 12 & $28.6(4.24)$ & 90 \\
\hline Level of education & & 11 & & 19 \\
\hline Low & $42.1 \%$ & & 51.1 & \\
\hline Medium & 40.1 & & 31.0 & \\
\hline High & 17.8 & & 18.0 & \\
\hline Steady partner (yes) $\left(\chi^{2}(1)=4.17 ; \mathrm{p}<.05\right)$ & $99.6 \%$ & 11 & 97,3 & 3 \\
\hline Paid job woman (yes) & $71.5 \%$ & 11 & 73.2 & 19 \\
\hline Number of prior pregnancies & & 11 & & 19 \\
\hline 0 & $55.7 \%$ & & 56.8 & \\
\hline 1. & 27.7 & & 24.4 & \\
\hline $2+$ & 12.3 & & 12.5 & \\
\hline $\begin{array}{l}\text { Number of weeks pregnant at intake }(M, S D) \\
(F(1,547)=11.1 ; p<.01)\end{array}$ & $12.5(2.31)$ & 2 & $13.4(3.43)$ & 5 \\
\hline $\begin{array}{l}\text { Number of cigarettes a day before pregnancy (M, } \\
\text { SD) }\end{array}$ & $16.0(8.41)$ & 5 & $16.2(8.63)$ & 2 \\
\hline Daily smoker at first visit with the midwife (yes) & $65.2 \%$ & & $58.4 \%$ & \\
\hline $\begin{array}{l}\text { Number of cigarettes a day at first visit with } \\
\text { midwife }(M, S D) \text { (only intake smokers) } \\
(\mathrm{F}(1,316)=4.69 ; \mathrm{p}<.05)\end{array}$ & $9.13(6.83)$ & & $7.69(5.01)$ & \\
\hline Age began smoking (M, SD) & $15.3(2.45)$ & 11 & $15.6(2.60)$ & 19 \\
\hline \multicolumn{5}{|l|}{ Minutes to first cigarette } \\
\hline$<5$ & $7.9 \%$ & 11 & 5.7 & 20 \\
\hline $6-30$ & 19.0 & & 18.7 & \\
\hline $31-60$ & 17.4 & & 14.5 & \\
\hline$>60$ & 55.4 & & 59.4 & \\
\hline Glasses of alcohol per week (M, SD) & $0.31(1.10)$ & 11 & $0.25(0.91)$ & 19 \\
\hline Partner smoking (yes) & $69.0 \%$ & 24 & 64.4 & 28 \\
\hline \multicolumn{5}{|l|}{ Anticipated help in effort to quit from partner } \\
\hline a lot & $32.7 \%$ & 2 & 32.0 & 3 \\
\hline average & 32.3 & & 28.3 & \\
\hline little & 13.1 & & 14.3 & \\
\hline none & 18.3 & & 18.0 & \\
\hline Breast feeding, 6 months postpartum & $15.2 \%$ & 42 & 14.0 & 45 \\
\hline Province (West) $\left(\chi^{2}(1)=145.4 ; p<.001\right)$ & $25.7 \%$ & & 76.9 & \\
\hline
\end{tabular}




\begin{tabular}{|c|c|c|c|}
\hline & $\begin{array}{l}\text { Video } \\
(\mathrm{N}=150)\end{array}$ & $\begin{array}{l}\text { Self-help guide } \\
(\mathrm{N}=176)\end{array}$ & $\begin{array}{l}\text { Post delivery booklet } \\
(\mathrm{N}=28)\end{array}$ \\
\hline credible* & $5.78(1.18)$ & $5.95(0.93)$ & $6.14(1.04)$ \\
\hline understandable* & $6.35(0.78)$ & $6.23(0.78)$ & $6.21(0.50)$ \\
\hline interesting* & $5.13(1.68)$ & $5.80(1.07)$ & $4.89(1.52)$ \\
\hline attractive* & $4.66(1.66)$ & $5.41(1.34)$ & $4.89(1.64)$ \\
\hline length* & $5.03(1.57)$ & $3.14(1.53)$ & $4.04(1.84)$ \\
\hline overall*** & $6.73(1.27)$ & $7.44(0.91)$ & $7.08(0.63)$ \\
\hline
\end{tabular}

* Scale of $1-7,1=$ lowest rating

** Scale of $1-10,1=$ lowest rating

\section{Outcomes}

In total, $34.8 \%$ of experimental women indicated to have quit smoking before the first visit with the midwife versus $41.6 \%$ of controls (spontaneous quitters), $18.7 \%$ of experimental women indicated to have quit during pregnancy after this initial visit versus $7.4 \%\left(\chi^{2}(2)=9.06 ; p<.01\right)$ (intake smokers). Seven-day abstinence at six weeks postpartum was reported by $33.9 \%$ of experimental group members versus $34.7 \%$ of controls (ns) (spontaneous quitters and intake smokers combined).

Six months postpartum, $27.4 \%$ of women in the experimental condition reported 7-day abstinence versus $30.6 \%$ of controls (ns). Percentages without including dropouts as smokers were $31.5 \%$ and $34 \%$, respectively (ns). Logistic regression indicated that women who indicated to be daily smokers at intake at the midwife's office, were heavier smokers at intake, started smoking at a younger age and had a smoking partner were more likely to be smokers. The same conclusions were drawn with logistic regression excluding dropouts. Multilevel analysis showed a marginally significant random effect of practice, but this did not seriously change size or significance of treatment or covariate effects (Table 5.3).

Continued point prevalence abstinence was reported by $24.6 \%$ of experimental women versus $25.3 \%$ of controls (n.s). Percentages without including dropouts as smokers were $27.7 \%$ versus $27.9 \%$. Logistic regression indicated that women who indicated to be heavier smokers at intake, started pregnancy care later, had a smoking 
partner and started smoking at a younger age were less likely to be 7-day abstinent at. both 6 weeks and 6 months postpartum. Logistic regression without including dropouts showed similar results. Similarly, a random effect of practice was found, but size or significance of treatment or covariate effects was not seriously changed.

The interaction between study condition and intake smoking status was not significant for both outcomes ( $p$ near 0.09). Additional analyses of the final models presented in table 5.3 among intake smokers only also did not show a significant effect of study condition on both outcomes $(B=0.38, S E=0.41, p=0.35$ for the effect of study condition on point prevalence abstinence 6 months postpartum, and $B=0.59, S E=0.45$, $\mathrm{p}=0.19$ for continued point prevalence abstinence).

\begin{tabular}{|c|c|c|c|c|c|}
\hline Point prevalence abstinence & $\mathrm{B}$ & SE & OR & $\begin{array}{l}95 \% \text { CI for } \\
\text { the odds ratio }\end{array}$ & $\mathrm{p}^{\text {-value }}$ \\
\hline Study condition ${ }^{1}$ & 0.11 & 0.28 & 1.11 & $0.65-1.91$ & 0.70 \\
\hline Number of weeks pregnant & -0.05 & 0.05 & 0.95 & $0.87-1.04$ & 0.25 \\
\hline Age onset of smoking & 0.11 & 0.05 & 1.12 & $1.02-1.22$ & $<0.05$ \\
\hline Smoking partner & -0.61 & 0.24 & 0.55 & $0.34-0.88$ & $<0.05$ \\
\hline Province & 0.16 & 0.27 & 1.17 & $0.69-1.99$ & 0.57 \\
\hline Breast feeding at 6 months & 0.54 & 0.33 & 1.72 & $0.91-3.26$ & 0.09 \\
\hline Intake smoking status & 0.79 & 0.35 & 2.20 & $1.11-4.37$ & $<0.05$ \\
\hline Number of cigarettes at first visit & -0.16 & 0.05 & 0.85 & $0.78-0.94$ & $<0.01$ \\
\hline Constant & -1.53 & 0.99 & & & 0.12 \\
\hline $\begin{array}{l}\text { Continued point prevalence } \\
\text { abstinence }\end{array}$ & B & SE & OR & $\begin{array}{l}95 \% \text { CI for } \\
\text { the odds ratio }\end{array}$ & $\mathrm{P}^{\text {-value }}$ \\
\hline Study condition & 0.15 & 0.28 & 1.17 & $0.67-2.03$ & 0.58 \\
\hline Number of weeks pregnant & -0.10 & 0.05 & 0.90 & $0.82-0.99$ & $<0.05$ \\
\hline Age onset of smoking & 0.12 & 0.05 & 1.13 & $1.02-1.24$ & $<0.05$ \\
\hline Smoking partner & -0.45 & 0.25 & 0.64 & $0.39-1.03$ & 0.07 \\
\hline Province & -0.13 & 0.28 & 0.88 & $0.51-1.52$ & 0.65 \\
\hline Intake smoking status & 0.62 & 0.38 & 1.87 & $0.89-3.90$ & 0.10 \\
\hline Number of cigarettes at first visit & -0.20 & 0.06 & 0.82 & $0.73-0.92$ & $<0.001$ \\
\hline Constant & -0.96 & 1.03 & & & 0.35 \\
\hline
\end{tabular}

1 Coding of variables: study condition (experimental $=1$; control $=0$ ); number of wecks pregnant at intake (continuous); age onset of smoking (continuous, in years); smoking partner (no $=0$; yes $=1$ ); province (East $=0$, West $=1$ ); still breast feeding 6 months postparturn $($ no $=0$ ); yes $=1$ ); intake smoking status ( (moker $=0$; spontaneous quitter $=1$ ); number of cigarettes at. first visit (continuous)

Abstinence 6 weeks post intervention was not predictive of receiving the post delivery booklet $(B=0.54, S E=0.63, p=0.39)$, neither was any of the baseline variables. 
Receiving the post delivery booklet was also not predictive of abstinence 6 months postpartum $(B=0.37, S E=0.69, p=0.60)$ or continued abstinence $(B=0.60, S E=0.74$, $\mathrm{p}=0.42)$.

\section{Biochemical validation}

At intake $47(14.8 \%)$ urine samples were collected among a random sample of women. Results indicated that overall $17 \%$ of self-reported non-smokers actually were smokers $(17.6 \%$ and $16.7 \%$ for the experimental and controbl condition, respecrively). Six weeks postpartum only 7 urine samples were collected. These samples all confirmed the self-reported non-smoking status.

\section{Smoking behavior of partners}

In total $86.1 \%$ of women in the experimental group reported having given the partner booklet to their smoking partner. Of those who received the booklet $46.3 \%$ read it. At intake $69 \%$ of partners reported smoking in the experimental group versus $64.4 \%$ of controls. Six months postpartum these percentages were $62 \%$ and $59 \%$, respectively. None of these differences were statistically significant. Logistic regression indicated that partners who smoked themselves at intake and who had a wife who was a heavier smoker at intake were more likely to be smokers six months postpartum (table 5.4).

\begin{tabular}{|c|c|c|c|c|c|}
\hline $\begin{array}{l}\text { Partner smokes six months } \\
\text { postpartum }\end{array}$ & B & $\mathrm{SE}$ & OR & $\begin{array}{l}95 \% \text { CI for } \\
\text { the odds ratio }\end{array}$ & p-value \\
\hline Study condition & -0.08 & 0.32 & 0.93 & $0.50-1.73$ & 0.81 \\
\hline $\begin{array}{l}\text { Number of cigarettes the woman } \\
\text { smokes at first visit }\end{array}$ & 0.08 & 0.03 & 1.08 & $1.03-1.14$ & $<0.01$ \\
\hline Province & -0.10 & 0.32 & 0.90 & $0.49-1.68$ & 0.75 \\
\hline $\begin{array}{l}\text { Number of weeks pregnant at } \\
\text { intake }\end{array}$ & 0.01 & 0.05 & 1.01 & $0.92-1.12$ & 0.79 \\
\hline Smoking status partner at intake & 3.51 & 0.28 & 33.49 & $19.4-57.9$ & $<0.0001$ \\
\hline Constant & -2.03 & 0.75 & & & $<0.01$ \\
\hline
\end{tabular}

${ }^{1}$ Coding of variables; study condition (experimental $=1$; contrai $=0$ ); number of cigarettes the woman smokes at first visir (continuous); province (East $=0$, West $=1$ ); number of weeks pregnant at intake (continuous); partner smokes at intake (no=0; yes $=1$ ) 


\section{Discussion}

While short-term effects were found (28) of the smoking cessation and relapse prevention program for pregnant women on smoking behavior, the findings of this study failed to show long-term effects for 7-day abstinence and continued abstinence. Most women received the video and self-help guide and the vast majority also watched and read them and indicated to appreciate content and appearance. However, very few women received the post delivery booklet, which was aimed at sustaining non-smoking postpartum. Hence, an explanation of the disappearance of the effect long-term is the implementation failure of the postpartum intervention (37).

Multi-level analysis did indicate a random effect of practice on both outcomes, but size and significance of treatment and covariate effects were not seriously changed. No effect of the intervention on smoking behavior was indicated in logistic regression analyses. Consistent predictors of 7-day abstinence six months postpartum and continued abstinence were starting smoking at a later age and being a lighter smoker at intake. Seven-day abstinence was further predicted by having a smoking partner and being an intake quitter. An additional predictor of continued abstinence was starting pregnancy care early.

The partner component of the intervention, consisting of a partner booklet was not successful either. Approximately $86.1 \%$ of the women reported having given the booklet to their partner, but less than half actually read it. Partner smoking rates did not differ six months postpartum. Logistic regression indicated no effect of the intervention on partner smoking behavior. Partners who smoked at intake and partners with a pregnant wife who was a heavy smoker at intake were more likely to remain smokers postpartum.

Several studies, which have focused on prenatal smoking cessation, have also reported relapse rates postpartum for intake smokers $(38,39)$ or intake smokers and spontaneous quitters $(14,20)$. McBride (38) compared the results on relapse data of three interventions: a self-help booklet only, prepartum relapse prevention and prepartum and postpartum relapse prevention. The intervention was delivered by mail and telephone without involving prenatal health care providers. The pre/post intervention delayed but did not prevent postpartum relapse to smoking. Secker- 
Walker (39) evaluated the effect of individualized smoking cessation advice provided by trained smoking cessation counselors. No significant differences on relapse rates were reported on data gathered 8 to 54 months postpartum. Mullen (14) reported the effects of a serialized smoking cessation program, the first part of which was given at the intake visit and the remainder were mailed weekly thereafter. The non smoking maintenance rate was not related to the intervention. The only study, which did achieve a significant improvement in maintenance 12 months postpartum, was the PANDA. project (20).

There were some methodological weaknesses to this study. One of the problems of conducting research in routine care is that, as a researcher, one should not intervene with standard practice. Therefore, women had to complete the pretest at the midwife's office, during the first consultation before the start of the intervention. As a consequence, some of the variables such as attiudes and intention towards becoming a non-smoker were not used as predictors for the outcome variables, since intervention effects for these variables were already expected.

Furthermore, although we tried to conduct cotinine analyses on $30 \%$ of women claiming to be non-smokers at intake and six weeks postpartum we only received a fraction of this number. Results of the cotinine analyses at intake indicated that in totall $17 \%$ of self-reported non-smokers actually were smokers. Percentages did not differ between study groups. Six. weeks postpartum all samples confirmed the self-reported non-smoking status.

An explanation for the absence of effects of the intervention on long-term cessation and relapse prevention for women might be that midwives perhaps did not pay specific attention to relapse prevention postpartum. An indicator is that only a very small percentage of women reported receiving the post delivery booklet. This may indicate that midwives need more training to convince them of the importance of paying specific attention to postpartum relapse before delivery. It might be that midwives do not consider themselves to be the right intermediaries for information. about postpartum relapse since they see their client for the last time six weeks postpartum. Therefore it will be essential to collaborate with pediatricians and baby' well care centers to remain consistent in the non smoking message postpartum. 
Having a partner who smokes negatively influences the chance of women to remain non smokers. Although the intervention contained a special partner component no effects were found on smoking behavior of the partner. A possible explanation could be that partners do not necessarily join their wives on their prenatal visits. This makes it impossible for the midwives to interact with them directly on the importance of their smoking behavior for mother and child. Therefore other access points to communicate with partners about smoking cessation during pregnancy and the positive role they can play in helping their wife to stop should be found. 


\section{References}

1. US Department of Health and Social Services. Avoidable losses: effects of smoking on reproductive health. State of Wisconsin;1988. Publication No (POH) 5086 (10-88).

2. Windham GC, Swan SH, Fester L. Parental cigarette smoking and the risk of spontaneous abortion. Am J Epidemiol. 1992;135:1394-403.

3. Shino PH, Klebanoff MA, Rhoads GG. Smoking and drinking during pregnancy; their effects on preterm birth. JAMA.1986;225:82-84.

4. Hanrahan JP. The effect of maternal smoking during pregnancy on early infant lung function. Am Rev Respir Dis.1992;145:1129-1135.

5. DiFranza JR, Lew RA. Effect of maternal cigarette smoking on pregnancy complications and sudden infant death syndrome. J Fam Pract.1995; 40:385394.

6. Jedrychowski W, Flak E. Maternal smoking during pregnancy and postnatal exposure to environmental tobacco smoke as predisposition factors to acute respiratory infections. Environ Health Perspect. 1997;105:302-306.

7. Schlaud M, Kleemann WJ, Poets CF, Sens B. Smoking during pregnancy and poor antenatal care: two major preventable risk factors for sudden infant death syndrome. Int J Epidemiol. 1996;25:959-965.

8. Albrecht SA, Rosella JD, Patrick T. Smoking among low-income, pregnant women: prevalence tates, cessation inrerventions, and clinical implications. Birth. 1994;21:155-62.

9. Verkerk PH, Van Noord-Zaadstra B. Leefstijl, omgevingsfactoren, uitkomsten van zwangerschap en gezondheid (Lifestyle, social environment, outcomes of pregnancy and health). Leiden:NIGP/TNO 1991.

10. LeClere FB, Wilson JB. Smoking behavior of recent mothers, 18-44 years of age, before and after pregnancy: United States, 1990. Hyattsville, Md: National Center for Health Statistics; 1997. Advance data. from vital and health statistics, No. 288.

11. Mosher WD, Pratt WF. Fecundity, infertility and reproductive health in the United States. 1982. Vital health stat. Data from the National survey of family 
growth. Series 23. 1987; 14:1-51.

12. Fingerhut LA, Kleinman JC, Kendrick JS. Smoking before, during and after pregnancy. Am J Public Health. 1990;80:541-544.

13. McBride CM, Pirie PL, Curry SJ. Postpartum relapse to smoking: a prospective study. Health Education Research. 1992;7:381-390.

14. Mullen PD, Quinn VP, Ershoff DH. Maintenance of nonsmoking postpartum by women who stopped smoking during pregnancy. Am J Public Health. 1990;80:992-4.

15. Sexton M, Hebel JR, Fox NL. Postpartum smoking. In: Rosenburg, MJ (Ed) Smoking and reproductive health. Littleton, MA: PSG Publishing; 1987;222-6.

16. McBride CM, Pirie PL. Postpartum smoking relapse. Addict Behav. 1990;15:165-168.

17. Windsor RA, Boyd NR, Orleans CT. A meta-evaluation of smoking cessation intervention research among pregnant women: improving the science and art. Health Education Research. 1998;13:419-438.

18. Mullen PD, Ramirez G. Efforts to reduce tobacco use among women: Pregnant women and mothers. In: US Public Health Service: Office on Smoking and Health. The health consequences of smoking for women. A report of the Surgeon General. Rockville, MD: US Department of Health and Human Services, 1999.

19. Lumley J, Oliver S, Waters E. Interventions for promoting smoking cessation during pregnancy. Cochrane Database of Systematic Reviews, 2000.

20. Mullen PD, DiClemente CC, Carbonari JP, et al. Project PANDA: Effectiveness in maintaining prenatal abstinence 12 months postpartum. (in preparation)

21. Mudde AN, De Vries H, Willemsen MC, van. Assema P. Development and utilization of a self-help manual for community smoking cessation interventions. In R. Richmond (Ed.), Interventions for smokers: an international perspective. 1994:293-322. New York: Williams \& Wilkins.

22. Pieterse ME, Seydel ER, De Vries H, Mudde AN \& Kok GJ. Effectiveness of a minimal contact smoking cessation program for Dutch general practitioners: a 
randomized controlled trial. Prev Med (in press).

23. Bolman CA, De Vries H, Van Breukelen G. Evaluation of a nurse-managed minimal-contact smoking-cessation intervention for cardiac patients. (submitted).

24. De Vries H, Mudde AN, Dijkstra A, Willemsen MC. Differential beliefs, perceived social influences, and self-efficacy expectations among smokers in various motivational phases. Prev Med. 1998;27:681-9.

25. De Vries $\mathrm{H}$, Mudde AN. Predicting stage transitions for smoking cessation applying the Artitude-Social influence-Efficacy model. Psych Health. $1998 ; 13: 369-85$

26. De Vries H, Backbier E. Self-efficacy as an important predictor of quitring among pregnant women who smoke: the $\varnothing$-pattern. Prev Med. 1994;23:167174.

27. Prochaska JO, DiClemente CC. Stages and processes of self-change of smoking: toward and integrative model of change. J Consult Clin Psychol. 1983;51:390395.

28. Bakker MJ, De Vries H, Mullen PD, Van Breukelen G. Smoking cessation by participants in a Dutch multi-media smoking cessation program for pregnant women and their partners. (submitted for publication)

29. Mudde AN, de Vries. H, Dolders MG. Evaluation of a Dutch community-based smoking cessation intervention. Prev Med. 1995;24:61-70.

30. Willemsen MC, de Vries $H$, van Breukelen $G$, Genders R. Long-term effectiveness of two Dutch worksite smoking cessarion programs. Health Educ Beh. 1998;25:418-35.

31. Roese NJ, Jamieson W. Twenty years of bogus pipeline research: A critical review and meta-analysis. Psych Bull 1993;114:363-375.

32. James H, Tizabi Y, Taylor R. Rapid method for the simultaneous measurement of nicotine and cotinine in urine and serum by gas chromatography-mass spectrometry. J Chromatogr B. 1998;708:87-93.

33. SPSS Inc. SPSS-X User's guide. Chicago: SPSS Inc. 1988.

34. Bryk AS, Raudenbusch SW. Hierarchical linear models. 1993. Newbury Park 
(Calif): Sage

35. Goldstein H. Multilevel statistical models. 1995. London: Edward Arnold

36. Statistic and Epidemiology Research Corporation. EGRET reference manual. 1993. Seattle (Washington).

37. Rogers E.M. Diffusion of innovations. 1983 New York: The Free Press.

38. McBride CM, Curry SJ, Lando HA, Pirie PL, Grothaus LC, Nelson JC. Prevention of relapse in women. who quit smoking during pregnancy. Am J Public Health. 1999;89:706-711.

39. Secker-Walker RH, Solomon LJ, Flynn BS, Skelly JM, Lepage SS, Goodwin MS, Mead PB. Individualized smoking cessation counseling during prenatal and early postnatal care. Am J Obstet Gynecol. 1994;171:1347-1355. 


\section{Summary}

Smoking during pregnancy is detrimental to the health of an unborn child. Research has shown that smoking during pregnancy can lead to for instance low birthweight, fetal growth retardation, spontaneous abortion, perinatal death and sudden infant death syndrome. Passive smoking by babies and young children can also have adverse effects on their health. However, many women do not quit smoking when they become pregnant and when they quit the chance of relapse is high after delivery. So far, in the Netherlands no research was conducted into the effectiveness of smoking cessation programs during pregnancy. Therefore, it was decided to conduct research into the development, implementation and evaluation of a smoking cessation and relapse prevention program for pregnant women.

For the development of the program the $A B C$ planning model was used. This model describes step by step the three different phases which can be followed when developing, implementing and evaluating an effective intervention. In the first phase an analysis is made of the problem, the second phase describes the development of the intervention and the third phase deals with continuation of the program.

In chapter 1 the application of the model on smoking and pregnancy is described. In the analysis phase a description is given of the detrimental effects of smoking both during pregnancy as wel] as passive smoking postpartum on the health of the (un)born child. Although smoking can be regarded as a more or less conscious choice woman make during pregnancy it is also important to take the environment of the woman into consideration. Research has shown that women with a smoking partner are more likely to remain smokers during pregnancy and to relapse after delivery. Furthermore, although women indicate to consider health care providers as the most important source of information regarding smoking, very few women actually receive information from their health care provider about smoking. A description is provided of the most important determinants of smoking and smoking cessation during pregnancy as well as the most important determinants of providing smoking cessation advice to pregnant women by midwives. In the Netherlands midwives are the usual providers of prenatal care. In the final step of the analysis phase the different 
access points are described which can be used for a smoking cessation and relapse prevention program.

Based on the results of the analysis phase it was decided to develop materials for the pregnant women, the smoking partner and the midwife. The intervention phase describes the goals and objectives of the different program components, the development of the intervention, the way the different components were pretested before the start of the study into the effectiveness of the program and the effect and process evaluation.

In the third and final phase it is described that it is necessary to collaborate with all actors who can play a part in the implementation of a program from the start of the project to increase the chance of successful implementation. Furthermore, factors are described which can play an important role in the successful diffusion of an effective intervention.

In the final section of the first chapter general conclusions are drawn and recommendations are made for research and practice.

In Chapter 2 the determinant study is described which was conducted among midwives before the development of the intervention. In total 368 questionnaires were sent to midwives of which 237 were returned. In the questionnaire questions were asked about the advantages and disadvantages of providing smoking cessation advice, the advantages and disadvantages of smoking cessation for the health of both mother and child, social support and self-efficacy of midwives with regard to providing smoking cessation advice. Results of this study indicated that midwives with a positive role definition regarding providing smoking cessation advice were more convinced of the advantages of providing smoking cessation advice, the health benefits of smoking cessation for mother and child and perceived more support from their colleagues with regard to giving advice. Self-efficacy with regard to providing smoking cessation advice was low among both midwives with a positive role definition as well as midwives with a less positive role definition. Based on these results it was concluded that it is important to develop materials and training to facilitate and stimulate midwives to provide smoking cessation advice to their clients. 
In chapter 3 the results of the process evaluation are described. After the implementation phase of the study was finished all 118 midwives who participated in the study received a questionnaire. In total 69 midwives returned the questionnaire. In the questionnaire questions were asked regarding the application of the different steps of the health counseling model, the difficulty of applying the different steps, the distribution of the program materials and the possibility of implementation of the intervention in routine care. Although midwives in the experimental group indicated to find discussing smoking behavior, motivation to quit and barriers which might hamper a successful quit attempt more difficult compared to their colleagues in the control group, experimental midwives more often indicated to provide the advice to quit, set a quit date with women motivated to quit smoking and made arrangements for aftercare. Midwives in the experimental group indicated to have distributed the different program materials to a large majority of their clients. There were no differences between midwives in the experimental and control group with regard to advising the partner to quit and to not smoke around his pregnant wife. Results of midwives were largely confirmed with data gathered among study participants. However, with regard to discussing smoking behavior postpartum results were contradictory. Only very few women indicated to have received the postdelivery booklet from their midwife or to have discussed postpartum smoking behavior with their midwife. It was concluded that it is feasible to implement the program in routine care but that more research is needed into the implementation of the partner smoking and postdelivery relapse prevention component.

In chapter 4 an overview is given of the short-term results of the intervention study. In total 318 smoking pregnant women were included in the study. Six weeks. after the start of the intervention $18.7 \%$ of women in the experimental group indicated to have not smoked a cigarette in the past seven days compared to $7.4 \%$ of women in the control group. Six weeks postpartum these percentages increased to $21.3 \%$ and $12 \%$, respectively. Receiving the intervention, being a less heavy smoker and having a non-smoking partner were predictors of non-smoking. At both time-points no effects were observed of the intervention on smoking behavior of the partner. Based on these results it was concluded that the intervention is effective in reducing the number of 
pregnant women who smoke, this effect is sustained up till at least six weeks postpartum. The partner intervention is not effective.

In the final chapter of this dissertation the long-term effects of the intervention are described. For the analysis of the long term effects data were used of 318 pregnant women who indicated to be smokers at intake and 238 so called spontaneous quitters (women who indicated to have quit smoking in the previous six months before intake). Since the interaction effect between intake smoking status and study condition was not significant it was decided to study the effects on both groups together. Six months postpartum $27.4 \%$ of women in the experimental group indicated to have not smoked a cigarette in the previous seven days compared to $30.6 \%$ of women in the control group. The difference between the two groups was not significant. Less heavy smokers and women who started smoking at a later age were more likely to be non-smokers. Women with a smoking partner and who were smokers themselves at intake were more likely to be smokers. There was no effect of the intervention on partner smoking behavior. Since the intervention did not tesult in long term cffects on smoking behavior it was concluded that more research is needed into determinants of postpartum relapse among women, the determinants of providing relapse prevention advice to pregnant women by midwives and new access points for the delivery of postpartum relapse prevention advice. 


\section{Samenvatting}

Roken tijdens de zwangerschap is schadelijk voor de gezondheid van het ongeboren kind. Onderzoek heeft aangetoond dat roken tijdens de zwangerschap onder andere kan leiden tot een. lager geboortegewicht, groeiachterstand, het vaker voorkomen van spontane abortus, een verhoging van perinatale sterfte en wiegendood. Ook passief roken door baby's en jonge kinderen kan nadelige effecten hebben op de gezondheid. Veel vrouwen stoppen echter niet met roken als zij zwanger worden en als zij stoppen is de kans groot dat zij weer beginnen met roken na de bevalling. In Nederland was tot nu toe geen onderzoek uitgevoerd naar de effectiviteit van stoppen met roken programma's tijdens de zwangerschap. Derhalve werd besloten een onderzoek op te zetten naar de ontwikkeling, implementatie en evaluatie van een stoppen met roken en relaps preventie programma voor zwangere vrouwen.

Voor de ontwikkeling van het programma werd gebruikt gemaakt van het A.BC planningsmodel. Dit model beschrijft stapsgewijs de drie verschillende fases die doorlopen kunnen worden bij de ontwikkeling, implementatie en evaluatie van een effectieve interventie. In de eerste fase wordt een analyse gemaakt van het probleem, de tweede fase beschrijft de ontwikkeling van de interventie en de derde fase richt zich op continuering van het programma.

In hoofdstuk 1 wordt de toepassing van het $\mathrm{ABC}$ planningsmodel op zwangerschap en roken beschreven. In de analyse fase wordt beschreven dat roken tijdens de zwangerschap en passief roken na de bevalling schadelijk is voor de gezondheid van het (on)geboren kind. Behalve dat roken tijdens de zwangerschap een al dan niet bewuste keuze is die door vrouwen wordt gemakt is het tevens belangrijk rekening te houden met de omgeving van vrouwen. Uit onderzoek blijkt dat vrouwen met een rokende partner meer kans hebben om zelf te blijven roken tijdens de zwangerschap, maar ook om weer te beginnen met roken na de bevalling. Verder blijkt dat hoewel vrouwen aangeven medici als belangrijkste bron te beschouwen voor het ontvangen van informatie over roken, slechts weinig vrouwen ook daadwerkelijk deze informatie ontvangen. Een beschrijving wordt gegeven van de belangrijkste determinanten van roken en stoppen met roken 
tijdens de zwangerschap maar ook van. het geven van stoppen met roken voorlichting aanı zwangere vrouwen door verloskundigen. Verloskandigen zijn in Nederland de gebruikelijke hulpverleners bij ongecompliceerde zwangerschappen. Tot slot van de analyse fase wordt beschreven welke kanalen het meest geschikt zijn voor een stoppen met roken en relaps preventie prograrnma.

Op basis van de gegevens verzameld in de analyse fase werd besloten tor de ontwikkeling van materialen voor zowel de zwangere vrouw, de rokende partner van de zwangere en de verloskundige. De interventie fase beschrijft de doelstellingen van de diverse programma onderdelen, de ontwikkeling van de interventie, de wijze waarop de diverse onderdelen zijn getest voor aanvang van de effectiviteitstudie en de effect en proces evaluatie.

De derde fase beschrijft dat voor succesvolle implementatic van een interventie het belangrijk is om vanaf het begin van het project samen te werken met de verschillende beroepsgroepen en organisaties die een rol kunnen spelen bij de implementatie van een programma. Verder worden factoren beschreven die een rol kunnen spelen bij de succesvolle verspreiding van een interventie.

In het laatste onderdeel van het eerste hoofdstuk worden algemene conclusie getrokken en aanbevelingen gedaan voor onderzoek en praktijk.

In hoofdstuk 2 wordt de determinanten studie beschreven die is uitgevoerd onder verloskundigen voor aanvang van de ontwikkeling van de interventie. In totaal werden aan 368 verloskundigen vragenlijsten verstuurd waarvan er 237 ingevuld werden geretourneerd. In de vragenlijst werden vragen gesteld over voor- en nadelen van het geven van stoppen met roken voorlichting, voor- en nadelen voor de gezondheid van stoppen met roken tijdens de zwangerschap voor moeder en kind, sociale steun en eigen effectiviteit van verloskundigen ten aanzien van het geven van stoppen met roken voorlichting. Resultaten van deze studie wezen uit dat verloskundigen met een meer positieve taakopvatting ten opzichte van het geven van stoppen met roken voorlichting aan hun cliënten meer overtuigd waren van de voordelen van het geven van stoppen met roken voorlichting, de voordelen voor de gezondheid van stoppen met roken voor 
moeder en kind en meer steun verwachten van hun collegae ten aanzien van het geven van stoppen met roken voorlichting. De eigen effectiviteit met betrekking tot het geven van stoppen met roken voorlichting was laag onder zowel verloskundigen met een positieve als verloskundigen met een minder positieve takopvatting. Op basis van de resultaten van deze studie werd geconcludeerd dat het belangrijk is om materialen en training te ontwikkelen voor verloskundigen om hen te helpen en te stimuleren om stoppen met roken voorlichting te geven.

In hoofdstuk 3 worden de resultaten van de procesevaluatie beschreven. Na afloop van de implementatie van de interventie ontvingen alie 118 verloskundigen een vragenlijst, 69 verloskundigen vulden de vragenlijst in. In de vragenlijst werden vragen gesteld over de wijze waarop stoppen met roken voorlichting was gegeven, de moeilijkheid van het geven van stoppen met roken voorlichting, het verstrekken van de diverse materialen en de mogelijkheid van implementatie van de interventie in de dagelijkse praktijk. Hoewel verloskundigen in de experimentele groep aangaven dat zij het moeiliker vonden om het rookgedrag van hun cliënten te bespreken, de motivatie om te stoppen met roken en eventuele hindernissen die een succesvolle stoppoging zouden kunnen belemmeren bleek dat experimentele verloskundigen vaker het advies gaven om te stoppen, een stopdatum afspraken met cliënten die gemotiveerd waren om te stoppen met roken en afspraken maakten over nazorg. Experimentele verloskundigen gaven tevens aan de diverse materialen verspreidt te hebben onder een ruime meerderheid van hun cliënten. Er werden geen verschillen gevonden tussen verloskundigen in de experimentele en controle groep voor wat betreft het geven van een stopadvies aan de rokende partner of het geven van het advies niet te roken in aanwezigheid van de zwangere vrouw. Deze resultaten werden grotendeels bevestigd met data verzameld onder cliënten. Echter, wat betreft het relaps preventie gedeelte van de interventie spraken de gegevens verzameld onder verloskundigen en cliënten elkaar tegen. Slechts weinig cliënten gaven aan het relaps preventie boekje te hebben ontvangen of postnataal rookgedrag te hebben besproken met hun verloskundige. Op basis van deze resultaten werd geconcludeerd dat het mogelijk is 
de stoppen met roken interventie te implementeren, maar dat meer onderzoek nodig is naar de implementatie van het partner gedeelte en het relaps preventie gedeelte.

In hoofdstuk 4 worden de korte termijn resultaten van de interventie beschreven. In totaal werden 318 rokende zwangeren geïncludeerd in de studie. Zes weken na aanvang van de interventie gaf $18.7 \%$ van de vrouwen in de experimentele groep aan niet te hebben gerookt in de afgelopen zeven dagen in vergelijking tot $7.4 \%$ van de vrouwen in de controle groep. Zes weken na de bevalling was dit percentage gestegen tot respectievelijk. $21.3 \%$ en $12 \%$. Het ontvangen van de interventie, een minder zware roker zijn en het hebben van een niet rokende partner waren voorspellers van stoppen met roken. Op beide meetmomenten kon geen effect worden geconstateerd van de interventie op het rookgedrag van de partner. Op basis van deze resultaten werd geconcludeerd dat de interventie effectief is in het reduceren van het aantal rokende zwangeren tijdens de zwangerschap en dat dit effect aantoonbaar blijft tot in ieder geval zes weken na de bevalling. De partner interventie was niet effectief.

In het laatste hoofdstuk worden de lange termijn resultaten van de interventie beschreven. Voor de analyse van de lange termijn resultaten werden de gegevens gebruikt van de 318 rokende zwangeren die werden geincludeerd in de studie en 238 zogenaamde spontane stoppers (vrouwen die aangaven recent te zijn gestopt met roken). Omdat de interactie tussen rookstatus bij aanvang van de studie en het behoren tot de experimentele en controle groep niet significant was werden de resultaten van beide groepen samengevoegd. Zes maanden na de bevalling gaf $27.4 \%$ van de vrouwen in de experimentele groep en $30.6 \%$ van de vrouwen in de controle groep aan niet te hebben gerookt in de afgelopen zeven dagen. Dit verschil was niet significant. Minder zware rokers en vrouwen die op latere leeftijd waren begonnen met roken gaven vaker aan niet. te roken. Vrouwen met een rokende partner en vrouwen die zelf nog rookten bij aanvang van de studie gaven vaker aan wel te roken. Er was geen effect van de interventie op rookgedrag van de partner. Omdat geen lange termijn effect van de interventie op rookgedrag kon worden aangetoond werd geconcludeerd dat meer onderzoek noodzakelijk is naar de determinanten van terugval onder zwangeren, de determinanten 
van het geven van relaps preventie door verloskundigen en mogelijke andere kanalen voor het verspreiden van voorlichting over het belang van niet roken na de bevalling. 


\section{Dankwoord}

Hoewel het soms voelde als een eenzame onderneming, zijn toch veel mensen betrokken geweest bij de uitvoering van de, in dit proefschrift beschreven, studie.

Ten eerste wil ik alle verloskundigen en vrouwen die betrokken zijn geweest bij het onderzoek hartelijk bedanken voor hun geheel belangeloze medewerking. Zonder hun medewerking en inspanningen was het simpelweg onmogelijk geweest om de studie uit te voeren. Verder wil ik hier ook de Nederlandse Kankerbestrijding, de Nederlandse Hartstichring, het Praeventiefonds en de Stichting Volksgezondheid en Roken bedanken voor het (mede) financieren van dit onderzoek. De leden van de project groep (de KNOV, het. NHG, prof. dr. Visser en Stivoro) bedankt voor jullie interesse in het onderzoek en het (mede) beoordelen van de geschiktheid van de informatic en het voorlichtingsprotocol voor de intermediairen en de doelgroep.

Ten tweede wil ik graag mijn promotoren Hein de Vries, Pat Mullen en Gerjo Kok bedanken. Hein, jij was er vanaf het begin af aan bij betrokken en we hebben er samen aan gewerkt om het tot een succes te maken. Pat, I really owe you my gratitude for your help and support. You welcomed me with open arms in Houston and together we made an important step towards finalising this thesis. Gerjo, reeds als student bewonderde ik je duidelijke colleges. Als mijn. (formele) baas ben je altijd positief geweest over mijn werkzaamheden. Ik kon altijd op je rekenen in times of trouble.

Gedurende het project hebben meerdere onderzoeksassistenten met mij samengewerkt (Helen Klip, Marlein Ausems en Stef Kremers). Hartelịk bedankt voor jullie inspanningen. Jullie werkzaamheden zijn van groot belang geweest in de diverse stadia van het onderzoek. Gerard, als belangrijke co-auteur, bedankt voor je nuttige adviezen over de statistiek.

Werken bij de vakgroep GVO (of is het nu capaciteitsgroep gezondheidswoorlichting) heb ik altijd met erg veel plezier gedaan. Bij deze wil ik mijn collega's bedanken voor het creëren van zo'n plezierige werkomgeving. Hoewel ik al weer een tijdje bij jullie weg ben denk ik er nog altijd met veel plezier an terug.

Op deze plaats is het ook van groot belang om mijn paranimfen te bedanken. Ingrid, als 'lotgenoot' (op dit moment weet ik nog niet of je voor of na mij 
promoveert), heb ik veel steun aan je gehad. Maar ook privé ben je een erg gezellig maatje. Er is nu weer meer tijd voor PdL, theater, saunabezoek en al die andere dingen die je kunt doen om het leven te vieren. Monique, ik vind het erg leuk dat jij straks naast mij staat bij dit evenement. Als 'buitenstaander' heb jij mij ultiem ondersteund bij het schrijven van dit proefschrift. Van 'Dr Phil's' wijsheden tot donderpreken, het heeft allemaal geholpen. Met jullie aan mijn zijde wordt het 7 december één groot feest.

Gelukkig omvat het leven meer dan alleen maar werk, je kunt ook tijd doorbrengen met familie en vrienden (al reduceert die tijd behoorlijk als je een proefschrift moet schrijven). Allemaal bedankt voor jullie belangstelling en steun bij het voltooien van dit proefschrift en ik ben er weer! Papa en mama, fijn dat jullie er altijd zijn voor ons (en mama, niet teveel stressen hoor, dat doe ik wel). Een speciaal dankwoord voor Marc, wat is het leven leuk met jou (ihhvvjenidebm).

Tot slot wil ik dit proefschrift graag opdragen aan mijn grootvader Hans Bernhard van Veen. In de jaren dat hij deel uitmaakte van mijn leven leerde hij mij dat je verantwoordelijk bent voor je eigen prestaties en dat je eruit moet halen wat erin zit'. Op de leefuijd van 95 was hij de meest moderne man die je je kunt voorstellen. Hoewel hij niet langer onder ons is, weet ik zeker dat hij erg trots zou zijn geweest.

Martijntje Bakker

Den Haag, 2001 


\section{Curriculum Vitae}

Martijntje Bakker was born on October 9, 1969 in Sneek. In 1988 she received her VWO diploma at the Nienoord College in Leek. In that same year she started studying Health Sciences at the University of Limburg (now called Maastricht University). In 1993 she graduated, specializing in Health Education. After graduation she started to work as a research assistant at the Department of Health Education of Maastricht University.

From 1994 to 1998 she was employed as a researcher at the Department of Health Education. In this period she conducted the study described in this thesis. In March 1998 she started to work as the European Project Manager for the European Smoking prevention Framework Approach (ESFA) project. The goals of the ESFA project were to develop, implement and evaluate smoking prevention materials for adolescents in six European countries simultaneously.

From September 1999 until July 2001 she has worked at the Department of Public Health of the Erasmus University Rotterdam as an editor of a book entitled Reducing inequalities in health: a European perspective. The goal of this book was to provide insight in effective interventions and policies to reduce socioeconomic inequalities in health in Europe.

Since July 2001 she is employed as a policy worker with the Public: Health Fund, the Hague. 
